\title{
Playing the Game and \\ Pulling the Fingers: \\ Working for and against the modern University
}

\#300235108

O.D Guthrie

2015

Copyleft 


\section{Table of contents}

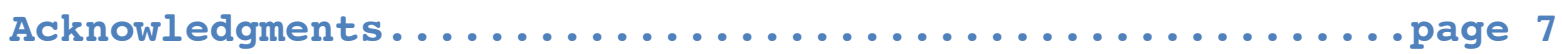

Abstract.................................. 8

Chapter 1: Introduction........................p 12

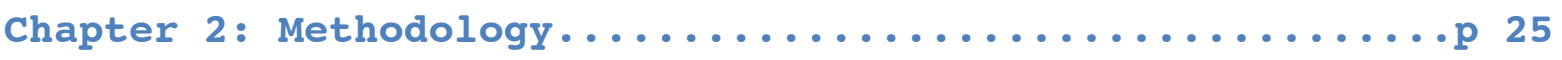

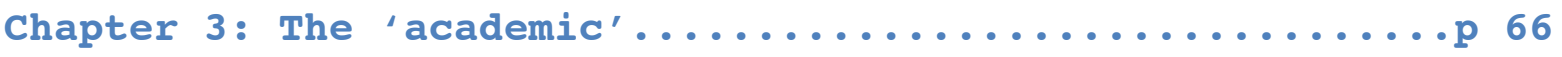

Chapter 4: Playing the game/ pressures on the academic...p 86

Chapter 5: Pulling the fingers/ resistance............p 129

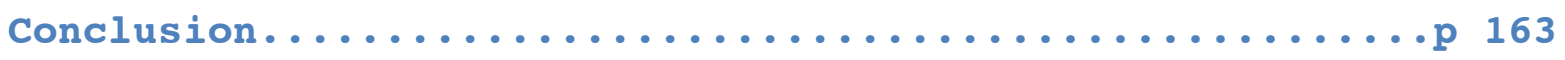




\section{Acknowledgments}

To everyone that was involved in this project, thanks heaps and I hope you like it. I've learnt a lot from talking with you all and hopefully this project conveys my gratitude for all that you have taught me.

Thanks to my supervisor Lorena for not letting me quit when I walked into your office and said I was going to, and for always pushing me to do my best.

To my other supervisor Chamsy, thanks for encouraging me to write about the topics I was interested in. My early essays on primitivism and 80's Hardcore may not have been that great, but the fact you thought they were interesting was enough to keep me writing.

You have both been big influences on my time at university, and showed me that even the girl who refused to wear her school uniform, and the boy who needed to spew mid-set of his horrible punk band First CrAp (or was it the Peter Plumley Walker Experience?), could become academics, and great ones at that.

To all the people who read my drafts, thankyou, and, I'm sorry. I've always been a terrible speller, and when drafts needed to be read and re-read I often lacked the discipline to do it. You guys and your fresh eyes gave me the helping hand I needed to get this thesis to a 'hand-in-able' state.

To my office buddy Morgan; I didn't realise that when you tutored me in my first year sociology course that I would one day be sharing an office with you. It has been quite the year and you have been a great support and source of wisdom and knowledge. Thanks.

And thanks to Mum and Dad. 


\section{Abstract}

Todays' universities are constantly evolving, and yet they are deeply traditional institutions that bring together often contradictory agendas, with multiple roles and expectations for those working within. I look towards the academics within these universities in order to get a better understanding of what happens when the personal meets the institutional. By reflecting on my time as a student, and talking with thirteen New zealand academics and post-graduates who in various ways challenge dominant ideas around academia, I aim to broaden and disrupt the academic imagination. Rather than think of this project as an academic study on academia, I like to think of it as me, a student, re-telling the stories of academics; seeking their wisdom, tactics and gaining inspiration from their ability to 'do' academia their way, even in today's tight confines. 


\section{A note on writing style:}

I wish I could say, like C.W Mills did (Perlman, 1969), that after having mastered the art of academic writing, and then realising how easy it is to be trained in such a rigid and often ineffective way of communication, discarded it in favour of something more accessible. I recognise the importance of language in shaping our political and social understandings. The words we use carry with them a whole host of assumptions, and taken for granted ideas, but then all language does.

This is a huge debate within academia, and one highlighted by Judith Butler (1999) who was awarded a 'prize' for bad writing by who she describes as a "small, culturally conservative academic journal" attacking scholars on the left dealing with topics like sexuality, ethnicity and class. Butler notes that, as academics within the humanities and social sciences, it makes sense that our work can be translated into something of everyday value. She also notes however, that we need to challenge notions of 'common sense', the status quo, and offer new ways of looking at our familiar and taken for granted surroundings, language included. Butler draws on the work of the philosopher Theodor W. Adorno who argued that no change could come from common sense. Both he and Butler write in ways that require reflection and an almost sentence-by-sentence analysis.

The way this thesis is written can be tied into this massive debate, but I think we want to be careful not to rule out any particular writing style, or privilege one over the other as having 'more to offer'.

But I also think it's a good thing to make your work accessible, and the way we write can help achieve this. As a student I battled to grasp some sort of understanding of 
jargon filled pieces of writing that seemed like they were saying something important, I just could't figure out what it was.

I use the language that comes naturally to me. People might not describe it as academic or formal, but I hope it makes sense and I hope they enjoy it. I also hope that even though it may not fit perfectly within academic discourse, that there's still a space for it somewhere.

There is always room within academia and life to be more accepting of a variety of modes of expression, be it written or otherwise. 
Chapter 1: Introduction 
This thesis looks at academia in New Zealand. More specifically, it focuses on the academics that work within our universities and explores what happens when the personal meets the institutional. The university is an institution with a particular collective of motives and goals. Today, these goals are moving increasingly towards commercial interests and profit seeking, and this is changing both the university as an institution and the roles of academics within our society (Kelsey 1998, Giroux 2009, Shore and Taitz 2012, Larner and Le Heron 2005, Shore 2011 and 2010, Coté et al. 2007, Milojevic 1998 and 2003). What is the effect of this commercial emphasis on the academics themselves? How do they view the changing nature of their own workplace? What effect is this having on their role as academics, within both the university and wider society? What happens when institutional ideals around academia come up against the personal values of individual academics? By talking with students and academics, I hope to answer some of these questions.

I have interviewed thirteen academics (including $\mathrm{PhD}$ and Masters students), from universities in the lower North Island of New Zealand. The people that were involved in the project, all had a range of different opinions and ideas around what it is to be an academic in our society, and to work as one within today's modern universities. It is the range of opinions regarding what an academic is, as well as the contested site of the university itself, that makes academia a phenomenon full of divergences but still bound by well engrained and dominant ideas. This thesis contains some of those opinions and while I have tried to capture the variance, it will become clear that I am writing from the point of view of a student within a university (and before that, a school), so the writing is either tainted or enhanced (depending on how you look at it) by those experiences. 
In this introduction, I outline what I have found to be the main themes and concerns that emerged throughout the course of the research, including interviews, everyday observation, as well as my own experiences of being a student. Over the course of a year (March 2014-April 2015), I attempted to carry out something called 'fieldwork', in order to get a better understanding of academia, a world that I had been surrounded by as a student, but still had some uncertainties about.

These uncertainties basically stemmed from witnessing the pressure many of my lecturers were under to perform. The pressure to perform as a charismatic 'rock-star' lecturer, putting on live performances and packing out lecture theatres with devoted fans/students. There is pressure to perform as an entrepreneurial academic attracting funding to your institution, as a researcher publishing articles in the most prestigious and highly rated journals. There is pressure to perform the increasingly administrative tasks that reign down in the institutional and bureaucratic setting of a modern day university. But maybe even more than this, my uncertainties around the university stemmed from the doubts I had about my own place within academia, the university, and I guess the education system more generally. In an environment based around intelligence, competition, testing, and grades, I was often quite put off by it all. This is something that goes back to my primary school days when the dreaded times-tables and spelling tests rolled around every Thursday morning. Despite these doubts, I continue to come to university on a daily basis and have now been here for what is beginning to feel like too many years.

The commercialisation of the university is also becoming more visible and intensified, and this makes me question how much I, as a student, value it. I almost feel like I shouldn't mention it ( I had been doing ok at pretending it didn't 
exist), but my student debt is also beginning to enter into my mind more. I once had a geography lecturer tell the whole class that his boss had recently told him to treat his students 'less like students and more like customers'. I have gone to university fee-setting meetings, where tables of rich old white people (mostly men), who had been paid to go to university, had chosen to increase student fees by the annual maximum of $4 \%$, every single year. I've seen students who protested these types of decisions get randomly selected from their Facebook profiles, and then disciplined by a management team who seemed very skilled in intimidation and knew exactly how to make the life of a resisting student very hard. I was embarrassed when my university turned down the proposal to pay all of its employees a living wage, or when questionable measures were taken in order to be awarded number one research institute in the country. I felt ripped off when as tutors we were doing work we weren't getting paid for, and, as the university slowly started to look more like a shopping mall or an airport, I began to feel like maybe it wasn't the right place for me.

And yet, I'm still here; and that's because I do actually love it. I love the weird and wonderful stuff that you can learn here. Really interesting people can tell you about things, or you can go and find out for yourself. I feel like I'm beginning to figure out what it is I'm interested in and the sorts of projects I want to do in the future, and I feel like my time at university has helped me arrive at that place. It's the people who are here, I think; what else would it be? And it's those people that I want this project to focus on, because they have made my time at university what it is. I'm not talking about the 'Wizard of Oz' Vice Chancellors and business managers that we rarely get a glimpse of. I'm talking about the people who have been my lecturers, supervisors, and 
fellow students; and I'm talking about the way they keep the university a place that I want to come to.

I guess this project could be considered a written version of the past year, in which I tried to get a better understanding of this place (the university) during a time when commercialism seemed to be the goal, and the role of education and academics had become increasingly dominated by political and economic objectives. Rather than thinking of this as an academic study, where I've collected data from participants through a number of methods in order to make an argument (or whatever), I tried to see it as me, a normal student, talking with other academics; seeking their wisdom, their tactics, and gaining inspiration from their ability to 'do' academia their way, even within today's tight confines. Thinking about it this way was a struggle however, when in the first week or two of the project I had to list three distinct methods I would be using. So I picked three methods. Maybe because they were the first three that I thought of, maybe because I thought those were the methods most anthropologists used, or maybe to me interviews meant chats; and participant observation meant hanging out in an 'on to it' way; and auto-ethnography meant I would always have something to write about. The following two chapters of this project are a justification for the approach I took towards these methods, or as I like to think of it, 'the way I did what I did, and why I did it like that'.

The methods I used included participant observation, autoethnography, and semi-structured interviews. Bang, bang, bang, and just like that. These methods significantly shaped the type of information I collected and how I went about collecting it. It has also been shaped though, by the ideas of John Law (2004) and Paul Feyerabend (1975), two theorists who I think have a realistic and an extremely valuable opinion on the way research is conducted. In order to move away from 
dogmatic takes on theory, Feyerabend calls for a lenient approach that allows the constant reworking of theories as new knowledge comes to light. Unlike the dominant views of unified scientific methods which lead to 'pure' and 'objective' 'truth', Feyerabend saw science as an anarchistic process where the only principle should be 'anything goes' (Tsou, 2003). In line with this, Law (2012:11) hopes

"that we can learn to live in a way that is less dependent on the automatic. To live more in and through slow method, vulnerable method, or quiet method [...], multiple method [...], or [a] modest method", which provides scope to a methodology which can often be prescribed in 'cookbook' fashions. An acceptance of mess, with an almost 'anything goes' approach to research has helped me to stay sane when words, paper, notes, transcriptions, articles, books, and drafts, seemed to be strewn all over the office, and when questions of 'what to do and what not to do' stopped me from doing anything at all. After learning about the thoughts of Feyerabend and Law I found it easier to focus on producing an academia that was meaningful to me personally, rather than trying to meet preconceived expectations around what it is that both a student and an academic should be doing and producing. This was an idea that drew me towards Paulo Freire's book Pedagogy of the Oppressed (1970) in which he challenges the idea of expertise, and the dominant 'banking' model of education which sees students as empty vessels to be filled with the 'experts' knowledge. Instead, Freire contends that we all have the ability to think critically about the world around us, but that first we must resolve the contradiction that lies in the teacher-student dichotomy which "denies the creative aspect of the act of knowing and perpetuates oppression" (Collins 1977:81). 


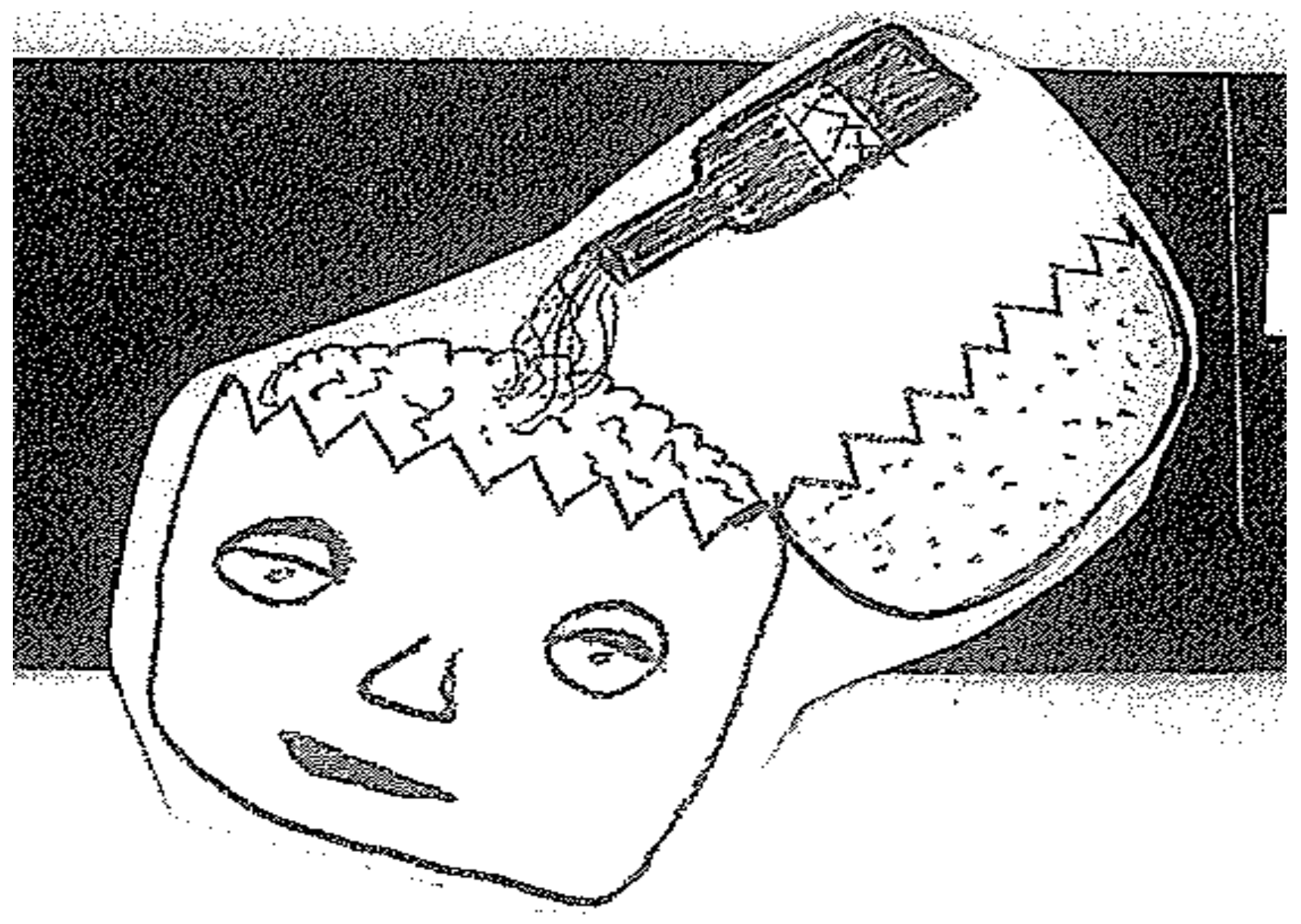

The Banking model of education. The Smashed Academy \#1: Punk Ethic from the Streets to the Universities (a one-off zine) available at http://thesmashedacademy.wordpress.com/ 


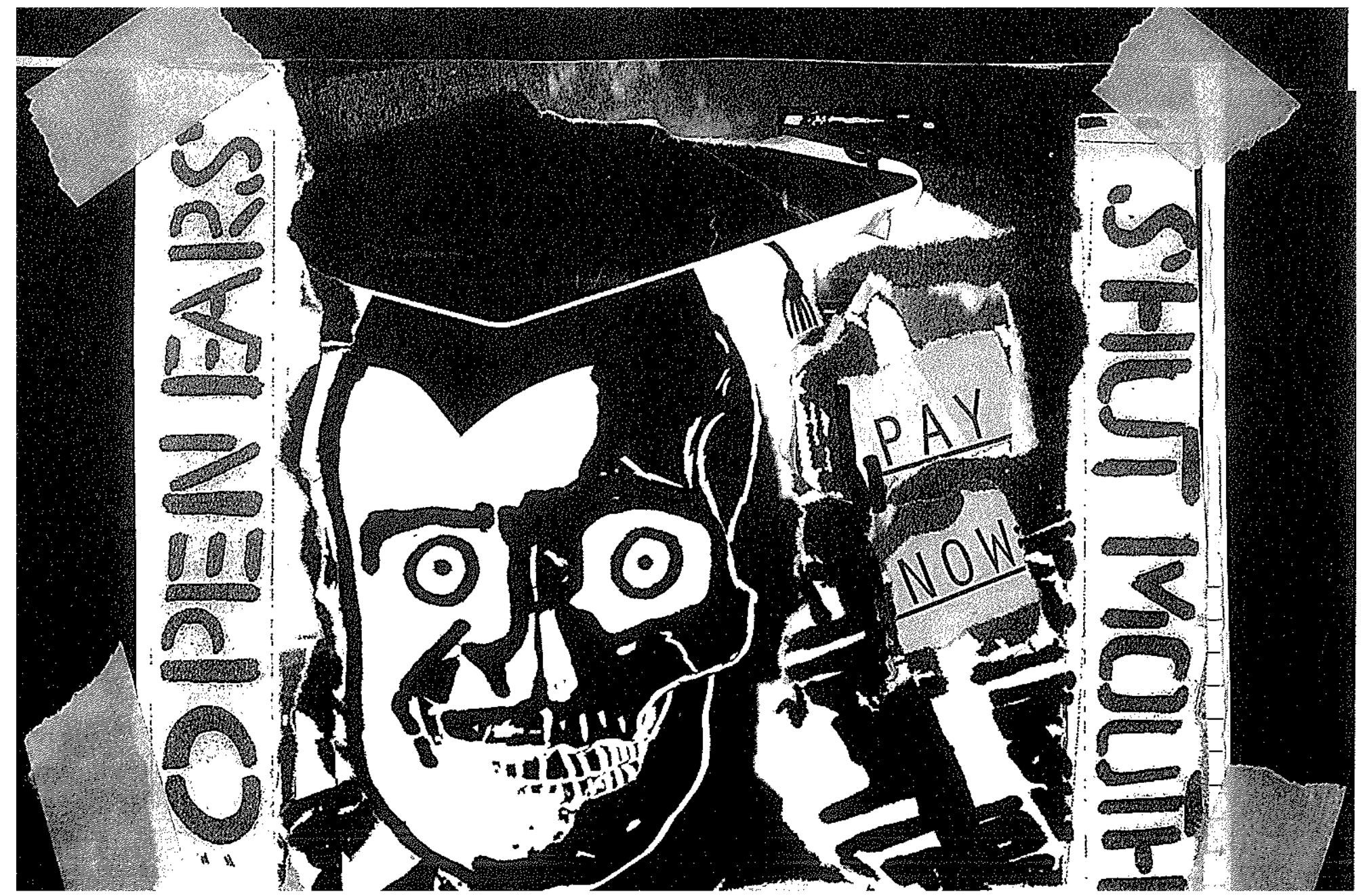

Collage from The Smashed Academy \#1: Punk Ethic from the Streets to the Universities (a one-off zine) available at http://thesmashedacademy.wordpress.com/ 
Well before I discovered all of these works though, I had an interest in punk and later anarchism, which I think touches on many of the same ideas as Freire, Feyerabend, and Law. Punk's focus on the Do-it-yourself (DIY)/anyone can do it mentality, the anti-mainstream/conformity/authoritative/hierarchical beliefs, and an emphasis on originality, creativity, and social change can encourage and be used (even) within the setting of academia, to challenge the dominant way things are done. And in many ways this is echoed in the work of anarchist authors like Graeber (2004), Kinna (2005, 2012), Purkis (2012), Forte (2014), De Leon (2008), as well as many others. These authors argue for what Shantz and Williams (2013:2) call "a practical approach to social transformation" and when applied to education aims to encourage free and critical thought, leading to an open, cooperative, and non-oppressive society (Haworth, 2012). An anarchist approach to learning, aims to create a space where individuals are encouraged to deconstruct oppressive ideas, practices, and structures that occur both inside and outside the classroom. With its critique of authority, hierarchy, domination and intellectual elitism, an approach that draws on anarchist thought has significant implications for an alternative way of 'doing' academia. As the university becomes increasingly a large branded business, anarchism stands in opposition with its organisation based on horizontal, consensus based decision-making and an emphasis on resistance to the state, capitalism, patriarchy, and all forms of domination (Haworth, 2012. Gordon 2008). I talk more about these issues, as well as the general approach I took throughout the research process in Chapter Two.

One of my key questions had always been 'what is an academic'? A simple question, yes, but there isn't necessarily a simple 
answer. In Chapter Three, I look at a range of theories dealing with what it is to be an 'academic', but also what academics could be. Here, I discuss Antonio Gramsci's traditional and organic intellectual, Edward Said's public intellectual and the idea of 'speaking the truth to power', C.W. Mills 'pragmatic intellectual', as well as Paulo Freire's take on emancipatory education. These theorists point to many promising practices for being an academic, practices that fall outside of and often in reaction to mainstream ideas of academia and education. What place, if any, do these ideas currently hold in the thoughts and practices of academics working within universities? Many of the academics I talked with were very familiar with the above work on intellectuals and drew on them when reflecting on their own role as academics. While this chapter deals with previous theories of the intellectual, as well as popular perceptions of the academic, it also considers the more subjective and diverse view of academia from the academics themselves. Maybe the question I should be asking is not 'what is an academic', but 'what does the state, the university, and the public want and expect our academics to be, and what is the motivation behind these expectations?'

In Chapter Four, I discuss the effects of a commercialised university. Like Shore (2011), Shore and Taitz (2011), Shore and McLauchlan (2012) Kelsey (2014), Giroux (2009), and Peters (2001), I agree that the commercialisation of the university has resulted in a changing of the nature between the university and business in an attempt to "translate university knowledge into revenue" (Shore and McLauchlen 2012:267). While these reforms are often considered one of the prime examples of 'neoliberalism' in practice, I discuss what it actually is, what sort of effects we can see it having within our learning environments and workplaces, and whether or not the term still has any use to us. Shaped by the conversations I had with 
academics, as well as the themes from within literature and my own observations, I then discuss the dominant concerns of the academics. These emerged as; Publishing and the Performance Based Research Fund (PBRF) and the effects that this is having on funding, managerialism and the audit culture that comes with it, academic freedom and the role of the critic and conscience of society. The demands on academics are various and there appears to be an expectation of a 'heroic' academic who can simultaneously fulfil all of these criteria. The 'academic entrepreneur' emerges from the commercially orientated university and is becoming more common and has its roots within the 'self-governing neoliberal citizens of theorists such as Foucault (1998 [1996]:155) and Rose ( $1992: 174$ )

In Chapter Five therefore, I look at the divergences away from these expectations and disciplining/self-imposed behaviours and the importance of small everyday acts of resistance in challenging these expectations and limitations around what an academic is. "Playing the game", "jumping through [just enough] hoops", and "kicking and screaming" became common phrases used throughout the conversations and touched on the academics' pursuit of an academia that was personally meaningful to them, whilst also fulfilling the requirements of their employer in order to remain employed. The chapter also looks at what happens when we critique our own universities, whilst also highlighting the importance of doing this if our universities are to remain/regain a valuable part of our society.

While much research has focused on the negative effects of commercialism and neoliberalism within universities, it also tends to bypass the positive things taking place in reaction to these destructive forces. Our universities may be becoming increasingly run like businesses, but inside these 
institutions are real people. Some have this pursuit of profit as their main goal, but there are other people doing things that fall outside a role aligned with corporate aims. There still remain small pockets of behaviour that counteracts or 'takes the sting' out of this dominant ideology, and this often occurs on a very 'everyday', perhaps seemingly mundane, yet significant level. How much more significant could 'everyday' be? There is room to "kick and scream", and maybe if we as students and academics tried doing it more often, we would realise that it doesn't always have to result in instant dismissal, and maybe the disciplining we receive isn't so bad. Often it's a "slap on the wrist and a talking to like you're a 5 year old", as one of the academics I talked to said before continuing... "I would like to see them try and fire me!". But then at the same time, we also need to consider the very real threat of job loss, especially considering the recent Tertiary Education Union (TEU) survey (2014), which tells us that two thirds of academics think their jobs are under threat because of these types of 'death by a thousand cuts' pressures that the sector is under. The importance of open and free critique is now at its peak. University management might not want to hear it, in fact it may even make efforts to squash and intimidate any critical voice, but by working together as students and academics, these small pockets of what said (1994) called 'quasi-utopian spaces', may be able to survive a little longer, and hopefully even grow.

Here, anarchism provided a large body of literature on practical forms of everyday resistance. As did the work of Michel De Certeau, whose book The practice of Everyday Life (1984) was suggested to me by an academic who had also found it an invaluable guide to surviving and understanding work within an institution like the university. Like most things however, I gained the most valuable knowledge from the academics themselves, all of whom dealt with these pressures 
in their own way, from 'playing the game' to 'kicking and screaming', or as my poetic licence allowed me to alter for purposes of a catchy title, 'pulling the fingers'.

It seems like if we continue in the current direction, our universities as we know them will die a slow and painful death and end up resembling some dystopian factory of education where lectures are delivered to thousands cash paying customers via cost effective holograms or talking robots. We may not be there yet, but we can already see signs of this type of thing occurring, and with this being the case, the question of whether or not the current university is one that we want to 'fix' at all. As Max Forte (2014:5) says in reference to our own beloved Anthropology, “...the real question should not be whether it is ending, rather it ought to be how can we go about ending it, quickly and once and for all". While there is a lot of literature that has focused on the negative direction our universities are travelling in, and while I agree that these effects are definitely destructive, a year long project focusing on this would have been depressing. Instead I choose to focus on the small pockets of greatness that emerge within and against this dominant ideological sludge. This is what this project boils down to; that yes there are various roles and expectations placed upon academics within our business focused universities, and we may have to fulfil them to a certain degree. But we should always be doing this critically, and openly discussing the contradictions within our own practices and workplaces, as well as staying true to our own political and moral beliefs as individuals working within these institutions. 
Chapter 2: Methodology 
While this is an academic study on academics, it's also a good excuse for me to try an get a better understanding of a place which has been a pretty big part of my life for the last six or something years. As a student, the university provides an ideal 'field site' (as weird a term that may be; makes me feel like I'm in the military or that I can differentiate between the 'field' and the 'not field' by looking at the painted white lines on the grass, because, of course, fields are always grassy), for me to carry out my research. What better place to do a project on, than the place I came everyday to work on that project? Something like killing two birds with one stone. I gave up thinking about the university as a 'field site' after deciding that I couldn't separate the familiar and day to day routine that was 'going to uni' as a student, and 'start' thinking about how every little detail could add to this project in some way. It seemed a strange thing; That all of a sudden the buildings around me were supposed to become my 'field site' and the people in them, potential sources of 'data'. People I knew. I began to think that maybe choosing a topic so close to my daily life might have been a mistake. But I still felt like there was something useful and important, or maybe even just interesting, to be said about academia, and that I could use my experiences of it as a student as well what I learnt from talking with academics, to write something worth writing, but more importantly, worth reading. I wondered if this now made me a real 'researcher' or 'anthropologist' or 'academic' or 'participant observer', and what this meant I had to do.

\section{[From notes ]}

-A pen and paper in my pocket could be a good start maybe? Anthropologists write stuff down a lot don't they? Perhaps I should walk around the campus holding my chin and thinking. 
I realised I had no idea what I was doing. I also realised that I had either better figure it out, or just come to grips with it, and do it anyway. When I was younger I used to watch The Havoc and Newsboy show on TV, two guys whose 'know nothing' approach to making a TV show actually resulted in a pretty cool TV show. I mused with the idea of writing the best thesis in the world without really having a clue what I was doing, and while I let my imagination get away on me, I decided to also let my naivety find some comfortable influence within this project.

Rather than thinking too much about the 'correct' way to go about my research, I like what Uri Gordon says about participant observation, probably the research technique most associated with anthropology. It's "precisely about testing and transgressing boundaries-those between institutional expectations and political commitments, between scholarly pursuits and real life, and between the intellect, the emotions and the body" (Gordon in Kinna, 2012:86). It is this more lenient approach to research that I needed to adopt as the boundaries between me, and my institution, were constantly being negotiated.

The approach we take to research cannot be disconnected from the values that inform that research (Purkis in Kina 2012, Armaline in Amster et al 2009). Guiding me throughout this project was a number of ideas that are both important to me personally, and also to what I 'do' as a researcher. Rather than getting too wrapped up in categorised methodological rules, I saw these guiding principals as something I could keep in mind in order to focus the project, without dictating how I went about doing it. The guiding principles were shaped by my experiences as a university student, but I guess more generally they are important to me within my everyday life. In this way, I agree with Buroway (1991:7) when he says, 
"participant observation is not only a paradigmatic technique for studying others; it also points to a distinctive way of understanding ourselves."

In this chapter, I will place myself as the researcher, within the research. It will cover why I have chosen to study academics in their place of work and the principles that have guided me throughout the process; more than just a way of working through the unease and confusion about my own place within academia, but an attempt to better understand the diverse, conflicting, constantly shifting role of the academic.

This is my seventh year of being a university student (the first couple weren't exactly successful), but it's the first time I have ever turned my place of study into my topic of study. What's the difference between what I was doing as a student interested in his academic environment, and what I'm doing as a student researching academia, or as an anthropologist even? As someone who is supposed to be 'doing' anthropology, I should have this worked out. But I don't think I have...It seems like we just adopt a certain attitude of paying more attention to the things going on around us, or that we carry little notebooks and take notes, and record everything everyone says. Some days, the familiarity of the university makes it hard to even want to pay attention. Trying to view such a familiar space through fresh and curious eyes is hard work when everyday seems like literally 'another day at the office'. Then again, many aspects of academia still confuse and intrigue me. As a space the university provided many events such as seminars, public talks, meetings, conferences, open days, protests, people and politics, in which I was able to experiment with what it meant to be an 'anthropologist' doing a study within familiar settings. This methodology could constitute an attempt at writing that 
experiment down, as well as a justification for the way I ended up going about it. As the excerpt below, taken from the notes I kept throughout the course of the project, shows, it's often hard enough trying to figure out what we are 'supposed' to be doing, let alone trying to go about it in a way which challenges currently accepted and dominant modes of being an academic.

[From notes] 15 $5^{\text {th }}$ August, The day of the conference.

I hadn't even thought of going to the conference. Everyone was pretty excited about it because Nikolas Rose was going to be speaking. I had never heard of him, but when my supervisor mentioned it, and said postgraduate students could volunteer and get in free, I couldn't really let the opportunity pass me by. It was going to be a weekend of academics, in one place, at one time, engaging in the classic academic pursuit that is the conference. Not only were there going to be formal academic lectures being presented, there were also morning teas, lunches, afternoon teas, and wine drinking in which I could observe academics as they socialised. It couldn't really get much better for a hungry masters student doing a project on academics and so I went along to 'do' some anthropology... whatever that happened to mean. Pen, paper, recording device conveniently left at home, and I was ready to observe some stuff with scientific accuracy....

The conference started at $6 \mathrm{pm}$. Me and Isaac had to be there at 5. We were helping out at the registration table but were also running quite late. Traffic was chaos as was usual for this time of day, but with some rather tactical driving, we managed to find a car park and quickly run to the venue. When we arrived, I received the 
task of correctly ordering some pamphlets and then stapling them (which was actually very tricky).

Then, as I'm fumbling with 45 bits of paper and a stapler, I remembered that I was supposed to be 'doing' some 'fieldwork'... but what does that mean? We were in such a rush to get here, I'd 'forgotten to remember' what being an anthropologist meant... 'Just stay cool and blend in with the crowd' I tell myself...staple some pamphlets...try...notice...some...stuff I guess...but how do I do that... what am I supposed to be noticing?...Everything!

In the above paragraph from my notes, I was struggling with what Dewalt and Dewalt (2010) say it means to be consciously carrying out fieldwork, and now that I think back on it, it seems silly that I tried so hard. How was it any different to what I normally did? Well, now I knew, and couldn't escape from the fact that I would have to be writing 30-40 thousand words on this at some stage. The conference provided an isolated event in which I could carry out participant observation. In the beginning of the project, I really did try to put on those 'anthropological glasses' or hat, or however it goes. As if by flicking a switch, I thought I could turn the academic inside of me 'on'; "when we are 'on' we have in the back of our minds the fact that, whether or not we are taking cursory notes at the time of the observation, we will be writing field notes later. Keeping consciously in mind that we will have to describe what we did and saw in itself keeps us attuned to the detail of the context (2010:69). But being switched 'on' in a supposed state of heightened awareness is a hard state to keep up. It drops in and out like bad cell phone reception. Rather than trying to maintain it, I slowly began to realise that I should just relax and enjoy my first conference experience while absorbing rather than identifying 
what was going on around me. Sometimes, trying too hard can get in the way of the overall experience (Dewalt and Dewalt, 2010). And so I forgot about my pen and paper for a while, relaxed a little, and ate some club sandwiches, which were delicious.

But when it comes to doing research on your own institution, it's not all club sandwiches and chardonnay. There does seem to be a negative view around doing fieldwork in the place you may be employed or heavily involved with. Morse (1998:61) says “it is not wise for an investigator to conduct a qualitative study in a setting where he or she is already employed and has a work role. The dual roles of investigator and employee are incompatible, and they may place the researcher in an untenable position". On a similar note, Brannick and Coghlan (2007:59-60) say that very little consideration has been given to insider academic research "and when it does, it is an argument against going native...Insider [is] frequently disqualified because it is perceived not to conform to standards of intellectual rigor because insider researchers have a personal stake and substantive emotional investment in the setting". Without going into concerns around the term 'going native', I don't see 'personal stake' and 'emotional investment' as bad thing, and I agree with Gordon (in Kinna, 2012:92) when he says that our own experiences, can actually be used as a "tool of interpretation, a source of theoretical sensitivity rather than bias". But it is important to recognise that I do have a particular view of the university, and it is full of all the biases of a particular student within a particular system. In drawing on my own experiences of university, I hope to expose my own insecurities, naivety, opinions, prejudices and privileges. Up until recently, this has been a joy, and pages and pages were scribbled out in notebooks. There comes a time though, when those "regrettable opinions" are going to be seen and read by others...They are 
going to be judged and marked, held up against some sort of measure as to what a 'thesis' should be. Now, as I write this, seven days until the due date, I still don't know if what I have produced constitutes a good thesis. But all those late nights staying up to watch Havoc and Newsboy's attempt at a TV show must have taught me something.

$$
* * *
$$

\section{"All I know is that I don't know, all I know is that I don't know nothing... and that's fine". \\ 'Knowledge' by Operation Ivy}

In the final year of my undergraduate degree, I did an anthropology paper on migration and identity. In the first class, the lecturer talked about something called the banking model of education, an idea from Brazilian educationalist, Paulo Freire. His critique of this model, in which students are considered empty vessels to be filled with the teachers (as expert) knowledge, breaks down the barriers between student and teacher within the classroom, leading to a more inclusive an equal style of learning.

It was the first time I had heard a teacher critique their own role as 'the teacher'. Even down to the way that the room was set up, with the student 'audience' all collectively facing towards the one speaker. We were encouraged to bring our own knowledge and experiences to the class, and it was organised in a way that put the students contributions at the centre. I talked with the lecturer for that course as part of my honours project, about how she implemented Freire's ideas into the 
classroom and challenged the 'banking model' and the dichotomy of teacher as expert and student as empty vessel. Below is an excerpt of that interview from the Smashed Academy, a one-off zine produced for my anthropology honours course, which looked into the influence of punk within academia. 


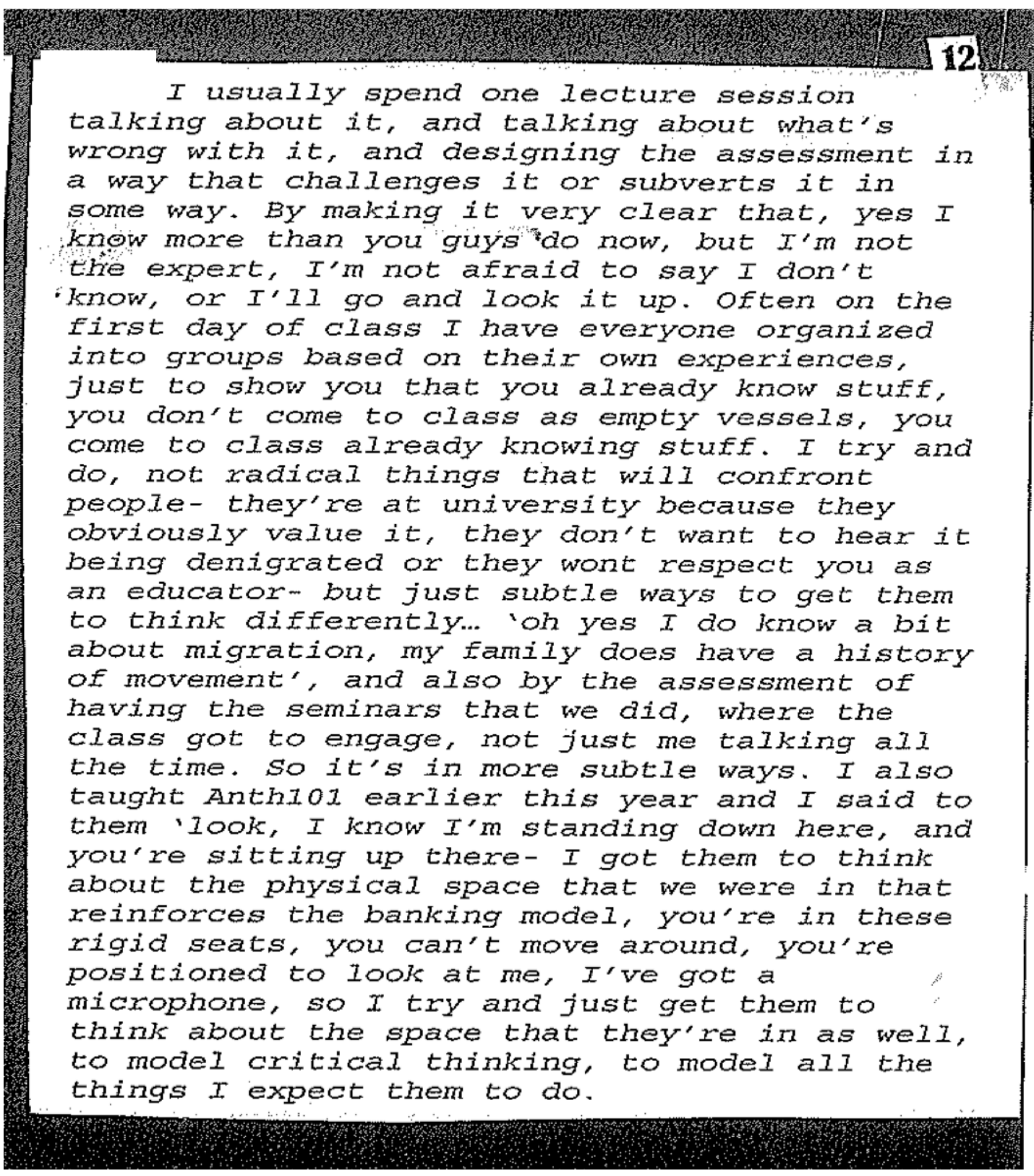

The Smashed Academy \#1: Punk Ethic from the Streets to the Universities (2013) [a one-off zine] available at https : / / thesmashedacademy • wordpress.com/ 
To me, the ideas of Freire seemed like the sort of thing we should have been telling all those kids that became disenfranchised with their education and ended up hating school. It really gave me a new way to look at my past education, as well as a new approach to my future learning. For the final essay of the class, we got to pick our own research topic, as long as we could relate it to the course somehow. This gave us the freedom to make the project our own from start to finish and allowed us to write an essay we were interested in.

I had an idea and went to broach it with my lecturer.

"...well...there's this band called the Bad Brains...." I said, and then began to think of how I was going to 'academise' it up a little, but before I could come up with anything substantial, the lecturer replied with...

"oh yea, I know the Bad Brains!"

I was kind of surprised. I guess I shouldn't have been, but my own stereotypes of academics told me that they probably wouldn't listen to the Bad Brains. The university seemed at odds with what punk was all about, and I wondered how many other academics were into it and how this affected their views and actions within the university. I wondered if the morals and ethics within punk like the DIY/anyone-can-do-it ethic, the anti-mainstream/conformity/authority/hierarchy beliefs, and a focus on creativity, originality, and social change, could be, or were being, used by academics within universities and what they were being used for. If punk ethics worked for amateur musicians like the Germs, and not so amateur musicians like the Bad Brains, then could it also work for amateur 
academics struggling with various workplace demands and expectations? This was something I wanted to learn more about, but I wanted to learn it through putting these ideas into practice, as well as through talking with academics and students and gaining inspiration from their divergences from the academic norm.

As the sun shone into the kitchenette/staffroom of a Fine Arts department I talked with Brian, a self described artist before academic working within a Fine Arts department, and learnt that there is room to challenge certain hierarchies and dominant ideas through the work we produce within the university. In this case, we can see how the ethics of punk such as DIY, amateurism, creativity, and anti-authority, can be put into play within the academic workplace:

"I make zines and I say that that is my art practice, and the university looks at them and goes "well you're self publishing, that's the antithesis of quality assurance, we require quality assurance to validate your research", you know and I'm just being bloody minded making zines, and I see the zines as a challenge to the hierarchy of quality assurance, of gatekeepers that qualify your work... Well that's not what zines are about. Zine making is kind of self publishing as empowerment where you don't have to worry about the middleman, whether that's academic referees or target audiences or advertisers or editorial boards. You just do it. And you get it out there with all its typos and regrettable opinions"

\footnotetext{
'Regrettable opinions'... Such a great term. We all have them, but to expose them within academia seems like it would be a big mistake. I imagine an academia more open to a certain spontaneity, or everydayness, before Brian touches on the same idea:
} 
"What is that?...It's probably that level playing field thing...of how that's antithetical to notions of quality assurance. And there's a certain egalitarianism that comes with that...a certain all comers kind of politics... which is probably why I make zines...they're wilfully kind of amateurish"

I see the morals and ethics held within punk as part of a positive and accepting, yet critical attitude, which is both conducive and antithetical to academia. The ability to fulfil both of these roles is why punk as a mode of practice interests me. The awkward discomfort in which it enters academia only serves to make it even more interesting.$$
* * *
$$

"If I were an anthropologist I could write quite an ethnology about that queer tribe of academics. But from my vantage point as an anarchist I can find even more to say" (Gelderloos, 2009 )
\end{abstract}

Not only did my interest in punk provide what I saw as valuable and practical tools for modern day survival, including inside a university classroom, it also led me to anarchism. In very general terms, anarchism is "a practical approach to social transformation" (Shants and Williams 2013:2). In more specific terms anarchism is a "faith that strives for the liberation of individuals from political and economic domination and exploitation through methods of direct action such as the building of alternative institutions as models for a working anarchist society" (Kinna 2005; Gordon 2008; Ehrlich et al. 1979). As a political movement, anarchism aims for a democratic decision making process whereby everyone has equal roles and society is collectively 
run. Coming up with a tidy description of anarchism is a hard task because there are multiple anarchisms occurring all the time, in all sorts of places wherever people are organising on their own terms (Haworth, 2012).

Within academia, the influence of anarchism has been wide spread, with notable contributions to pedagogy, feminism, sexuality, gender, contemporary political theory, economics, cultural studies, as well as other disciplines (Kinna, 2012). Contemporary links between anarchism and academia place a reflexive emphasis on the role of the academic, particularly concerning teaching and research. Anarchism, with its commitment to challenge authority, hierarchy, domination, and elitism, points towards a teaching method based on mutual learning and research done with and for, rather than on people.

Despite the wide and somewhat scattered influence of anarchism, Gordon (2008) gives four general themes within:

- A direct action politics focused at the grassroots level, fostering both community and confrontation

- Organisation based on horizontal consensus based decision making. Anarchism seeks new forms of social, political, and economic arrangements that enable people to live in a way that frees them from hierarchical power systems that oppress those in subordinate positions (Haworth, 2012). An anarchist society, pedagogy, or collective would be based on organisation, co-operation, and freedom.

- Encouragement of diversity in cultural expression.

- An emphasis on resistance to the state, capitalism, patriarchy, hierarchy, and all forms of domination. Here, we should mention that the influence of the state in our lives is fully entrenched through a myriad of often un recognisable forms. Today, 'the state' and the violence it inflicts, has infiltrated our society and lives, and 
is no longer an easily recognisable enemy behind big steel gates. As Ward (1966) says "the state is not something which can be destroyed by a revolution, but is a condition, a certain relationship between human beings, a mode of behaviour; we destroy it by contracting other behaviour, by behaving differently".

The diversity of anarchism and the vast forms it takes within everyday lives may make it hard to encapsulate, but this is also its greatest strength. As Shantz and Williams nicely put it, "anarchism is the never-perfectible balance between collective unity and individual autonomy, the equilibrium between collective power and restraint, and individual responsibility and choice" (2013: 30).

There is also tension when it comes to anarchism and academia. In 'The 'New' Anarchists (2001: 1), Graeber points to what he describes as the "gulf between intellectuals and activists; between theorists of revolution and its practitioners". I talk about this conflict more in chapter 3 .

While the goals of anarchism may not sit to well with everyone, it is the focus on action which is particularly important. By this, I am referring to a closer more critical look at the systems and methods through which we work to achieve a particular result as academics. From an anarchist perspective, this would involve both figuring out how to use the rules of the academy to support radical research, but more importantly "challenging the assumptions, values, and structures that underpin the practices and behaviours that anarchist sociologists and anthropologist seek to study and critique" (Kinna 2012:8).

It was the idea of doing academia differently which attracted me to the ideas of Paul Feyerabend. When I first heard of 
Feyerabends book 'Against Method' (1975:23), it wasn't in a class on methodology, but on the social construction of knowledge (Crotty 2003; Wilson 1999; Tsou 2003; Martin 1996; Fischer 2007). Feyerabend argues that "the only principle that does not inhibit progress is: anything goes". More than just an appeal to those punk ethics we just talked about, this account highlights not a lack of variety or experimentation with method, but the domination of method by hegemonic accounts of what it should be. I agree with Law (2004) when he says "if 'research methods' are allowed to claim methodological hegemony or (even worse) monopoly, and I think that there are locations where they try to do this, then when we are put into relation with such methods we are being placed, however rebelliously, in a set of normative blinkers. We are being told how and what we must do when we investigate. And the rules imposed on us carry, we need to note, a set of contingent and historically specific Euro-American assumptions" (2004:4-5). Max Forte (2014:2) has also commented on this, specifically in terms of Anthropology as a discipline. He writes, "Anthropology arose not a mere 'handmaiden' of imperialism but as one of its very children and it served the knowledge-gathering, planning, and ideological purposes of the imperial fatherland"...[and as] a particular historical baggage of conventional assumptions, traditional methods, and received theories and concepts". Forte argues that the Anthropology (with a capital 'A') that is currently being practiced within university departments is quite different from the... "many informal, mundane, and everyday anthropologies produced consciously or reproduced unconsciously by diverse communities and persons everywhere, as well as the anthropological narratives that are produced by (inter) state institutions and non-government organisationsanywhere people have an interest in understanding and explaining themselves, others, and their place in the wider world" (2014:2) . 
We know that our methods produce a certain reality. We can't escape this, but we can attempt to loosen those methodological limitations in which we place ourselves. Feyerbend puts it nicely when he says, "any such method is in its last resort a method of deception. It enforces an unenlightened conformism, and speaks of objective truth; it leads to a deterioration of intellectual capabilities, and speaks of deep insight; it destroys the...tremendous power of imagination, and yet speaks of education" (1979:179).

One possible path towards a more lenient take on method comes from the work of John Law, who in his book After Method: mess in social science research (2004), asked:

"If this is an awful mess...then would something less messy make a mess of describing it?" (Law, 2004:1).

What happens when we try to approach the "things that slip and slide, or appear and disappear, change shape, or don't have much shape at all?" Law suggests we need to look at new ways of knowing: through our bodies, through our emotions, "knowing the indistinct and slippery without trying to grasp and hold them tight" (Law 2004:3). Law says, "my hope is that we can learn to live in a way that is less dependent on the automatic. To live more in and through slow method, vulnerable method, or quiet method. Multiple method. Modest method. Uncertain method. Diverse method. Such are the senses of method that I hope to see grow in and beyond the social sciences" (2004:11). Malcom and Zukas (2009:498) state that "although disciplinary boundaries and identities are constantly shifting, contested and dissolving, discipline...is a crucial organising principle for academic work. Academic workplaces are usually constructed physically, organisationally, culturally, managerially and in many other 
ways by discipline; many of us work in disciplinary departments with our own cultures and practices; we are managed (at least immediately) by members of the same broad discipline; we spend much of our time each day with our 'disciplinary' hats on, regardless of the activities with which we are engaged" (2009:498).

In the beginning of this project, I may have been trying to 'put on' my 'anthropologist hat'. I should have realised however, that for the last six or so years (if we only count university and not everyday of my life), a permanent hat had been forming, and was being formed, on my head. To try and take it off may be impossible, but it is certainly worth a try.

"Yes, but what makes your project Anthropological?"

Lecturers seem to ask this a lot. And I don't know what to tell them. Probably because I still don't really know what anthropology is or isn't, and how it's different from many of the other social sciences.

Then again, it's not called a discipline for nothing.

"I'm doing it within the Anthropology department" I could tell them. It's the only thing that comes to mind. But somehow I don't think it will fit the bill.

Although I haven't fully come to grips with the forms of discipline within my own discipline of cultural anthropology, I would argue, as Malcom and Zukas (2009) told us above, 'disciplines' have a powerful effect. Frowler (2008) might even refer to it as 'epistemological essentialism', a notion that sees the 'discipline' as a closed structure. This project, has to be an 'Anthropological' one because I'm 
enrolled in an Anthropology course, and it will be held up against 'Anthropological' academic standards, not 'Sociological', or 'Geographical', or any other discipline. But as long as I don't really even know what the difference is between these disciplines, the standards this project aims for are scattered and confused, at times non existent, at others overwhelming. While I recognise the power of discipline and disciplines in shaping ideas and actions, "what makes this project Anthropological?" doesn't seem like an important question. It was either Max Forte or David Graeber (is it important which one? Possibly...) who said something like "the difference between important questions and questions important to Anthropology, are often quite significant". For me, important questions are important questions, and while we should be aware of the disciplinary constraints that live throughout our work and ourselves, I don't think we should be overly concerned about making our work appeal to some specific category of knowledge. In fact, I think we should be trying to shake off the constraints of discipline and the baggage that comes with it. Maybe then, we will be able to see our beloved areas of knowledge thrive at their full and various potentials.

In probably one of the most well known studies of academics, Pierre Bourdieu's Homo academicus, we see an attempt to "trap homo academicus, supreme classifier among classifiers, in the net of his own classification" (1988:xi). Although the title of Bourdieu's work may give off an attempt to view the constantly shifting academia like a scientist through a telescope, his emphasis on academic reflexivity is what I see as the most important idea within the text. Wacquant (1989:12 ) writes, "Bourdieu's aim is to show how sociologists can overcome the antinomy of objectivist explanation and subjectivist understanding and account for the very world within which they live on condition of turning upon themselves 
the scientific tools for objectivation that they routinely employ upon others so as to neutralize the biases inscribed both in the contemplative relation between the social observer and her object and in the fact of occupying a particular location in the universe under investigation". Homo academicus, can therefore be seen as a political intervention for academia....[T]his book can be used in academic struggles to help increase the autonomy of the scientific field and thereby the political responsibility of its participants by making them more aware of the hidden determinations that operate within and upon it" (Waquant 1989:2); a goal this project would be silly not to want to support.

An approach and 'method' which considers the ethics of punk, anarchism, accepts mess, is open to the diverse ways of being and knowing, and aims to free itself from notions of disciplinary and academic legitimacy, can, of course, have a precarious relationship within academia and the university. I'm told anything is possible as long as you can justify it appropriately, and on these lines, Gordon (in Kinna 2012:91) has some advice: "at the end of the day, all you need to do is convince your examiners and/or committee that the piece of research that you have produced passes the bar in terms of disciplinary legitimacy. This will obviously be more difficult in relatively conservative academic institutions, but should be possible as long as you dress up your material correctly"; A 'methodological 'apologia', in Gordon's terms. But what if it's exactly the 'disciplinary and academic legitimacy' that you want to challenge? What if, for some bizarre reason, you'd rather dress your work down, than dress it up?

There is a way in which we, and the work we produce can appeal to both an academic audience, but also challenge the restrictions and gates around what constitutes 'academic work'. It might be hard to please everybody, but then that's 
probably not the best reason to do it. As Brian tells us below, it can be a bit of a balancing act between 'playing the game' just enough to enable some challenging of the rules by which it's played.

Back in the kitchenette/staffroom the sun had began to shine in my eyes and maybe even make my forehead sweat a bit. I squinted and took a sip of black coffee. It reminded me of every teacher I had ever had, breathing down coffee and basic facts. It also reminded me that at one university department I visited, good plunger coffee had held an important role as the bringer together of academics; creating a sense of community, building morale, exchanging ideas, and all the other good things that happen when we get together as a group of humans. When it was decided that changing to instant coffee was the best way to save money, there just wasn't quite the same effect.

But anyway, as the sun shone in my eyes and my forehead began to sweat, and as we drank our coffee, me and Brian talked about the rules of the research and publishing game:

"I had a sort of ambivalent relationship to the kind of research component of my job. It doesn't support some of the very kind of punk informed grass roots activity that I see as research. But because the politic of punk was a level playing field and an invitation to participate, that's sort of the antithesis of academia in a way, and the antithesis of professionalism where you carve off a niche and go 'I am the expert, come to me to find out about this subject area'. I think that's where professionalism and/or academia comes from. And that flows into something like PBRF [Performance Based 
Research Fund] in terms of who of repute has given the green light for this project to show it's quality assurance or something like that so this ambivalent relationship with those notions. I think in the first PBRF for example, performance was not considered a research output or it was hard to kind of push that thing through. But by the second round it was something that artists could have acknowledged as the types of research were wrestled away from a sort of science model and it being all about words and papers and chapters and you know reports and that sort of thing. I'm not deluded enough, romantic enough to be surprised that these mechanisms, these hierarchical mechanisms are in place in terms of what research is accepted. I groan about it a bit, I get on with it, I do my projects that are going to fail that criteria and then I do some projects that are hopefully going to answer to that criteria without completely selling out. So yea it's definitely walking a line where its like ok I'm never going to be the star researcher...as long as I sort of bloody minded try and buy into particular notions of the kind of publishing that I want to do..."

In much the same way as Brian's zines challenge the notions of expertise, quality assurance, and academic gatekeeping, Jeppeson (2011:1) argues that the function of literature has a dual function. It is made up of, "interventionist perspectives [which] interrupt the dominant image machinery, and the cultural prefiguration whereby anarchist values are engaged within the text, prefiguring the society we are building through our actions". Like Brian's focus on critiquing the rules and elitism of academic publishing through the zines he produces, Jeppeson notes the consistency that exists within anarchist literature (although not necessarily) between the modes of production that go into the making of the product, as 
well as the content and form of the text itself. Without having to make a vocal statement on the politics of publishing, Brian's zines speak for themselves and can be seen as an intervention into the academic mainstream that dominates the publishing environment.

Apparently, Guy Debord, French Marxist and founding member of the Situationist International, bound one of his first books in heavy sandpaper so that all others that came into contact with it were literally slowly destroyed. Stopping short of this (although I have seriously considered copying the idea, and think it's really cool), every copy of this thesis has been either lovingly, or not so lovingly (depending on the amount of time I have left when it comes time to bind), handbound, using old filing cabinet cardboard separators and an individually stamped title. No doubt, (at the time of writing this, I haven't actually made the thing yet), it will look like it was made by me; mistakes, spilt glue, crooked edges. No canvas binding and, no royal blue or black cover, no golden inscription, no red dangly thing to keep your page, although that would be useful. It doesn't look like a normal thesis to be deposited into the bottom of a dark university basement. It can be reproduced and distributed cheaply and easily; the university can be a source of free printing (as well as the paper it's printed on), material for covers (because filing cabinets seem to be becoming redundant), not to mention the various stationary required to essentially make a book (pens, tape, glue, rulers, various clips and staplers etc.). I would like to think that part of the story that this thesis is trying to tell, is told through what you as a reader are actually holding.

According to stoller (1997) the idea that texts are to be read and analysed only is Eurocentric. For anthropologists who often work within societies that place no value on texts, 
Stoller contends that we need to be more aware of the 'sensuous epistemologies' that play into human experience. Everyone likes the smell of books don't they? The way the edges curl, the notes previous readers have left in the margins, maybe what they were eating for dinner at the time of reading. Perhaps it's a bit romantic but the point is that reading a text can be about more than just reading it. It can also be about the object itself, which has its own messages to go along with, and add to, the words inside.

It is in this way that I see this text embodying the values that are talked about within it. Along with this, I thought it was important that my actions, and the way I went about gathering information also embodied these values. The nature of being a master's student within a university programme required that I had three distinct methods for the collection of data. The decision to choose participant observation, interviews, and auto-ethnography, at first occurred somewhat automatically. They seemed like good methods, the ones everyone else was using, the ones most people seem to use. While the labels that are attached to these methods carry with them a whole lot of baggage, and ideas on what to do and what not to do, I looked for an alternative way to carry out these ethnographic methods. In his essay on participant observation for example, Jonathan Purkis (in Kinna 2012), draws on hitchhiking as a model for an anarchist social science. The hitchhiker notion relies on the process of mutual aid. A hitchhiker receives a ride and in return keeps the driver company who has made the decision to pull over and pick them up. More than that though hitchhiking merges theory with practice. The hitchhiker travels across the country experiencing and observing "the landscapes of power through which they are moving, yet seeking alternatives to its hierarchies and formal economies through constant negotiation and exchange" (Purkis, in Kinna (ed) 2012). 
I may not have been an expert of ethnographic methods. Hitchhiking on the other hand is something I'm more familiar with. As a student in Dunedin, I discovered traveling home to New Plymouth could be done all for the price of a couple of pies and a ferry crossing. It was a 24 hour adventure that relied on the kindness of individuals, a faith that those individuals don't always want to kill you, and that it could actually be an enjoyable experience for both parties. With the only direction being North, and the only limitations being money, the hitchhiker can't buy a plane ticket, or even pay the taxi fair to get to the airport; They must look for alternatives. So they wait on the side of a road with a sign, or their thumb sticking out, hoping for a ride and trying to appear like you're worth picking up. The ride you're looking for only comes when a driver decides to pull over and pick you up, and the decision is theirs alone. Sometimes it feels a bit like the driver just felt sorry for you and wanted to help you out, like maybe that guilt inducing look you were giving them worked. Other times, it feels like you are helping the driver; they might be travelling a long way and feel like some company. In which case the hitchhiker should of course respond with pleasant chit chat. Not too much though, or the driver who so kindly offered you a ride may regret ever doing so. Things might start off a bit awkward but before long you're talking and listening and learning things from each other. When you reach your destination (this should be convenient for the driver and not out of their way) and it's time to get out of the car, the hitchhiker says 'Thank You' to the driver and they part ways leaving each other with only the memories of conversations and time spent in the small space of a car. This seems like a nice approach to research; a relationship of mutual aid in which both the researcher and participant have something to gain, that something being based on the time and knowledge they have shared with each other. 
On a similar note, Alejandro de Acosta's (2010) three 'meditations'; daydreaming, fieldtrips, and politics of psychogeography, also point to new ways of becoming within an environment. According to de Acosta, daydreaming relates to the fact that we can only dream of the future, but "we are dreaming, fantasizing, but in a particular concentrated way, acting on ourselves in the present" (de Acosta 2010:9). We probably all have our own 'utopian' academia; our perfect idea of what academia (or anything) should be like. While it may be an unachievable goal, there are ways of acting that can bring it that little much closer to becoming a reality. The fieldtrip is a "speculative anthropology of geographical spaces" (p12) and calls for engagement with material space rather than through written or spoken discourses. This approach sees scientific procedures put on the back burner, or ignored completely, and instead considers the importance of place, of the organisation, history, the make up of space, and the development of a thesis in relation to that space. In de Acosta's words, this involves "the unusual idea that it matters where one is when one thinks." (2010:13). While we may think of academia as something which takes place within the walls of the universities; in offices, lecture theatres, laboratories, and classrooms, our spatial disciplinarity is not as closed as we might think. As Malcome and Zukas (2009:500) explain, "as you read the paper, perhaps in bed, or on a plane between countries, at some time in the future, or interact with us in the past, at a laptop on the kitchen table in the house which neither of us live in, and a city where neither of us works. The workplace does not produce work; rather, purposive academic work itself creates the workplace in a way which evades the spatial and temporal discipline of the academic institution and of the educational policy structures which drive it". Defining where academia takes place is therefore a hard thing to do. However, while academia 
may escape spatial restrictions, a large part of it does occur within the distinct space that is the university, and this space has a strong effect on the work that takes place within it. Unfortunately, universities seem to become a place where people want to spend less and less time, and the reasons for this are not coincidental. I have heard lecturers say a number of times that they prefer working from home because as soon as they come in to the university, phones need to be answered, forms need to be filled out, and the general bureaucracy of the place quickly makes itself evident. Often, this results in an institution filled with closed doors, dark corridors, and an isolated institutional feel:

"So I go through moments of that where I you know as we drive up towards Kelburn, I get what I call the giant foot on my chest. I get the feeling like someone is restricting my breathing by pushing down on my chest, and that's something the environment can tend to bring down on people and you know those are symptoms of being bullied and harassed and I don't mean by individuals. I mean by the system. For me it comes and goes but then I get all buoyant and defiant and ridiculous and whatever else I get or I find a moment... So I had the most amazing two classes last semester and suddenly I spring into life again you know little things. But I know it's a common condition for my colleagues because you walk around here and see it. You can walk around Victoria University and see nothing but closed doors and no lights on and I've said sometimes the academics are in there, they're just not signalling they're in there so that nobody disturbs them. So that's a bad thing. But sometimes its because they just don't want to come on to campuses because if they come on to campus, the regime oppresses. So they stay off. And again that hollows out the nature of the 
institution. You know, it's a sad fact. I mean it's not all doom and gloom because there are fantastic parts to the job and there are fantastic parts to being in an education system and there are fantastic moments but they are becoming smaller, tinier and less..."

This quote being, from Sandra Grey who has been one of the academics most willing to stand up and comment on her own institution, although not without thinking carefully about it. As the current president of the Tertiary Education Union (TEU) it could be argued that Sandra has the support in place to be able to do so. However, the solidarity that she has found within the union, after struggling to find it elsewhere in academia, isn't enough to silence the disciplining mechanism within the neoliberal university

“I've never been disciplined for speaking out. I would invoke critic and conscience pretty damn quickly if I was. But I was asked to speak by a student group recently. The policy is that that's not public space, that you're supposed to have university permission. I rang the union prior to going to that to ask 'will you defend me if I do get arrested and I find myself in front of disciplinary hearing, are you going to come and...' I knew they would but it's always good to check first. But I thought long and hard about it. I mean, nothing happened, but I am...the fact that I...probably one of the most willing to do these kind of things goes...' 'and will I get into trouble?'... and so I process it first and then...It's one of the most fearful things I've ever done. It's easy to speak on other peoples campuses, very hard on your own. I mean I am conscious that it's not sanctioned. It's not. And I am saying things inside my own institution. I'm probably on public record as saying them. But it's much easier to do it about others than 
about your own. Your own Vice Chancellor and your own space. But yeah, you think about it and then you do it anyway. I don't see any option. I no longer see any option. And my biggest challenge is to my colleagues to stand up and do the same".

Sandra talks about these ideas within her own research (Grey 2013), saying that resistance to the neoliberal university must take place on a day-to-day basis and be carried out collectively between students, academics, staff, and members of the community. With a tight knit community offering support and encouraging active engagement, an environment can be built in which dissent and resistance has an important and celebrated part to play.

It may seem trivial, but these small environmental aspects have significant effects. Psychogeography, a term used by the Situationist International, relates to the effect that the environment has on our emotions and behaviours. As Guy Debord wrote in 1955, "psychogeography could set for itself the study of the precise laws and specific effects of the geographical environment, consciously organised or not, on the emotions and behaviours of individuals" (1955:1). de Acosta (2010) wants to not only understand the effects of environment, but act on them, thereby producing other effects and lines of flight. Drawing on the Situationist notion of the derive, or the "experimental behaviour of wandering across an urban space with no determinate destination" (de Acosta 2010:16), Acosta sustains that by being within and travelling through "landscapes of power" to use Purkis's term, we begin to see the emerging detachments, movements, escapes and evasion, as well as creative flights of fancy" (2010:16). To use Deleuze and Guatarri's term, these 'lines of flight' point towards a "world of continuous variation, becoming, and chance, rather 
than one of constancy, being, and predictability" (Deleuze and Guattari 1988) •

These types of 'tactics without teleological strategies', that de Acosta (2010:199) gives us provide endless amounts of opportunities and possibilities, (not to mention failures, which can end up resulting in even better success), because they are blind to barriers and borders, seeking only mobility and the freedom of open space. As Ferrell writes in his paper “Against method, against authority...For anarchy' (in Amster et al. 2009:73) "the only strategy for anyone serious about progressive knowledge is a refusal to take seriously the cannons of received wisdom". The way that these ideas manifested themselves within my methods are hard to pin down exactly, but they gave me the confidence to pursue an academia which was open to the constant reworking and mistakes made by myself as I attempted to view the space around me in a way which would enable me to write a thesis about it.

Given that my decision to focus on academia and academics grew out of my own experiences of university, auto-ethnography seemed like a suitable method to add to the list. As with participant observation, auto-ethnography "foregrounds the multiple nature of selfhood and opens up new ways of writing about social life" (Reed-Danahay 1997:3). At its worst, this has the potential to result in narcissistic ramblings, however, at its best provides a better understanding of our own uneasy role in the social world (Chmiel, 1995). What do I mean by 'narcissistic ramblings'? Perhaps Amy, a social scientist within a school of design said it best:

"The reason I don't like auto-ethnography is because it's too 'I' centred. It just always comes back to the person. I mean it teaches us a tremendous amount about the person whose doing it and my personal perspective is that it 
teaches us significantly less about the rest. Put it in the hands of students and it doubly reinforces what they're already taught to do".

Lock (2009) and Doty (2010) also question the self-indulgent nature of turning your own place of work into a 'field site', however, this doesn't take away from the importance of understanding the institutional context in which knowledge is produced. As Reed-Danahay (2009:28) reminds us, “our scholarly production takes place in the context of particular social fields within which we negotiate as social actors". I have found, as have Humphreys (2005) and Holt (2008:5), that my own story, as well as the stories of academics are "hinged on a series of clashes between my personal teaching history (in my case my personal educational history) and the...ideology of the research institution I had joined". It's here that I see auto-ethnography having value as a method. I can't separate this project from the experiences I have had as a university student. Instead, I aim to use them in order to add to, rather than overpower, the variety of experiences and opinions expressed within this project.

There have been many auto-ethnographic pieces of work done within academia (see Bourdieu 1988, Strathern 2000, Ortner 2005), but as Reed-Danahay (2009) explains, little of this has focused on the practices of academics themselves and is largely 'tales from the field' oriented. Humphreys (2005) makes a contribution here, as it is his intention to use 'episodes' from his own working life to express his involvement within the academic world; quite a nice idea I think. He uses what Saldana (2003:221) calls "meaningful life vignettes" in order to "encourage readers to taste the flavour of a crucial period in my academic life placing myself as one of the actors firmly within the play itself" (2005:842). 
[From dairy]: "Just spewed again. The $4^{\text {th }}$ Friday morning in a row, before a tute and I'm not even really tutoring. The lecturer is there too- I just go around the groups and talk about the readings and stuff. But it's enough to tie my stomach in knots the night before; I can't think about anything but the class in the morning, spend way too much time going over the readings, then get pissed off that I stopped getting paid for this hours ago, I can't eat anything, pretty much just freak out. That part I can kind of get used to. But the spewing? I've never been so nervous about something that it made me spew and definitely not every Friday morning for 4 weeks. Obviously this means I can never be an academic. They're in front of people all the time. Performing. Presenting. Taking it all in their stride. Where are all the ones that spew before giving a lecture?

In what Lerum, (2001) referred to as 'academic armour' I hope that the auto-ethnographic elements give an honest account of some of the more unheard of aspects of academia. Ronald $\mathrm{J}$. Pelias's (2003:369) article, The Academic Tourist: An Autoethnography is "written in an auto-ethnographic style, [and] offers a sociology of the academy through descriptive details. It invites emotional identification". Emotion was something that I always wanted to have a central part in this project; I wanted to know how is feels to be an academic, but the conversations usually ended up focused around larger structural issues. According to Fabish (2014: 52) the thing that she found most useful about researchers using autoethnography was "their willingness to turn towards their own emotional responses as a source of information about society". Pelias's (2003) article gives us an honest glimpse into the life of an academic, which no doubt inhabits each and every one of us; "you will know that you could read more-it's surely available- but you probably won't, because who wants to read 
an article when Friends is on, or when friends are available for a drink, or when you could just take a nap (Pelias 2003:307)... and you feel exhausted, but you want more than anything else for this essay to be off your desk and you think that you'll just cancel having a drink with your friends tonight and that you'll just take a nap because your feeling tired, even though Friends is on" (Pelias 2003:373). To read something like this in the form of an academic article kind of inspires me, but possibly also comes with a risk for the author. What sort of lazy academic watches re-runs of Friends instead of re-reading Foucault? (people may ask, for example). As Brogden (2010: 370) says, “The autoethnographer, by laying bare some aspect or aspects of her or his being is offering a story and taking a risk". Like this project, Brogden is interested in "querying the discursive production of said identities through a reviewing of some of my own ways of being and becoming and in transforming fragments of "I/i " in research". He quotes Tami Spry (2001:710-711) who says, "autoethnographic methods recognize the reflections and refractions of multiple selves in contexts that arguably transform the authorial 'I' to an existential 'we'". This has been quite a struggle because like Jenks says (2002:171), "It's taken a long time write about my experiences, and I'm still not sure my own narratives are appropriate 'data' for analysis" .

Geertz (1988) said that the use of auto-ethnographic vignettes (a small piece of writing like the one above) gives the reader a sense of being there, and of experiencing the events for themselves. But for them to be effective and not just random snippets of 'too-much' information, these bits of autoethnographic prose, could benefit by being weaved with theoretical debates, as well as the 'data' I've been collecting throughout my 'fieldwork'. A bit like telling a collective story, my own and those of others, the meaning of 
which isn't stated explicitly but is left up to that collective to decide. I don't really see the point in looking to encapsulate the 'true essence' of academia; such a thing surely doesn't exist. Instead, I like Michael Taussig's approach to writing. He sees it as his job to take the stories of others and then craft a story of his own, a 'creative nonfiction' as he calls it. Like Taussig says, "I see anthropology-let's put it this way- as the study of culture. But in studying culture, you remake culture through writing or making a film or whatever other representational mode grabs your fancy" (Taussig 2013). While this project includes the stories of others, I, as the 're-teller' of these stories have always had the significant power of deciding how it gets told; something which doesn't exactly sit easily with me as I'm constantly thinking I'm telling it wrong, or could be telling it better. As Anne Game (1991:186) puts it in her book 'Undoing the social: Towards a deconstruction of Sociology', “over the last twenty years or so there has been a crisis in authorisation: who can speak for the other? From what position and on what basis?... What is of particular importance in this is the acknowledgement that the (self) Same-Other relation structures knowledge...This calls, then, for a process of constant critical checking, a critique of 'the present', and importantly, self critique" (Game: 1991: 186).

While there is always going to be a personal reflexive element to anthropological work, I had always intended the stories of the academics I talked to, to be at the centre of the project. One of the motivations behind the research was simply to talk with people about how it feels to be academics working within today's universities. I wanted to learn more about the experiences of those who spent their days at the same place I did, those who valued the university but at the same time were aware of its contradictions. It's a strange thing to talk about 'selecting' the people you want to participate in your 
project. Why did I select some and not others? In a couple of cases, people volunteered, or were roped in by another participant and I was saved the decision. However, either way, I was still faced with the question of why I 'selected' the people I did. It's a tricky question to answer, and one that I think I put off answering for a while. I didn't want to develop certain criteria with which to assess the suitability of participants; that seemed like a weird idea. But I was 'choosing' particular people. How was I supposed to justify my choices? What would I say when asked "why did you choose to me?" Surely "because you seem different to the others" would not suffice.

Returning to that sunny Kitchenette/staff room, I joked with Brian about the awkward idea of labelling the people I wanted to talk with:

“' 'Outsiders', 'procariates', 'trouble-makers', the 'disillusioned', 'disenfranchised'" The list of potential labels sounded strange enough in my head.

"Heathen academics!" chimed in someone at the sink washing their cup.

"What about Heathen academics?"

Even the participants had an idea of the participants I was interested in.

"Yea, I need a whole bunch of cool terms to throw at you guys"

"You've gotta invent one! Invent one and that's ya PhD!" 
So with images of 'heathen academics' in my mind (but not really), I started to make a mental list of some of the people I'd like to talk to. I already had a number people in mind, two that I had interviewed the previous year for my project on academics and punk. I guess I was looking for those who displayed these non-conformist, any-one-can-do-it, Freireian ideas within their own academic practice. Those who made academia work for them, despite pressure to fulfil a certain role and those academics I had admired for doing just that.

Once I had a few people in mind, I either emailed them, or if it was possible, I went and saw them in person, and asked if they would like to participate in the project. It still seems a bit cheesy, and as much as I despise those elevator speeches that everyone's always saying you should come up with, I had one semi-ready and the email contained a brief outline of what it was I thought I was interested in. Usually something along the lines of...

“ $\mathrm{Hi} \ldots \ldots+\ldots$

I was wondering if you would like to take part in my master's project. I'm interested in academics working within universities (or students thinking about becoming academics) and how they negotiate their personal identities within their workplace.

I think what I pretty much want to do is talk to other students and academics that may be in a similar position to me, to get more of a dialogue going about what it means to be an academic today.

Your participation won't require anything too arduous. I plan to do some preliminary interviews over email (This will be done a question or two at a time which can be answered at your own pace), then some in person 
interviews (probably an hour), and if I can get three or more of us together at the same time, a group interview. I was also thinking it could be useful to give you each a notebook to keep any thoughts about the topic that may arise throughout your day. But I understand that this could be a hassle- if so, no worries. Everything will be confidential and you can pick or be given a pseudonym. If you're interested, that's great and you can get back to me with any questions or ideas and I can email you an information sheet. If not, it's all good. I'd still like to hear any thoughts you might have".

Generally, everyone was more than happy to participate; in fact, I was quite surprised at how quickly some of them said yes before I had even told them much about the project. I think this was probably because the first few people I asked had either been interviewed by me before, had been my lecturer, tutored me, or we just knew of each other from attending the same university. Rice (2010), as well as Mikecz (2012), state that when interviewing those in a higher position, gaining access, acquiring trust, and establishing rapport, can be a challenge. With many of the participants however, I had already formed some sort of relationship. This may have made the interview process slightly less daunting, but the range of opinions that the participants held led me to question how I was going to 'keep them all happy' while still saying the things I wanted to say. Although the academics I talked to all seemed to bring up similar concerns regarding their common condition as academics, the way they responded to those conditions varied considerably, and at times I struggled to situate my own opinion, which sometimes differed greatly from that of the interviewees, within this variety.

In a couple of cases, those already participating in the project recommended people for me to speak with. Even better 
than that though, as word of my topic began to spread, people came to me and asked if they could be involved. If people left the interview and felt comfortable talking to their friends about it, and even encouraging them to be involved, this must be a sign that it was an enjoyable experience, or at least not a bad one. I couldn't turn them down, and so, at the start of the project I may have been looking for a specific type of academic, as it progressed, the academics began to choose themselves.. The fact that these 'real' academics actually wanted to be involved in the project was a big boost to my confidence as a researcher and encouraged me that there were important things to be said about academics and their place of work. Receiving emails like the one below told me that I must have been doing something right:

"Hey Olly,

Great interview. Really enjoyed it and it is an awesome area that you are researching. Couple of thoughts..."

It really did seem like the academics knew exactly what it was they wanted to tell me. I suppose academics are the type of people that think a lot about all types of things and their own position within academia was certainly one. Perhaps surprisingly however, it wasn't a topic they often talked about, and this came through in comments like;

"I'd thought a lot about it, but never really talked to anybody about it. It was nice to be on the other end of an interview".

I had previously worried that as an interviewer I wouldn't have enough to say; that these academics (who were probably expert interviewers) would be left thinking what an amateur I was. I had a list of questions in case I was left with a mind 
blank and nothing to say, but I didn't want the whole thing to be reduced to a question answer session. Lucky though, Henderson (1974) states that when interviewing elites, or those in a more powerful position, the interviewer should be willing, even eager, to let the interviewee indicate what the problem, question, or situation is. In some cases, and maybe a bit cheekily, I asked academics "if you were me, what questions would you ask?" This led to the interviewee constructing a list of a few aspects that they saw as being significant to their own experience as an academic working inside a university. This provided a number of talking points for me to continue with and meant I didn't need to rely on the list of questions in front of me.

With no real idea of how to go about interviewing someone, and a number of concerns that these experts would think I was doing it all wrong, I decided to ask for advice:

"How do you do interviews Charlie?"

"Well to be honest, I haven't really done an interview since my $P h D$ so $I$ wouldn't really know..."

This took me by surprise. Maybe, for some reason, I thought all academics interviewed people. Even though Charlie may not have done an interview for a while, I still knew he would have something useful to say.

"How would you do them then?" I asked further.

"Well I guess it's just a case of finding what works for you and isn't too weird for the person you're interviewing". 
"So you reckon a casual type conversation approach is all good?". I'm hoping he says yes.

"Yeah I reckon you don't want anything to formal or rigid especially considering interviews are a pretty forced, on the spot type of method".

At that moment something clicked. I had this realization, and it now seemed so obvious. Of course interviews were a staged and unreliable way of gaining information; who would ever tell an interviewer exactly what they were thinking? No matter how much I wished my interviews to be more like a casual conversation with an old friend, sometimes there's just no getting around the fact that it will always be an interview. Rapport (in Skinner 2012) says that the distinction is a messy one, but "interviews are limited both in terms of time and of function, they are more focused than conversations which can last a life time and meander and sprawl and dissipate". Pool (1957) states that interviews are a place where people are forced to articulate how they feel about certain topics. It is in this way that 'truth' or knowledge is actively constructed 'on the spot' as Charlie had told me. Kasper (2007) follows on from this idea and argues that interviews are essentially question-answer sessions, in which the delivery and nature of the question has a significant role on the given answer. In what Kasper describes as an 'elicited conversation', the interviewee may take on a role which is in some way assigned by the interviewer. While all this meant that my doubts about interviews as a method were increasing, I felt like it was better to be aware of these weaknesses and do your best to minimize them, the information you were receiving was in any way reminiscent of objective truth.

This chapter has attempted to place myself within the research as I negotiate what it means to be 'doing' research within my 
own university. I have discussed the ideas that I consider to be important for my research as well as the way I went about talking with other academics in order get their point of view. While this research has a significant personal element, I aim to interweave this with the narratives of others in order to craft a collective story of our common, yet diverse condition as academics working within a modern day university. Purkis (2012) and Armaline (et al. 2009) say, the approach we take to research cannot be disconnected from the values that inform that research. I have outlined how punk, with its emphasis on Do-it-yourself, amateurism, non-conformity, originality, and anti-hierarchical and authoritative views, has inspired and enabled me to pursue an academia that was both successful and meaningful for me within an educational environment which I had various doubts about. Along with this, the importance of anarchism urges us to do more than critique the world around us, and to move towards a way of being which renders those old oppressive structures redundant. This, I feel, also comes out in the work of theorists like Feyerabend, Freire, and Law who taught us that we all have something of intellectual value to add, and if only what we saw as 'intellectually valuable' didn't exist within such strict confines, then this might be more evident. The methods I chose to use were standard, predictable even, but the ideas that I applied to them, gave me the freedom to pursue them in a way that I felt comfortable with, while also recognising the powerful shaping effect they had on the 'information' I collected and how I viewed that 'information'. 
Chapter 3: Theories of the academic 
In this chapter I discuss some of the dominant ideas around what it means to be an academic. To start, I asked academics what they thought their role was: Were they to be the 'critic and conscience of society' 'speaking truth to power'? Or were they 'just well paid middle class people, working for their own interests?'. Not surprisingly, the answers they gave me fell anywhere between these two poles. In a country like New Zealand, there is often suspicion towards academics. I discuss this public perception and look at some of the reasons behind it. I then move on to discuss some ideas we can draw on in order to resist the disciplining forces within our neoliberal universities, which aim to shape us all into a certain kind of subject. These ideas come to us from theorists such as Paulo Freire; who advocated a non-oppressive and liberating form of teaching and learning. Antonio Gramsci; whose concept of the 'organic intellectual'; grew out of the working class and had their best interests at heart. Edward Said; who asks the academic to question rather than consolidate power. Michael Foucault; who taught us about the 'indignity of speaking for others'. And C.W. Mills; who critiqued the professional careerism that is evident within academia. Many of these theorists sit comfortably within the camp of the Marxists, who have in turn, found a comfortable place within the academy. Here, anarchist thought provides a crucial critique that urges the academic to do something, whilst at the same time, dismantling the hierarchical structures that say they are the only ones capable of doing so.

\section{The public's perception of academics}

We all have those stereotypes of what an academic is. They may be made up of images of rich old white men in corduroy jackets with patches on the elbows, sitting in leather armchairs, reading leather bound books, drinking single malt and smoking 
pipes. While the whiskey in the top draw may have disappeared (or maybe I just didn't get offered any), we are still left with certain stereotypes of what it means to be an academic. Try telling a bunch of builders that you've spent the last 6 years at university, amounting thousands of dollars worth of debt with no real prospects of a job at the end. Apparently, me, and all the others with large student loans, are going to get conscripted to the army when world war three starts; $A$ short stint as cannon fodder and our debts will be wiped... or so my brother tells me. I asked someone at my house the other day what she thought an academic was and they said something about a person who knows heaps of stuff, but doesn't do anything with that stuff. The public could be right to think these things about academics, and it's a good thing to be critical of what we are actually doing and whether or not it is of any practical use to the society we live in. Maybe even more so than in other countries, the New Zealand public views its academics with suspicion and probably thinks they are all wasting tax payers money. Bridgeman (2007) reckons that our small population, isolation and the lasting effects of our once largely rural and pioneering culture places practical kiwi ingenuity, over intellectualism any day.

In many contexts, it can be slightly embarrassing admitting you're an academic, even a student who has spent too much time at university. "Time to enter the real world", they tell me, as I approach the end of my Masters. I hadn't really realised I was living in some kind of fake world, but there is certainly a rift, and level of isolation within and between academia within the 'ivory tower' and what actually goes on out in the community. When the academic finally meets with the outside world, the results can be slightly awkward. Joe, for example, an academic within an anthropology department, told me of the fun/disagreements he had with 'business people': 
"Do you ever...like..." I pause for a while because I think I'm about to ask a silly question. Maybe a few more 'likes' will help.

“...feel...like...a bit...like...weird about being an academic?"...

My sentence ends in a high pitch. In this academic environment, I'm even slightly embarrassed about admitting my embarrassment. I hope my question doesn't seem...stupid...

"Depending on the social context it can get up to embarrassment or unease, and it depends on the social context that your in. You don't want someone to think you're a wanker!"

"Are you a wanker though?", I ask... The pitch at the end of the sentence is even higher this time. I wait for a look of disapproval.

"Well either a wanker or an asshole ahahah...I've been in fights...not physical fights...but almost... with business people. My wife used to work for the Bank of New Zealand and I'd go to these parties with these business people and they'd say something disparaging about humanities and social sciences and stuff like how useless the degree is, and I'd tell them well at least they're getting an education, and they'd go 'what do you mean? I've got a bachelors in business and administration' and I'd go ahahah, I'd laugh and go ahahah yea you know that's like the same as going and learning how to be a refrigerator repair person...it's not like an education. A refrigerator repair-person is as educated in their field as you are in banking. But you're not well 
educated, and I'd say 'do you have any philosophy papers, do you have any humanities papers, social sciences, history? Ah astronomy....ah you know, what do you know about physics? What do you know about psychology, what do you know about sociology? What do you know about economics?' And they go 'well those are useless things, because I got my business and commerce degrees' and I go well then you're not a well educated person, you're well trained... and then they get angry....and I start thinking I better shut up now, and they all start thinking I'm an asshole...'That Joe guy, he's an asshole'".

Joe erupts with laughter and a cheeky grin that makes me think he quite enjoys winding up those funny business folk. Those business folk within the general public have a tendency to view academics with suspicion and a certain distaste. Roberts (1999:79) says "university bashing has become a favourite pastime for prominent representatives of major business and commercial organisations", and if you're within the arts and humanities, its even worse, as Joe's conversations with bankers at parties tells us. Increasingly though, it's not just at parties we encounter these types of business-centric ideas; they are very prevalent within our universities.

\section{The politics of education}

As universities become "increasingly reliant on external sponsors and concerned with their brand image in a competitive tertiary sector, the fear that academics will hesitate to go public on controversial positions that might raise the ire of the university management" is heightened (Bridgeman 2007: 139). One of the most important things that we learn from Freire is that education is a non-neutral, and political process (Roberts 1999: 103). Both teachers and students bring 
with them a bunch of different beliefs, values, motives, and life experiences, but on top of this, education is shaped by government and institutional 'policies', and 'strategic goals' which in turn affect the curriculum, that is, what gets taught. Our current context though is one in which education is not recognised as a political process; it is reduced to "the transfer of informational content from teacher to student, who are not required to apprehend it in order to learn it" (Roberts 1999: 104). For Freire though, education, at its most fundamental level, was about an interaction between people, people bound by constraints, but also subject to possibilities. If we would like to term our current context 'neoliberal', which I think we can, then we see a clear conflict between the two. According to Roberts (1999:101), "the philosophical assumptions underpinning Freirean and neoliberal approaches to higher education are fundamentally antagonistic. At an ontological level, neoliberals conceive of humans as self-interested, self-contained, rational, perpetually-choosing individuals. Freire, by contrast, sees humans as social beings shaped by their relations with others and the world with a variety of interests and commitments".

Importantly, the spaces in which our ideas, decisions, and actions are made, in this case the university with its own norms, customs, structures and values, shape what it is we see as 'rational'. In this neoliberal context, Freire believes "its' cynical fatalism and its inflexible negation of the right to dream differently, to dream of utopia" (1998: 22) negatively effects education by turning us into efficient consumers and dispensers of information, without asking wider ethical questions about that transfer. It "ignores the dynamism of learning, the interconnectedness of different subject areas and forms of understanding and the importance of seeing knowledge as necessarily incomplete and always evolving" (Roberts 1999:102). One of the most crucial elements 
of education, a critical engagement with the world around us, is being eroded by a system which places market demands at the forefront of importance.

This is in high contrast to what Freire was all about; according to Escobar (et al. 1994), he thought that the university should be a place where differences collide in a positive and stimulating debate, leading to numerous possibilities and opportunities for all those involved, no matter how dogmatically defensive, to learn from that experience. For differences to exist side by side in a somewhat 'comfortable discomfort', we all need to feel free to express ourselves in an endless variety of forms. We are, after all, humans with our own feelings, passions, morals and motives, and experiences, offering a range of perspectives that broaden our understanding of the world around us. As Gramsci says, 'the intellectual's' error consists in believing that one can know without understanding and even more without feeling and being impassioned" (1971:418). The university should be a "space where academics can be open with their students about their political leanings and students can feel comfortable disagreeing with their teachers...[however]...it seems likely that in the long term greater homogeneity in political orientations, a narrowing in research and teaching concentrations, and a dampening of differences will ensue" (Roberts, 1999:107-108). We need to build an environment that is not afraid of risk. Unfortunately, our universities are risk averse. While academics say they often have a certain amount of freedom in terms of the research they do, as well as their teaching, there are certainly pressures and 'benefits' to steering your research in a certain way that may align more closely to the goals of the university and areas that are likely to attract funding. 
Moving beyond critique: Merging theory with practice

The pressures to perform as a 'certain kind' of academic are numerous within a neoliberal university. Possibilities for resistance will rely on academics combining knowledge with action. Freire called for the raising of consciousness and the coming together of theory and practice; he uses Marxist term praxis. Collins states, “by combining reflective activity with his actions man gives human meaning to history and culture. If he contends himself with mere reflections (only theorizing about his relationships with the world), he fails to harmonize these relations because he limits himself to verbalism" (Collins 1997:48). However to act without theorising, without thinking, is almost as pointless and possibly more destructive as it fails to recognise and respect the needs and motives of other human beings. Only when we combine thinking with doing, reflection with action, can we achieve a praxis which, to use Marx's thesis eleven, moves past a mere interpretation of the world, and into the realm of changing it (Marx 1845:Thesis on Feuerbach). For academics, this involves doing more than critiquing oppressive structures in journal articles and books, and calls for a critical engagement with the world around us. Given the powerful effect that the environment in which our work takes place has on the work we produce, the university should be the first thing that we look at in a sustained effort of self reflection. Understanding that our educational institutions are being eroded by neoliberal, hyper-market ideology is one thing. However an "understanding of the complex processes of oppression and domination is not enough to guarantee personal and collective praxis". As Grey (2013:708) argues, "one of our first aims must be to collectively reconfigure what 'counts' as academic work".

Antonio Gramsci also urges the academic to do something, and not just analyse other people 'doing the doing' with what he 
called 'theoretically oriented action'. In line with Freire's conscience raising, Gramsci said that we must first come to realise that our ideas are built within a hegemonic context requiring two different forms of control. The first, coercion (the constant threat of punishment for stepping 'out of line'), and the second, consent, in which we as individuals make a decision (although often we're not given much of a choice), to conform to the status quo in order to avoid punishment, or gain reward as it may be. Like Freire's conviction that education is a political act, Gramsci saw hegemonic relationships of power as pedagogical, that is, they lead allies and dominate enemies (Gramsci 1971:57). We can though, both become aware of these forms of control, and also the potential to subvert them. According to Fischman and Mclaren (2005:431) "this means acknowledging the roots of capitalist exploitation as located within the extraction of surplus value from the surplus labour of workers by owners [as well as] the potential for resistance that resides with the workers on whom the system on capital depend". While, in typical Marxist fashion this sounds a bit 'factory-centric', the university hasn't come to be known as an 'edu-factory' for no reason, and as one academic signed off in an email "see you at the factory", the similarities are there. If the so called 'knowledge economy' relies on the knowledge that academics produce, then academics hold a powerful position as the producers of that knowledge. The problem is the context that we're in can take that power away.

In line with the idea of 'praxis', Gramsci's concept of the 'organic intellectual' is an attempt to turn resistance, which he saw stemming from discontent, into action. The organic intellectual grew out of the working class and their ideas were closely linked to the everyday lives of that class; that is "intellectuals therefore carried out universal functions that situated social activity within local and specific class 
struggles and in defence of class interests" (Fischman and Mclaren 2005: 433). Gramsci (1971) tells us that this takes more than intellectual ability to fulfil the role of organic intellectual, it also involves gaining the trust of a collective of people.

Richard's office was at the other end of the corridor to mine. I had seen the poster on his door advertising a Flesh D-vice and Horror story show at a bar in town. It stuck out because it wasn't a poster of a clever quote from Foucault or... someone else. Flesh D-vice were one of Wellington's most infamous punk bands, and Horror Story, another punk band, came from my home town of New Plymouth and put on misfits-ish performances in black leather and white face paint. If we consider office doors as a sign of your academic identity (and I reckon we could), then Richards was interesting. Walking towards the library one day, Richard and I crossed paths and did the usual "how's your work going" thing. I ended up telling him a little about what I was thinking of looking at, and after he showed some enthusiasm for the topic, I asked him if he would be keen to be involved. I get the feeling that whatever Richard does, he does it to the best of his ability. Without hesitating, he said he would love to be involved and we hashed out a time and place to do an interview. Richard knew exactly why he had come to university, and he knew exactly what he was going to do when he left.

On the afternoon of the interview, we met in the tutor's office. As usual, I started by asking if Richard had any particular topics he thought were important to him as a student. He told me what motivated him as a postgraduate student and why he wanted to become an academic:

"The thing for me is, you know that there's people like myself who do have academic intelligence but the opportunities to coming here are sealed off from us in 
our youth. So for me, I'm driven by social justice. I see many young men in my community that have skills, that have intelligence that they could transfer into employment or education, but the opportunities are sealed off to them right from the start. So for me it's really important for me to succeed so I can be an exemplar for other people coming from similar backgrounds. I had to go to university and become a Master's student and then I could write about my community and be taken seriously. So that's what motivated me to come here, and I do have their best interests at heart, they aren't germs in a petri dish, they're human beings from my community, so I have their best interests at heart and so it does drive me. It should be about capability building in that community and allowing that community to develop its own researchers, its own research methods. Who knows about that community the most? That community..."

The motivations behind Richard's academic work exemplify aspects of Gramsci's organic intellectual. Richard went to university in order to get the qualifications he needed to make a real difference to the community he grew up in. His knowledge and experiences of that community, combined with the knowledge he had gained through his studies, mean that Richard is well placed to see where help is needed most, and how to provide it. I guess it's unfortunate in a way, but Richard's qualification was the legitimacy he needed for people listen.

It is important, that when we read the work of Gramsci and talk about his ideas in relation to todays context, that we keep in mind the context in which he was writing; mostly during the 1920's in Italy, where he was a key member of the Italian communist party. It was this political parliamentary party that Gramsci saw the organic intellectual as operating out of. But the privileging of the political party and 
parliamentary politics “overlooks the potentialities of forms of political organisation that move beyond mass-based, parliamentary forms of representation" (Cote et al. 2007:322), and in my opinion plays into a vangardist notion of 'us vs. them". Like that great song by the Subhumans 'subvert city', in which oppressed mutants rise up from the sewers and become the new oppressors, another hegemony is created. It may be a hegemony that is different from the previous, but it's a hegemony none the less, even if it is one in which working class interests are supported.

Marx (1845) may have been right when he said "philosophers have only interpreted the world in various ways; the point however is to change it", but if we leave it solely up to 'philosophers' the chances of that happening are slim. The idea that academics are the only ones capable of making change or fulfilling the role of critic and conscience of society is one that relies on the elitist idea of the academic as an expert and the only legitimate source of that expertise. This isn't a role all academics are happy to fulfil however and many of the ones I talked to, touched on this discomfort. Charlie for example, spoke of the effect that anarchism had on his own subjectivity as an academic:

"I think you don't want to get too carried away and smug about what we do here...' 'We're saving the world! We're the critic and conscience of society, the only ones left!' and that's partly my own embarrassment about that kind of view of academia and it comes from the whole anarchist punk thing which says 'no you're not, you're not the critic and conscience of shit. You guys are just well paid middle class people, working for your own interests', and so I think that's really good to have that kind of critical nagging voice in the back of your head as a teacher thinking about your own attitudes to 
students and issues of hierarchy, and a warning that this is a privileged place, and don't get too carried away about what you're doing here..."

The role of the academic is certainly a privileged one. They are given the time, resources, and space to engage with a wide variety of knowledge, for the betterment of our whole community. Gramsci (1971:5) said, "all men are intellectuals...but not all men in society have the function of intellectuals". While this is certainly true, we can critique Gramsci's conception of the intellectual as suggesting that we, as a society, 'need' an intellectual to emerge in order to become educated and organised, as if we aren't capable of doing it ourselves. And here lies the contradiction: Marxism seeks to solve, to resolve, to offer a solution. Anarchism, on the other hand, or at least the anarchism favoured by Purkis and Bowen (2004) and informed by theorists like Foucault and Deleuze, seeks “a perpetual process of struggle that brings individuals together in complex networks of action, facilitating the expression of their differences rather than seeking finally to resolve them" (Kinna, 2005). In other words, this type of anarchism avoids totalising at all costs and instead aims to breakdown the overarching structures and ideas that dictate the way we think and act.

An anarchist approach to academia would reject all forms of vanguardism (Graeber, 2004), and consider people as both the subjects and the creators of knowledge, not simply an object controlled by those with the power to construct and maintain dominant 'truths' (Armaline, cited in Amster et al 2009). But we haven't seen much of anarchism within academia, certainly not like we have Marxism (Graeber, 2004, el-ojeili 2012). We could argue that, that's because anarchists are more concerned with 'real-world', on the ground action, while Marxism is well 
rehearsed on authoritarian organisation and a 'final solution' vangardism. This is, of course, a huge oversimplification of both movements, and such long running debates that seem to bring out the most orthodox elements, quickly get boring and cliché. More importantly though, it serves to fragment any collective action in which anarchists, Marxists, or any other variant of 'the Left', are working together. If anarchism is the accepting, diverse, and experimental movement it claims to be, then perhaps we can look to Marxism for points of convergence, rather than departure.

On this point, the work that Foucault did on the intellectual ties in well with anarchist thought and moves away from the arguably hegemonic conceptions of Marxism. (Cote et al: 2007 ). Foucault's 'specific intellectual' can be seen to be based around affinity rather than class hegemony and instead of restricting the intellectual within the confines of a political party, it calls on the intellectual to engage with creativity, family life, personal attitudes, the conscious and unconscious, as well as particular local concerns of power (Cote et al 2007:323). By focusing on these aspects, the specific intellectual is open to the variety of local concerns and the individual subjectivities involved and takes a step away from hegemonic transactions of knowledge and power. In Foucault's words "the role of the intellectual is no longer to place himself a 'little bit ahead or a bit to the side' so as to speak the silent truth to all...[r]ather, it is to struggle against the forms of power in relation to which he is both object and instrument" (Foucault and Deleuze [1977:104). Deleuze speaks highly of Foucault for teaching us the about the 'indignity of speaking for others' (Deleuze and Foucault 1977). This does not reduce the intellectual to silence, but “is a result of an ethico-political commitment to strive to facilitate the conditions so the others can speak for themselves" (Cote et al. 2007:324). Rather than see the role 
of the academic as a type of expert with the power and knowledge to 'fix all', this approach recognises the importance of everybody having the ability to produce positive change within their own lives.

The academic still, however, holds a privileged position of power, and with that power, comes immense responsibility. While both Gramsci and Foucault saw the intellectual as having the potential to be a revolutionary force, Foucault differed in that he wasn't solely focused on the working class, but all those who "operate cogs in the power/knowledge machine and thus expose and disable it" (Kurzman and Owens 2003:70). The specific intellectual struggles against the forms of power that exists around them. Foucault tells Deleuze that, "to speak on this subject, to force the institutionalised networks of information to listen, to produce names, to point the finger of accusation, to find target, is the first step in the reversal of power and the initiation of the new struggles against existing forms of power" (Deleuze and Foucault 1977:214). This calls on the academic to focus critique on their own environment and the power imbalances that exist around them and this needs to be done in public and without secrecy. Yeatman (1998:33) for example says 'an activist who is required to act in ways which are secretive, unaccountable, and not open to dialogical engagement with others is an activist who is displacing activism in favour of professional elitism".

C.W Mills was critical towards intellectuals and the role they were fulfilling in society. He said that they "have succumbed to career pressures and a fear which leads to selfintimidation...sometimes politely known as 'discretion', 'good taste', or 'balanced judgement'...The means of effective communication are being expropriated from the intellectual worker. The material basis of his initiative and intellectual 
freedom is no longer in his hands" (Mills [1944] 1963:297 cited in Kurzman and Owen 2002:70). Drawing heavily on Mills' work, Freddy Perlman (1969:9) spoke "of the intellectual as a member of a manipulated and dependent mass" within a well engrained status quo, and an unquestioned acceptance of the present (Mills 1945:241).

I had my own ideas about what the academic status quo was, but I wanted to ask someone who had more of an inside view. The answer I got wasn't exactly positive. In a hotel café across the road from the university building, I talked with Amy, a lecturer in the social sciences, and asked what the academic status quo was exactly:

“...Hyper conservative. Perform or else. Submit. I have nothing good to say about the academy at large. I think it's one of the most atrocious institutions we've ever come up with. It's oppressive as fuck. It's horrible. It makes people produce without thought. It asks for things that it refuses to support. It's is dehumanizing and commercialising... and no, it's broken it's sad, it's not good"

We glare out the window at the now horrible looking building.

Academics often find themselves employed within an institution that they are against on many levels. Mills, for example, tells us:

"As channels of communication become more and more monopolised and party mechanics and economic pressures, based on vested shams, continue to monopolise...opportunities to act and communicate politically are minimized. The political intellectual is, 
increasingly, an employee living off the communicational machines which are based on the very opposite of that which he would like to stand for" (Mills 1945: 242-243).

There are lines of departure we can take in order to move away from Mills" above depiction, but first, there is a need "to smash the stereotypes of vision and intellect with which modern communications swamp us" (Mills 1945:299 cited in Perlman 1969: 10). This means moving our focus away from only understanding. "Simply understanding is an ideal of the man who has a capacity to know truth but not the chance, the skill, or the guts, as the case may be, to communicate them with political effectiveness" (Mills 1969:11). In opposition to this, Mills calls for the intellectual to stand for a 'politics of truth', and do more than evaluate the problems around us, but confront and solve them (Perlman 1969). Mills though, can be critiqued along similar lines to that of Gramsci, in that he had the vanguardist notion that “independent artists and intellectuals are among the few remaining personalities equipped to resist and fight the stereotyping and consequent death of independent thought" (Sawchuk 2001: 30). Again, we see an over inflation of the importance of the intellectual/academic as the only ones able to effect positive change. From an anarchist stand point, Gramscian notions of the intellectual are critiqued as relying on party politics and a view of the working class as the privileged agents for change.

The question of who academics serve is an important one, but also one that is soaked in politics and power battles. Academics should not, and cannot, remain objective in these battles. Edward Said, asks the intellectual to be constantly questioning power, rather than consolidating it. On this, he says "I think the major choice faced by the intellectual is whether to be allied with the stability of the victors and 
rulers or- the more difficult path- to consider that stability as a state of emergency threatening the less fortunate with the danger of extinction" (Said 1994: 35). A hard task it is too, because as said continues, this involves...
"a state of constant alertness, of a perpetual willingness not to let half-truths or received ideas steer one along. That this involves a steady realism, an almost athletic rational energy, and a complicated struggle to balance the problems of ones own self-hood against the demands of publishing and speaking out in the public sphere is what makes it an everlasting effort, constitutively unfinished and necessarily imperfect" $(1993: 23)$.

Within the university, Said suggests that one factor that needs unmasking is that of 'professional behaviour', which he says is made up of ideas around "not rocking the boat, not straying outside the accepted paradigms or limits, making yourself marketable and above all presentable, hence uncontroversial, and un-political and 'objective'" (Said 1993: 74). Chmiel (1995:415) adds to this, saying that to buy into the idea of the 'cult of the certified expert' in which we try to maintain 'neutrality' through apparently 'neutral' methodologies, often critiquing abuses of power elsewhere, while at the same time ignoring and even benefiting from their own governmental and institutional abuses of power. To combat the currently promoted 'professional behaviour', said thought that an 'amateurism in intellectual life' would be more appropriate. This involves exiting from our 'intellectual homes', whether they be in the university, in our offices, or in our heads, and making moves to form and maintain an open minded dialogue "so that intellectual work can recover its connections with the political realities of the society in which it occurs" (Rizvi and Lingard 2006:300). 
Said's representation of the intellectual is specific to those housed within a university, and although his notions of representation, amateurism, and affiliation go well beyond the demands of the 'professional' academic, we are at times left with an internal contradiction. That is, how are we as intellectuals supposed to have a broad and engaged dialogue with the publics around us, while at the same time aligning ourselves against, and in direct opposition to the already established regimes of power, without alienating ourselves and the people we stand alongside? This is something that can not be solved in any 'final' way, but keeping it in the forefront of our minds is important. Like said said, it's an "unfinished and necessarily imperfect" (1994:23) line to be walking. But as long as we know what side of the line we wish to walk; the side of the less fortunate and not that of the solidified powerful, the role of the academic will remain/become a necessary one.

The role of the academic is certainly a contentious one. This is heightened within a social climate that often views academics with suspicion, in combination with the disciplining effects of the neoliberal university. While the call to fulfil the role of critic and conscience of society is often made, this can be a difficult, uneasy, and complex responsibility. If it is to be fulfilled at all, academics must first 'speak truth to power' within their own institutions. The ideas of Freire, Marx, Gramsci, Foucault, and Said, all offer paths of resistance, but rely on us moving past critique and into the realm of action. This is a task that comes with great power and responsibility. Here, anarchist ideas of the academic can ensure that this responsibility stays grounded in 'real-world' action in which academics work alongside, rather than speak for, our communities in order to bring about positive change. 
I think that the important thing is that we have the freedom to pursue whatever lines we see as valuable to the society around us, and this requires that we feel comfortable being the academics we want to be. Currently, we don't have this environment, and as long as the bureaucratic and performance driven neoliberal agenda keeps being pushed, we are unlikely to reach it in any real collective way; we will continue to be shaped into the types of entrepreneurial academics and passive students/customers. This however should not be a point of defeat, but a recognition that for those of us willing to step outside of the university's expectations of the academic, to challenge and expose them, there will be a precarious place for us inside its walls. With a little elbow work it may become less precarious, because as Brian told me, "I think if people are prepared to live in those kind of grey areas it's a healthy recipe for all sorts of social and political outcomes". 
Chapter 4: Playing the game 
In 1424, John Wycliffe, a past academic at Oxford University, had been dead and buried for 44 years. However, he was declared a heretic, and his body was unearthed to be burned.

In 1926, Antonio Gramsci was sentenced to 5 years confinement and 20 years imprisonment by a fascist government which saw his mind as a threat.

In 1989, Simon Eastern was studying in Korea and took the time to visit an ex professor of his. The professor had been put in prison by a military dictatorship. While I sat and talked to Simon, an academic who I had been lectured by, I tried to imagine doing the same thing only within the confines of a Korean prison in the late $80^{\prime} \mathrm{s}$ but the nice pot plants and smell of coffee made it hard.

I asked Simon what it would have been like to be an academic in Korea during this time:

“There could be suspicion of academics and under Park Chung Hee and Chun Doo Hwan, academics would be taken in and tortured as well, especially people in Sociology or seen as too far to the left. Put in prison was a professor of mine at Berkley. When I went and studied in Korea in 89-90, I visited him, it was when he was in prison. He was in a detention centre so I went with another friend of mine, and yea it's different right! This is 25 years ago. It would be very rare...not impossible because Korea still has a national security on the books...but put it this way, I suspect that if Nicki Hager were operating in Korea 1986, he'd be in jail at this moment..."

We both gave an uncomfortable laugh. Poor Nicki, a New Zealand Journalist, had just had his house broken into by the cops, and while our own pseudo-dictator may not have thrown him in 
jail, there is certainly suspicion on the part the government towards left academics, or any academic who may raise a point of disagreement. The price of speaking 'truth to power' and fulfilling the role of critic and conscience of society can be a hefty one. It may not be as hefty today as it once was, but there is still a price to pay for 'stepping out of line' so to speak. This occurs despite academic freedom being supposedly protected in legislation. Part 14 of the Education Amendment Act 1989, section 161 (p374) states:

"It is declared to be the intention of Parliament in enacting the provisions of this Act relating to institutions that academic freedom and the autonomy of institutions are to be preserved and enhanced"

Just below there is a list of what academic freedom actually is :

For the purposes of this section, academic freedom, in relation to an institution, means-

(a) the freedom of academic staff and students, within the law, to question and test received wisdom, to put forward new ideas and to state controversial or unpopular opinion:

(b) the freedom of academic staff and students to engage in research:

(c) the freedom of the institution and its staff to regulate the subject matter of courses taught at the institution:

(d) the freedom of the institution and its staff to teach and assess students in a manner they consider best promotes learning:

(e) the freedom of the institution through its chief executive to appoint its own staff. 
However, as Birtwistle (2004) and Jones et al. (2000) recognise, there is potential for both political and economic pressure to undermine the freedom of academics despite recommendations from UNESCO (1997) (United Nations Educational, Scientific, and Cultural Organisation) to uphold..." the right, without constriction by prescribed doctrine, to freedom of teaching, and discussion freedom in carrying out research and disseminating and publishing results thereof...". Importantly, the recommendation also highlights our right to critique our own places of work; "Freedom to express freely their own opinion about the institution or system in which they work"... and that this should take place... "without discrimination of any kind and without fear of repression by the state or any other source". In more specific terms, and as Swinnerton-Dyer (1995:186) explains, "without placing themselves, their jobs, or privileges in jeopardy". While it is a good start to have such statements written down, it does little good if nobody actually enacts it. A problem comes when those in powerful positions within the university think they can begin to dictate what is and is not an 'acceptable' form of expression or mode of doing academia.

What are today's consequences for speaking out in ways that may not align with the university or the government? What happens when academics critique their own universities? Hopefully, bodies won't get dug up years after death to be burned like poor old John Wycliffe, but there are very real consequences and a number of ways you can get punished within an institution like a university. Sandra Grey, President of the Tertiary Education Union and university lecturer, told me of her decision to speak out about the university and government despite the threat of workplace punishment. Interestingly, Sandra, whose real name I use, mentioned that 
she was happy to use her real name because she thought academics should feel free to talk about these issues openly and without fear of reprisal. While this would be ideal, Sandra told me that the fear that exists is very real:

"One of the fears about speaking out about university policy...or about government policy to do with tertiary education...or about being an active unionist, or an active supporter of critic and conscience...one of the fears is that it will put you in the firing line, and because this sector has shrunk and shrunk and jobs have gone and departments have gone and people have been booted out left right and centre to meet government demands, people go "but if you put your head above the parapet you'll get your head chopped off".....I have watched lots and lots of my colleagues be very very silent, close their doors and not engage with university politics and still loose their jobs. So I guess I go whether I go out kicking and screaming or I stay silent, if I'm going to loose my job I'm going to loose my job. And security is a real fear in this sector and the survey we did of the sector shows two thirds of us think our jobs are under threat because of the pressure on the sector... Well, you know ... what does it really matter? I might as well go out being principled in what I believe in".

In this chapter, I look at the commercialisation of the university. It sure is in full swing, but what does it mean for the academics and students who attend these institutions? The reforming of the university under a hyper-market model has often been referred to as an example of neoliberalism in practice, and while the effects are often quite visible, what this term actually means is a topic for debate. While neoliberalism is a contested topic, I have come to understand 
it along similar lines to that of Coté (et al. 2007) who recognises two main aspects; a political and economic task seeking the globalisation of capital, and the intensification of control and disciplining mechanisms. And it's here that we begin to see why the modern day university is the go-to example of neoliberalism. As the university becomes increasingly driven towards industry requirements and the creation of wealth, there is pressure placed on the academics to help achieve this goal. A significant amount of that pressure is exerted through a 'publish or perish' environment, whereby academics are judged on their ability to publish a high quantity of research for the most prestigious of journals. Judgment is given through a system called the Performance Based Research Fund (PBRF), which assigns each academic a rating. For academics, it becomes clear that some research is more likely to attract funding than others, and there is pressure placed on them to steer their topics in a direction which somehow fits into the financial or 'strategic goals' of the university. Driving these policies is an influx of business managers who ensure that academics are on the right path. However, a rift is created between academics and managers when their ideas on the role of the university and the academic differ. We do though, as students and academics, have a responsibility to challenge our managers and the decisions that are often imposed within our institutions, not only to fulfil the role of critic and conscience, but to ensure that pockets of dissent and divergences away from this dominant ideology, can survive and grow. 
Neo-liberalism and the commercialisation of higher education

The Neoliberal University certainly doesn't fit in with the images of a bastion of free thinking and site of social debate. The universities goals have now been redefined by what Shore and MacLauchlan (2012:280) call “an increasingly pervasive emphasis on income generation and commercialisation". They go on to state that "the aim of the neoliberal university model appears to be to foster innovators and entrepreneurs who will contribute more effectively to national wealth creation by being more attuned to economic imperatives and more enterprising in their use of knowledge" (Shore \& McLauchlan 2012:281). For those of us whose personal goals lie, sometimes well outside the creation of wealth for the university, is there any other choice? The ability for the neoliberal regime to be defined as 'just the way things are' is having an effect on academics who often see "becoming more commercially orientated... [as an] "unavoidable reality'" (2012:281). But if I can end this depressing fate with a big call from Birtwistle (2004:215), who says, “complacency is not the answer... Let us not be accused by future generations of complacency but act now to give a proper statutory framework to academic freedom...Failure to at least openly debate this important issue is tantamount to complacency... Belief is not enough- action is needed now".

We don't need to read up on the commercialisation of the university to know that it is happening. We can see it when we walk through the halls, past the Wishbone café, or in university policy that makes it 'against the rules' to give out free food in central university areas, endless million dollar property development resembling commercial shopping malls, or the competition between university advertising that we see at bus-stops. Degrees can now be bought in shiny 
plastic packaging all for the tidy sum of a life-time of debt, as a result of what Ritzer (1995) called 'Mcdonaldisation'; a process which pushes efficiency, constant monitoring, standardisation, and control (Hayes, 2002. Hanley, 2011). We can feel it as we shuffle from one lecture to the next, PowerPoint after PowerPoint, test after test, and fee rise after fee rise. Under neoliberalism, the student has become a customer and the academics are the ones who ask us if we want more fries. We need to be questioning what is going on within our universities, especially considering todays neoliberal context which inevitably leads to a decline in democracy, student involvement in decision making processes (Larner, $2003)$. With upwards of 300 in some classes, it's sometimes easy to get the feeling you're just another number being schooled in what and how to think. The notion of going to university to learn how to 'think critically', is often thrown about, but we are never told to think critically about our own education, about how and why this information is being taught to us. The university system that is supposed to challenge the status quo and foster critical thinkers becomes a factory producing conforming and obedient students and citizens (Harker, 1984. hooks, 2010. Marshall, 1996).

On top of this, we see an increase in what shore and McLauchlan (2012:267) call 'third mission' activities; or, "activities aimed at commercialising universities and creating more entrepreneurial academics". With the increasing view that higher education is a personal gain rather than a public one, investment from the state is on the decline and the universities are being "forced [although they don't seem to be putting up much of a fight] to find new income streams to balance their budgets, meet new 'key performance indicators' and in some cases stave off the threat of insolvency". This is in complete contrast to Academic Freedom Aotearoa, a watchdog group to protect academic freedom, whose Kaupapa states that: 
“Universities and other tertiary education institutions in New Zealand operate for the public good and not to further the interests of individual staff, students, or the institutions. Neither do our public tertiary education providers exist for the benefit of economic and political elite. In order to ensure universities and other tertiary providers fulfil their public good role, it is necessary to both defend and practice academic freedom- the free search for truth and its free exposition" (Academic Freedom Aotearoa).

We may have images of a 1970s institution that supported "critical enquiry and autonomous learning" (Shore 2010: 15), and although there may still be traces of this, it is under a significant assault, an assault that many have labelled 'neoliberal'. Although what that means exactly, it seems no one is too sure.

The term neoliberalism is one we seem to hear constantly, but do any of us know what it means exactly, and if we do, can we explain it? In Mudge (2008), and then Flews (2014) introductory words, it is "oft-invoked but ill-defined". Keeping in mind that this isn't a thesis on neoliberalism (thankfully), it's still important that I give an outline of the terms use, as well as a description of how I intend to use it. The myriad forms in which neoliberalism arises means that I can't capture it all and the contradictory make up of the term makes defining it in any whole sense an impossible task. I am mainly concerned with neoliberalism within the context of New Zealand universities. As Shore (2010:1) says “[t]he restructuring of New Zealand's universities is often considered a paradigmatic case of neo-liberal reform and governance". But what does that mean, both generally and in terms of the university? How have the academics and students 
inside the university been affected by these reforms? Some say it would be an oversimplification to label today's universities 'neoliberal'. While I would agree that many aspects of the university and the people inside it fall outside, and react against, what might be called neoliberalism, there is a hegemonic dominance within our universities, and I would argue that that dominance sits quite comfortably under the roof of neoliberalism.

My first port of call, when trying to get my head around neoliberalism, was a couple of sociology PhD students. Both seemed to have a wealth of knowledge when it came to neoliberalism as a topic; Jared in particular, held a critical view of the usefulness of the term itself:

“...Because I've realised how much it irks me to hear people just turn around and dismiss things so easily 'oh well it's just neoliberalism', that's lazy. There's something more. I mean you were at Nikolas Rose's speech weren't you?

I think to myself; "yea I was there...Couldn't understand a word he sad though", but reply with a simple "Yep", before Jared Continued...

“...you know when he sort of said he doesn't use neoliberalism anymore because of the way in which it's used...that's kind of how I feel ...very much how I feel...that it's just these old terms that are just thrown around...stretched..."

Questioning of the relevance of the term neoliberalism is shared by Flew (2014:51) who argues that if it is a term being used as a synonym to mean many different things, "then it is a term best abandoned as it's had its intellectual 
currency devalued through excessive use". The government is neoliberal, the school is neoliberal, the university is neoliberal, the whole world is neoliberal! Flew identifies this as the first of his six themes of neoliberalism: "an allpurpose denunciatory category" (2014:51). I am, and probably will continue to be, guilty of doing this myself, and I think this is because, rightly or wrongly, we can all feel the invasiveness in which 'something' is changing the nature of our workplaces, our schools, our universities, our lives, and the term neoliberalism seems to be the best word to sum up. Boas and Gans-Morse (2009) comment that neoliberalism has become a term that everybody loves to hate, and even if we're not completely sure what it means, we will use it as if we do.

There is a strange belief that "human wellbeing can best be advanced by liberating individual entrepreneurial freedoms and skills within an institutional framework characterised by strong private property rights, free markets, and free trade" (Harvey 2005:2). Under the neoliberal regime, everything is for sale, including our own education and the knowledge we produce (Giroux 2004). But for what ends? Harvey (2005:176) takes a piece from the World Trade Organisation (WTO) agreement, of whose aim is apparently to... "rais[e] standards of living, full employment and large and steadily growing volume of real income and effective demand, and expanding the production of and trade in goods and services while allowing for the optimal use of the worlds resources in accordance with the objective of sustainable development, seeking both to protect and preserve the environment and to enhance the means for doing so in a manner consistent with their respective needs and concerns at different levels of economic development". So it's onwards and upwards for the human race! or it would be if that actually worked. 
Q: How does the trickle down effect work?

A: Well the rich people get all the money....

Q: And then what happens?

A: ... Nothing...
\end{abstract}

Obviously, neoliberalism has not been the answer to all our problems; it is in fact one of the problems. The neoliberal regime both demands and encourages:

“...individual responsibility and liability; independence from state interference (which often places the regime of rights in severe opposition to those defined within the state); equality of opportunity in the market and before the law; rewards for initiative and entrepreneurial endeavour; care for oneself and ones own; and an open market place that allows for wider ranging freedoms of choice of both contract and exchange" (Harvey 2005: 181).

Add to this, "the right of private property... and the right to freedom of thought, expression, and speech" (Harvey 2005:181) and we have a list of freedoms that would of course entice mainstream society. As we know however, the reality is quite different. While we may value and depend on these 'rights', "we do so much as beggars live off the crumbs from the rich man's table" (Harvey 2005:181). Like Cotè et al. (2007), I would say that neoliberalism's apparent focus on individual freedom is somewhat of a contradiction, and the various mechanisms of control and discipline that are increasing within our society are a sign of this. For Coté (et al. 2007:318), neoliberalism refers “a multifaceted political and economic project that includes the globalisation of capital as well as the intensification of the societies of control". 
Under neoliberalism and its 'societies of control', individual human beings, with their own beliefs, morals, and dreams, are reduced to merely a small part of the production process, including the production of knowledge. Neoliberalism seeks to strip away the protective coverings that embedded liberalism allowed and occasionally nurtured". Under this schema, profit comes before people. Not unlike the experiences of some of my peers and lecturers at uni, Harvey (2005:167-168) tells us that "workers are hired on contract, and in the neoliberal scheme of things short-term contracts are preferred in order to maximise flexibility". The effect of this is often nearzero job security for those 'up and coming' academics. We see this occurring within our universities, as new academics in particular are placed on short-term contract after short-term contract. 


\section{Publish or Perish: Neo-liberal pressures within}

\section{academia}

I found from the interviews I did, that a major concern for up and coming academics is simply getting your 'foot in the door' and then surviving the precarious nature of the job. I talked to a recent PhD graduate from Canterbury University who, after years of tutoring, hoping it would increase her chances of being employed full time, had finally given up hope and looked elsewhere outside academia for work. For many, a foot in the door seemed to be attained by writing articles and getting them published in journals. I asked Jordan, another PhD student, if he was going to start having to think about this if he wanted to be an academic. Sure enough the process had already started:

"I already am", Jordan told me...

“I'm already working towards it. I mean I've got an article published, or sorry I've got an article accepted for publication. I've been told very carefully I'm not allowed to say published. The number which is required is three I think for PhD students and trying to get them into international journals instead of New Zealand journals"

"So you are going for those more prestigious journals?", I asked.

"yea exactly because either you want to oppose it; you think its wrong, which I do think it's wrong, a good piece of research would be a good piece of research no matter where it is. Getting it out there to a large audience is good, but simply getting it out to a better 
journal is wrong, if that makes sense. But I want to research what I'm interested in and have some freedom to say what I think based on my research, not what is going to get published or what isn't going to get published. That sort of thing for the journals, that worries me a little bit. You've just got to figure out how to go about doing it and how to work your way around it..."

The emphasis within university has now shifted towards making a profit (although the place has always been for and controlled by the elite). Economic efficiency has infiltrated all areas of the university system. Publishing, for example, is showing signs of becoming a quota filling operation, in which academics churn out article after article, to be published in the most prestigious of journals. Fail to do so, and you may face the axe. The current 'publish or perish' climate within universities is increasing pressure to produce 'financially beneficial' research which often results in institutional managers pressuring staff for higher productivity and performance (Cupples and Pawson, 2012. Furness, 2012). Expectations to "produce (ever) more with less and less" has real effects within the university environment, by reducing collegiality as a result of high levels of competition (Larner, Le Heron, 2005; Ashcroft, 2007). It's easy to see how this could effect the academics working within these places.

Davies (2012) argues that academics have largely been unable to generate any collective resistance, and says that this could be because of a lack of unionization, job security, income reliance, on top of high workloads. Sandra, who is the president of the Tertiary Education Union (TEU), picked up on this in her own workplace: 
"Increasingly, if time is precious in these spaces, what has fallen of the edge...Well several things; Pastoral care of students, time to sit and chat about life and all things and our academic work, and anything that's seen as extra, and union work is the extra. So once upon a time people would have made time for their union work quite easily because they would have seen it as a crucial part of the whole role. Now it's the add on and extra 'if I have time'".

The importance of coming together as a group and discussing our 'common condition', as Sandra called it, can't be understated. But many of you will know that when you've got a bunch of marking to do, articles to publish, funding to find, classes to teach, research to do, and a life outside of university, it can quickly become a case of 'go to uni; get as much work done as possible, then get out of the place. But is publishing books and articles really more important than connecting with the students and academics around you as some form of community? It could be argued that in today's university it is, especially when there seems to be efforts made to encourage disengagement between students and academics. While academics often found connecting with their students to be one of the most rewarding aspects of their job, I guess this doesn't fit into the market model very well: How is the university supposed to make money if academics are talking with students for...FREE? Below, Sandra tells us what happens when she engages with her students:

"In the email that I got recently that said I was a little too invested in my students. Which I don't get. I find it a really interesting comment. Because I am invested in the wellbeing of my students, and the wellbeing of my profession, and the wellbeing of my sector, and I don't see that as a bad thing. So I get 
those comments which are kind of meant to say disengage somewhat" •

The driving force behind the 'publish or perish' environment is the Performance Based Research Fund (PBRF). The PBRF is essentially a rating that gets assigned to academics based on the research 'output', taking into consideration the number of publications and prestige of the journals. There is a fear that the PBRF "will commercialize research" (Salient: 2014: 7: 76: 7) and "encourage New Zealand academics to write for other academics rather than the public, with career achievement largely based on publication in journals that are only read by fellow academics" (Bridgeman 2007: 139). However, according to Boston (2006/2007), it originated with good intentions. These included a need for a boost in levels of public funding available to universities, a means of differentiation between New Zealand universities with an aim of increasing "greater functional specialization and better overall performance" (2006/2007:12), and a belief that it would increase the accountability of universities in terms of the majority of teaching being carried out by academics who are also involved in research. Despite these good intentions, the majority of the research on the $\mathrm{PBRF}$ has been largely negative and academics appear extremely concerned by its effects (PBRF seminar attended 23/5/13). I'm not saying some sort of performance measurement isn't a good thing; after all, we want lecturers to be doing a good job. But universities are using the PBRF to put a lot of un-necessary pressure on staff. Policies such as the PBRF support and maintain a culture of commercialism, hierarchy, and alienation and the overall 'publish or perish' climate. In other words, and as Sandra eloquently put it:

“The PBRF system is a stupid, ridiculous, disciplining tool that has changed the nature of education in these 
institutions, changed the nature of research. There is no doubt that it is silly. I do not want to take away from the quality of work done by my colleagues, but I know they do quality work, I don't need an external ranking exercise to tell me this..."

Despite the wide spread negative views that academics have towards the PBRF, its place within the university is significant. All but one academic I talked to, and most of the post-graduate students, raised it as a concern.

Jess, an anthropology lecturer, had taught me in a couple of her courses. She gave great lectures, in which she told stories of her travels to far away places, which would evolve into stories from her everyday life. Course material wasn't spoon fed through easily digestible Power Point slides, but shared through conversation. As students, we needed to engage in that conversation, and by doing so we took part in more than a transfer of knowledge, but an on-the-spot creation of it. To me, Jess seemed like an academic that was engaged and invested in working out in the community, and placed importance on this over efforts to make her work fit into the commercial and controlled expectations of the university.

During our interview, which occurred early in the year before Jess had to go overseas to work on a project, I admitted that I still wasn't sure in what direction my project was going. The significance of the PBRF was raised in the suggestion Jess gave me:

“[The] PBRF is what the university is functioning under. So if you really want to get an idea of the latitude for change, you could look at that. It's what the university is pushing for. They want people who will score high on the PBRF. In our range of endeavour, it's just for 
publishing. And it's for publishing in world ranked journals and there's factors of journals, you know, everyone gets like an impact, journals get an impact factor, and the impact factor is based on how many people read them and cite them as opposed to did it get people to you know, stop using land mines...."

If you're getting ranked highly as an academic, the PBRF might not be so scary. But for many academics, it serves as disciplining tool that often leads to feelings of incompetency as they try to succeed according to the demands of a ranking system.

Even a Professor, considered one of the world's leading experts in his field, noted this feeling of failing to meet the universities judgment:

"Now there's a lot more pressure with PBRF and stuff where basically there's an implication that you're incompetent, you know because PBRF literally grades us. It's bazar. It's like being a student again. Every five years I get a grade from the system and the grading system is really harsh, and essentially most people are $B^{\prime} \mathrm{S}$. I'm a B because it turns out to be an $A$ is based on this international standard which is basically like well name the five best universities on earth and say 'well how do I compare the five best universities on earth, and I don't know they might be Chicago, Cambridge, Harvard you know, and you know they have huge salaries that attract... Most of those are private universities that pay a lot more and they are able to attract the very top echelon of academics. So if you compare yourself against that, almost nobody is going to be of that standard. So it turns out that like eight per-cent maybe, maybe less, maybe six-eight per-cent of people get an A rating from 
the system. So even though I'm a professorial rank, and in the hierarchy I'm close to the top, in terms of the amount of stuff I publish, I'm relaxed about it because I know I publish a lot. In terms of the competitive system I'm closer to the top than I am to the bottom shall we say. But its kind of funny to be told every five years you're a B, and you kind of go 'well you know I kind of think I'm an A and screw you if you want to call me a B because I'm not a Nobel prize winner' or something like that... well then yea fair enough, I accept that I'm not a Nobel prize winner but I don't think that I'm inadequate or something. Because I'm not. So that kind of pressure where every five years you've got to turn in all your work and some bean counter goes over it and then somebody tells you... And that's ok again if you're like me a $B$, an $A$ or a B, but see if you're not, then there's a bunch of pressure coming down on you, especially if you're an entry level person, you're a young person whose just finished your PhD. So right away you're thinking, 'I'm going to need to get some publications out because that PBRF thing is going to come by and they're going to give me a low grade..."

Things are always harder for those at the bottom and for those just starting out in the world of academia. The PBRF can be a confusing mechanism that can open and close the doors on any future academic career.

Will, was a past sociology tutor of mine and was about half way through his $\mathrm{PhD}$ at the time I talked with him. Becoming an academic was one of Will's options for after he had finished his study. It wasn't his only option however; jobs are few and far between in academia, especially for those just finishing their PhD's, and maybe Will didn't want to set himself up for disappointment. As he told me, there are first some 
requirements that he must meet, and a certain kind of publishing takes precedent:

"What would it take to become an academic?" I asked Will.

I can think of heaps of things that it would take, but the pervasiveness of the cut-throat publishing environment seems to always make its way to the top of the list.

"I'd have to publish journal articles that are counted under the PBRF. I don't think you'd even get your foot in the door at this place without publications", he says.

"And you have to do that at the same time as you're doing your PhD?" I ask, as I remember that Will also tutors a couple of courses, helps out with other teaching, and has a job outside of university also.

In a small burst of positivity, Will tells me:

"I do have one article...."

I'm happy for him. But then he continues....

“... Which doesn't count....", he adds.

"Why not?", the question on everybody's mind.

He pauses...."um...."

Then with a note of disappointment in his voice he continues.... 
“The PBRF has got some specific guidelines about what counts as research".

The word specific hangs in the air....

\section{Research and education priorities under the PBRF}

We can get a sense of this specificity within universities as pressure is placed on academics to research certain topics and to publish in certain places. Jones et al (2000:22) argues "a commercially focused council or board could exert pressure on staff and students to ensure that they do not in some way offend potential funders or contributors". As with many aspects of academia, it is often expected that the academics as individuals will align themselves and their work with the institution's 'commercial focus'. I like to view what academics do, and I guess what $I$ as a student am practicing doing, as more of an art. It's creative, it's personal, it can provoke and engrain, critique and be critiqued, and the thought of having to make it fit into what someone else thinks is useful, to me, almost renders the whole process pointless. Despite my inability to see the point, there is one, and there's no prizes for guessing what it is. As Joe told me, the point is, of course, related to funding:

"They come up with these buzzwords, like our 'research focus' or something for the university. So ours are buzzwords like 'sustainability', and they go 'well how does your anthropology class contribute to sustainability?' And it may or it may not, but you start to feel like maybe you're now becoming second tier, and they're like 'what we want to emphasis is that academics here are working in sustainability, and you kind of go 'well I'm an English professor, how is my [work supposed to fit into 'sustainability'], you know!?' And that can 
have impacts on the way [the university] distributes its research funds... where you apply to the university for research funds and if they set these priorities and now your field doesn't fit one of these priorities then maybe it doesn't mean you wont get funding, but it's all competitive and those who fit these priorities are more likely to win out in a competition for funding".

While the academic may be expected to 'fit in' with these types of promoted discourses, the university is also beholden to the government who appears to view education solely in terms of the market and job creation. Academics however, view it somewhat differently and are aware of these conflicts:

"What kind of research is more important than other kinds of research, you know? Is it research that earns money? You know what I mean? These kinds of values come in. How do they evaluate your research? Well if your research earned the university a lot of money, well it's valuable research. If your research doesn't sell books...how much money does that earn us? Well that's not as important as Agricultural Science where they developed a patent for a new form of grass that increases beef and dairy production by two per-cent or whatever, and therefore has monetary output. And that of course is the National party's view of tertiary education, which is that it's just about jobs..."

Across anarchist literature on pedagogy, it has been widely argued that the focus within education is toward labour market demands. This results in schooling and state sponsored education more generally, becoming a process that benefits industrial elites who are supplied trained and disciplined workers (Haworth, 2012. Amster et al, 2009. Deleon, 2008). Emma Goldman, in her 1906 essay 'The Child and its Enemies', 
makes a wonderfully brutal critique of every state institution, schools and universities included. Goldman tell us :

\footnotetext{
"Every institution of our day, the family, the state, our moral codes, sees in every strong, beautiful, uncompromising personality, a deadly enemy; therefore every effort is being made to cramp human emotion and originality of thought in the individual into a straightjacket from its earliest infancy; or to shape every human being according to one pattern; not into well-rounded individuality, but into a patient work slave, professional automation, tax-paying citizen, or righteous moralist" (1906:2).
}

Michail Bakunin (1869) had been arguing along similar lines over 30 years prior. Bakunin pointed out that specialisation and categorisation of 'ideal citizens' is the bourgeois socialists desire to retain a class system in which, for example, one class becomes educated, while another takes the role of the workers. Bakunin goes far enough to identify a common critique of such a standpoint; the bourgeois socialist often exclaiming something along the lines of: 'workers needing to work so that intellectuals, poets and such could devote themselves to their particular field, which of course also advances the lives of all of us'. However, Bakunin saw past this and highlighted the crucial yet often overlooked point that only "a tiny fragment of society, to the exclusion and, thus, detriment of the vast majority" (1869:4) are positively influenced and favoured by science and the arts. This is an important point for me to keep in mind throughout this project; while it's a good thing to look more critically at your learning environment, we also need to remember that in doing so, we are speaking from the highly privileged position of a university student. The 'ivory tower' may, in many ways 
be isolated from the communities in which they are housed. However, we also need to remember that they, in turn, house many members of the community, whose ideas shape, and are shaped, by what goes on inside this space. Given this, surely we are all invested in a closer and more critical look at our institutions and our own roles within them. 
THERE IS A WORLD INSIDE YOUR HEAD WHERE BOUNDARIES ARE CHALLENGED, IDEAS COME AND GO, WARS ARE WAGED AND WISD O WON. YOU ARE THITL DER OF THIS WORLD. WHERE ARE YOU TAKING IT?

\section{KNOW YOUR MIND PAY YOUR FEES!}

$$
\begin{aligned}
& \text { WICTERIA } \\
& \text { UNI WERSITY } \\
& \text { WHLLINGION }
\end{aligned}
$$

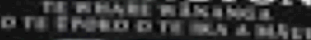

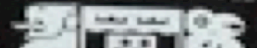

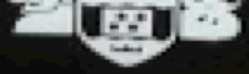

A student's addition to a marketing campaign promoting

'knowing your mind' and 'challenging boundaries'. 


\section{Alternatives to the neo-liberal university: Academics as the critic and conscience of society}

To many of us, the thought of tailoring our creative output to economic demands is understandably repulsive. But what other option is there if this type of thing is so heavily seated within the universities publishing environment? In a state institution like a university, creativity is stifled. The authoritarian nature in which these institutions operate, results in individuals losing their sense of individuality. The path through these institutions is so narrow and crowded that we forget that we can act for ourselves. On top of this, authority pushes conformity. Moral values and behavioural norms are favoured over individuality and uniqueness (Kinna 2005). An important first step towards any alternative is to talk more openly and honestly about the demands of our workplace with our colleagues and students, and to support as well as join the ones who are critiquing such structures. But as we know, the university is not always willing to listen to such critiques; in fact they often make efforts to silence them.

In 2012, I participated in a 'box university' in which a group of students occupied the university's overbridge overnight. The idea behind this was, that we built our own university out of boxes, and the students passing by could join in and build the sort of university that they, the students, actually wanted. This was in reaction to our feelings in an environment focused on chasing profit at the expense of our education. It was completely harmless and peaceful, not to mention a creative and positive way of giving students voice. The most heated it got was when the head of security told us to 'stop burning incest' (we were burning no such thing- incense?). But management, of course, didn't see it this way. So while they 'allowed' us to stay overnight (after calling a few very 
relaxed cops on us), in the weeks following students were selected at random from Facebook photos of the event and 'dragged through the ringer' so to speak by managers and university employed lawyers who had the skill of intimidation and deception down to a fine art. These were PhD students and undergraduates, just your average students, who cared about the state of their institution and didn't want to be silent as they watched it go slowly but surely down hill.

Students who engage in these sorts of actions do take on a risk, and they are made aware of those risks: Doug, a graduate student I talked to, for example, spoke of the fear of being disciplined and the effects this would have on his qualification:

"I manage to try and keep within the code of conduct, like no plagiarism, keep a low profile. And also don't take no part in radical student protests. Occasionally I've heard a few protests and they asked me if I'd like to join them, and I say oh no thank you. A bit of the fear factor because I thought that if you get caught you will get disciplined and I thought at the end of the day, you're the one who loses out, not the university, and it's not really worth it with the high tuition fees we pay, we pay a lot of money to be here now..."

My own experience with student activism has taught me that intimidation and punishment is readily dished out to students with dissenting voices deemed 'too loud' by university management. This is where there lies a big contradiction in the academy. While critic and conscience is a written piece of legislation, the university, again has some specific restrictions around the 'proper' way to do this. While the university may openly promote 'knowing your mind', 'challenging boundaries and status quos', and fullfilling the 
role of critic and conscience, those who work within are aware of the contradiction that discourages inward critique.

Amy, for example, told me how great she thought it was that the critic and conscience function is written into her contract as an academic. But she also acknowledged the fact that the university can often be hostile towards academics that critique their own institution:

"I love, love, love that as part of my contract here, I am to be the critic and conscience. I think that's fucking brilliant. It's amazing. It's just fabulous. I cannot understand why people do not avail themselves of it more often".

I imagine a huge barking university building, frothing at the mouth, growling through sharp teeth and spitting out human remains. I try to turn this image into some sort of question.

"Does the university see it that way?" I asked.

"Oh they push it quite a bit, which again is one of those weird contradictions that the university has, because they keep telling us to do that, but I'm pretty sure it's only as long as you say things which are good. So you're allowed to be the critic and conscience of everything...except for the academy".

With those teeth is it any wonder? After all we don't want to 'bite, or be bitten, by the hand that feeds us'? Then again, an institution so determined to steer any negative critique away from itself, almost invites it. Even if this is the case, there are still consequences to doing so, as Amy explains: 
"I think it's there [freedom to critique your own institution], if you're willing to suffer the consequences for it, and I think that's actually always been the case and that by and large, people aren't willing to suffer the consequences for it. It might be something as simple as having somebody pissed off at you, to being ostracized from your community, to serious repercussions whether it be institutional, legal, financial, whatever. I mean there are lot's of good reasons not to do it, and that's where that sense of. Where's the radical spirit? Radicals have to be willing to lose something and in times of austerity it's far less likely" .

Less likely maybe, but the important thing is that there are academics and students still critically engaging with their workplace, regardless of the consequences. And I'm happy to say that there are a few out there. These academics often develop a reputation as some kind of 'trouble maker' and with that reputation, there is often a price to pay (and it's not just me wanting to interview you for this project). One of these so called 'trouble makers' (although to me, he just seemed like someone who cared about his work) told me of the lengths he goes to when resisting certain structures within his job:

"My resistance mode is to push it until I almost have to threaten my job because you know, you do alienate your managers and it turns out its not a good thing to alienate your managers. You've got no idea what they do behind your back. Like you think everybody's collegial and everybody's professional and stuff like that, but you know, once you piss people off, if they think you're a trouble maker, your reputation starts to suffer among management people, and you don't know what they do...They 
have to approve, they have to sign stuff off and they can hassle you and do all kinds of stuff..."

This came from an academic, who self admittedly, had quite a secure employment position within the university. Not everyone does though. In fact, many of the newer academics have quite precarious contracts and still end up with an uneven share of the workload, as they struggle to prove their worth.

Sandra Grey (2013: 708) advocates the "active engagement of senior staff, many of whom will need to distance themselves from the policy makers". Perhaps then, we should be looking to those academics in these 'safe' positions to take a more active role in thinking more critically about their workplaces. It may still be a risk, but it's certainly not as risky as a beginning academic doing it. Pauken (2007: 24) issues a challenge to:

"the speakers with the recognised academic, economic, and political credentials and abilities to set circular course; to strike positive relationships; to delegate the discovery, creation and dissemination of knowledge to those we most trust to find and share it-the faculty and students; and to open up a dialogue inviting all speakers to the ever changing table".

If we can see those we look up to and respect, such as our lecturers, our supervisors, our tutors, and even (although maybe not as likely) our managers and the Wizard of Oz-like Vice Chancellors, talking openly and honestly about the university, then others will be inclined to follow suit. Amy, who had experience within the cut-throat universities of Canada and North America, highlighted the fact that in New zealand, some of us may have the job security to be more politically active within our own universities: 
“Technically, I should be willing to go all out. I'd like to see them try and fire me. I think it would be really hard. I mean there's a small part of me that would like to see what it would take".

Not all academics have this luxury though and the survey by the Tertiary Education Union (2014) showed that two thirds of employees in the sector thought their jobs were under threat. People, including academics, have mouths to feed and bills to pay, and unsurprisingly, keeping your job becomes more important than reflecting on, let alone challenging, what is going on around you.

A fellow postgrad student once told me,

“The thing with academia is it's just like China..."

I struggle to make the connection and hope that the look on my face shows this...

"It doesn't matter if you're a black cat or a white cat, as long as you catch the mice".

As crazy as it sounds, he was right. If academics are 'catching the mice', or in other words performing well within a profit focused university, then it doesn't really matter what your views on the university are. You're too busy catching mice to even care anyway, but maybe there is a way to do both? Catch mice, therefore keeping your managers happy, as well as, openly critiquing the university? For example, while Sandra Grey could be considered the most vocal and critically reflective academic, she also 'plays the game': 
“...I also protect myself because I work hard and I tick all the boxes at the same time as I aggravate. So you know...winning a Marsden Grant, a high level of publishing, really strong student evaluations. I obey most of the rules, most of the time and do my job really well... at the same time as I kick and scream, a lot".

Even though the tools of discipline are ready to be used when needed, there may be a more effective form of control, the rewarding and affirming of conformity. When the two work together, the university really does become efficient at producing a certain kind of individual. The power of affirmation is strong; who doesn't like to be rewarded and told they are doing well? Those willing to conform to the academic status quo, to 'play the game' without 'kicking and screaming' will surely climb the academic ladder and receive the benefits that come with this. As Nelson (2010:22-23) states, "disciplinary training opens intellectual opportunities for students and faculty alike; it generates intellectual excitement and agency. It also closes off options and curtails dissent..." He continues:

"of course, rewards for conformity are also balanced by potential punishment, and the cultural wars, campus speech codes, and political reprisals against controversial speech have all contributed to a climate in which compliance, with its rewards, looks better than resistance, with its penalties" (Nelson 2010:23).

The university can therefore be seen as a technology that creates a certain kind of political subject; a subject under increasing pressure to align themselves with the strategic goals of the university. In Bourdieuian terms, the academic that conforms and obeys is the ideal employee. This is not so much pointing towards employees that require discipline 
(although those mechanisms do exist), but ones that don't require discipline, because they are in fact disciplining themselves, and this, as Sandra told me, is becoming more evident to those working within the sector:

"I think that the more market, new public management, audit and accounting, fiscal responsibility or whatever we want to call it, that model is so embedded now that anyone who isn't following that can't be co-opted because they were never going to follow it. But, everybody else has reluctantly, and perhaps unconsciously in some cases, gone on board. So I think we are disciplining ourselves to be the good actors and the neoliberal new public management, more market model of the university, which is an awful thing to say but I think we are managing ourselves in that space in ways that keep ourselves safe" •

The academic entrepreneur for example, isn't 'doing what they do' because they are being told to, but because they feel it is the right thing to do regardless. Becoming an 'academic entrepreneur' has increasingly become the norm. What does this mean for those that are not considered entrepreneurial? It means they are often left at the bottom of the hierarchy as "new forms of cultural capital and new hierarchies of mana (or institutional "prestige')" are created (Shore and MacLauchlan 2012:282). With these new missions of the university, it has become even more stratified and divided, and it seems like the academics hold on the university is being taken over by business managers. 


\section{Managerialism}

As result of the hyper-market focused university, we have seen an increase in managerialism (Larner \& Le Heron, 2005).

Throughout the course of my study, but particularly as I moved onto post-graduate study, it became clear that the relationship between academics and managers is rocky to say the least. I'll never forget being told by a senior academic after a conference:

\footnotetext{
"There is nothing worse than an academic who has become a manager. They're fucked!" He looked me intently in the eyes and said it through clenched teeth.
}

This sort of thing wasn't just a one off. The academic vs. manager was a recurring theme in most of the interviews I did. It appears it's a case of keeping your managers happy by 'jumping through their hoops' while at the same time resisting this by working together with your colleagues (in ideal casesand if the collegiality is there) in a bit of a Hogan's Heroes type fashion. In the TEU's state of the sector survey (2013) they found that 59\% of respondents disagreed with the statement that there was competent leadership among top-level managers at their institution.

In boxy offices filled with books and paper I listened to the hushed voices of academics, their voices quiet because the managers who they were talking about were always in close proximity, sometimes just through the wall, perhaps lurking in the corridor. Again I let my imagination get away on me and started thinking about mutinies on ships and plots to get rid of evil dictators and while the drone of hot computers and ticking clocks quickly bought me back to the $7^{\text {th }}$ floor of a social science building, the references to fascism seemed severe but also not unjustified. As Joe explained: 


\begin{abstract}
“...coz you know, managerialism ...like...I'd tell them to piss off to business studies. Managerialism is just fascism in the business sphere. And they go 'oh no fascism is too hard a word'. No, No. We're talking about a command and control system. It's just like the military. The power is at the top and it's delegated downwards, and the power relationship between each person in the network of the hierarchy is strictly spelt out in job descriptions"
\end{abstract}

I shudder at the thought of the militaristic working world but then realised that, while in some ways, I may have seen university as something to stall my own descent into the drudgery of a 9 to 5 job, there was no escaping the web of hierarchies, power relationships, and competition.

As a student, I had always found it weird that in a humanities department, there was an accountant at the top making all of the decisions, and decisions that we would expect accountants to make. We had all these professors and doctors who knew all this stuff about hierarchy and power and inequality, but it seemed none of this knowledge was being used on a day-to-day basis within our own workplace. There always seemed to be this one manager at the top making decisions people didn't seem very happy about, and this appeared to be just the way it was. While I'm sure in many cases academics and managers work well together as colleagues, I also got the sense that academics often felt that, although some official 'consultation' processes were in place, their managers had no sincere desire to listen to them. I asked Mark, a lecturer from my university, if it was a democratic place. He had to pause for a second, then gave a drawn out "ummmm" before figuring out what to say... 
"On the surface...oh yea there's..."

Mark stopped suddenly and appeared to change his line of thought.

“...No....Increasingly it's not. I mean there was a good example recently with the new vice chancellor actually putting forward a change proposal to create a different kind of management structure and he was actually on the panel that made the decision and it's just obviously not the done thing. Everybody knows about conflict of interest, but it just didn't seem to occur to them but they just went ahead and did it anyway. And I think increasingly there are agendas and plans and they've already decided and they've put out some nominal notion of consulting the staff... and they were going to do it anyway...I mean that is the suspicion that we are increasingly under and it's quite destructive really..."

All I could think to ask was 'why?... why are we being managed by managers?' A question academics had probably been asking themselves for quite some time, and many had arrived at an answer along similar lines to that of Joe:

“Well my sceptical...my political side says control. That's what managerialism is all about. When you empower managers, the first thing they want to do is take control. So to me it's mainly about control. You know like Weber used to say about bureaucracy; 'what is the purpose of bureaucracy? Well it's to improve management...No! It is control, the purpose of bureaucracy is control'. I would say domination and control. So when this managerailism came in, I would say that they may not recognise it as such, but actually if 
you pinned them down they'll probably have to admit it; That yeah, the point to them is some kind of quality control. And the operative word there is control. That if you want to have quality control, then you cant just have academic freedom run rampant, even though my view is that yes you can because we've been doing it for generations and it worked. It worked really well, and people didn't complain about it. No one ever said it was broke. But all of a sudden... See with the managers, their point is that, their kind of view is that it can be improved, which sort of implies that maybe, if it wasn't broke, it wasn't perfect or whatever, that they somehow, by imposing their control on it, can improve the quality. So yea, from the top down perspective it's about improving the quality of what we do, of our teaching and our research. But our view is that if you want to improve the quality of our research, you should give us academic freedom to do that, and give us resources, and listen to our suggestions, you know bottom up kind of idea. That's the whole point of academic freedom. The academic decides what's important. Not the power holders and the funders because if they decide, their motives are different, their motives are profit. They don't give a shit about democracy. Democracy? Don't make me laugh. All they're interested in is how to subvert democracy. So suddenly now some bureaucrat is going to tell us what to do based on their biases and their politics and what they think should be done. That's a decline in the quality of education".

Managerialism is supposedly in place to support quality control, but what does an accountant know about the quality of the Fine Arts, or Cultural Anthropology? For managers, 'quality' seems to be assessed by purely economic means. University managers are aiming to trump the critic and conscience function with "new roles as producers of 
intellectual and commercial property...reapers of research funds... and pawns in the commercialisation of a competitive knowledge "enterprise'" (Charters 2007:8 cited in Shore and Taitz 2012:214). In line with Foucault (1991) and Rose (1998 [1996], the university aims to produce subjects (students and academics) who act as a 'go between', bridging the gap between academia and industry; a classic neoliberal example of reducing humans to "rational economic actors in every sphere of life" (Brown, 2006). It is in this way that managerialsm can be seen as yet another disciplining tool to produce a certain kind of academic; one that performs effectively in the business world, as well as in the academic one. The difference between those two worlds however, is becoming less clear.

There has been some criticism of the hostility we see towards managers, and perhaps we should not be so quick to 'write them off'. Jones et al (2000: 20) identifies one of the threats to academic freedom as the "rejection of 'managerialism', without seriously addressing the issues raised by managerialism for academic freedom". This, apparently, comes in large part from,

"academics who think academic freedom is an unchallengeable right, assuming that they are a law unto themselves and need not be accountable for the way in which they undertake their scholarly duties" (Jones et al 2000:20).

Of course, academic freedom does not mean we have the right to say whatever we want, or that anyone at all should even listen. Jones et al (2000:8) notes that:

"The entitlement of individual academics to academic freedom is a freedom within bounds, determined principally by the scope of their expertise. This is based on the premise that, 
if academics show competency in certain fields, their opinion within these fields is worthy of protection".

What about when important things need to be said which may fall outside of our apparent 'expertise'? Shouldn't we still fulfil the role of critic and conscience if we feel strongly about certain issues? No matter what field or discipline they may come under? Just because I'm not an 'expert' on a certain topic, or more correctly, considered an expert by some obscure notion of discipline, doesn't mean that I shouldn't feel like I can express my opinion on it. According to Shore and Taitz (2012:15), it is our unions (TEU) perspective, "that academic freedom is increasingly being compromised by management policies seeking to restrict academics making statements to the media on areas deemed to be outside of their competence". This is a sentiment that came up in the interviews, and the excerpt below shows a level of hesitation about speaking on political issues which may not happen to fall into an academic's particular disciplinary 'expertise'. Whether this is solely down to management policies is hard to say, but what we can say, and what we should say, is that we want an environment where we all feel comfortable to talk on issues we find important, not one where this is restricted by over specific categories of expertise. However in some cases, academics did appear to have, if not internalised, then at least considered, some of the ideas around only raising issues in areas of their own expertise. Sam, for example, noted this in an interview:

"The issues that I know the most about aren't necessarily the ones that are the most relevant. I feel like certain things...I have some strong feelings about the deepening nature of state surveillance across the board, around the globe, you can see it in so many places, or the increasing penetration of neoliberal ideology into all 
phases of life but if I were to write about that, that to me gets problematic because I would feel like I would almost be... I wouldn't say abusing my authority, but it's almost like, 'aha! I've got $a \mathrm{PhD}$ and I'm an associate professor at Victoria. I can get out there writing about things which aren't my particular expertise...I think people who have knowledge in particular areas should be doing what they can to make an impact, but it is very much related to what we work on. Put it this way, I feel like academics should be allowed, very strongly, to speak their mind, without worrying about it having an impact on their employment. If they want to critique the government, and it can be a delicate issue, and they should especially be allowed to critic their senior administrations at universities..."

Pauken (2007:9) states, “academic and intellectual freedom rights have their limits...the academic freedom granted to an individual does not carry with it the right to publish unfounded accusations against university officials, when those accusations have not been properly investigated..." With freedom comes a number of "expectations, responsibilities, and accountability", and as Jones et al. (2000:19) continues, this includes a high level of ethical behaviour, a duty to other academics as part of a community, and an obligation to respect the academic freedom of other academics, and to prevent and resolve conflict. But all this can be hard to maintain when the system pushes competition amongst our peers, individualism, and conformity. The role of critic and conscience and the academic freedom that protects it, may well be written into legislation, but as we have seen, there are a number of institutional factors that inhibit academics ability to fulfil this role. If we would like our universities to be a place where we feel comfortable to pursue the academia we see 
as important, then these factors need to first be exposed before we move on to dismantle them.

Today's university has become a commercialised business due to the infiltration of neoliberal ideology. Along with a business focus, this also entails elements of discipline and control in order to mould academics into perfect 'economic actors'. We can see clear examples of this within the performance based research fund, which produces a 'publish or perish' environment and pressures academics to align their research and publishing with the economic goals of the university. Overlooking these drives, is the emergence of business managers who closely monitor this alignment; yet another facet of the disciplining machine. As a result, it is becoming more difficult to live in what Brian referred to as 'grey areas'. Perhaps, by 'playing the game' we only serve to diminish the grey even further. On the other hand, if the 'game' must be 'played' in order for academics to remain employed, then maybe, to a certain degree, it has to be done. As with all games, there are strict rules. The best players know the rules of the game well, but this doesn't mean they follow them obediently; they bend them and rework them. They look for areas where the rules can be disregarded altogether without anyone noticing. Like Joe will tell us in the next chapter, this isn't dishonest. It's political, and I think it's something that should be openly talked about more often. We all know that academics are under immense pressure to perform in a number of ways. What isn't so clear though, is how they manage these pressures, challenge them, and subvert them. If this was to become clearer among both the student and academic community, then instead of playing the game, perhaps we would me more willing to pull the fingers; my crass way of advocating a rejection of the rules altogether, and a desire for the reworking of academia away from the grasp of business elite. 
Chapter Five: Pulling the fingers/Resistance 
It's a typically windy and rainy day as I drive out of Wellington towards Palmerston North. I had an interview at 9.30 in the morning with Joe, a lecturer at the university. I got in contact with Joe by email after my supervisor recommended that I talk to him. Apparently he gave great lectures, was political, critical, said what he thought, and was a little bit like Jello Biafra, singer for the punk band the Dead Kennedys.

I arrived at the campus which seemed more like a set from Pride and Prejudice with big lawns and park like surroundings. The brutalistic Social Science building that stuck out of the ground made clear that I was in fact in a university. After walking up and down a few corridors, I eventually found Joe half way through a conversation with one of the admin staff. I hang around for a second or two, not wanting to interrupt before my presence did exactly that.

Joe seemed to know exactly who I was and what I was there for as he cheerfully introduced himself and we shook hands. We walked into Joe's office and sat down. It was a typical four by four-meter space; desk, computer, three chairs (one swivel computer chair and a couple of those more comfortable lower ones. Variety of seating is very important when you're an academic), shelves on the walls full of books, a filling cabinet and all the other usual office 'stuff'. There were a number of pot plants and a view that looked out onto the garden like campus grounds. Joe continued the conversation he was having with the admin staff, with me. I hurried to start the recorder, which always seems to be a slightly awkward moment, and listened as Joe told me of an issue he saw with the demands around teaching: 
“...'coz they introduced that policy and then they also launched into a big programme to improve our teaching and I told them, I said 'well we can't improve our teaching, coz then the grades would go up, and if the grades go up they don't meet the scaling', and when they say our grades don't match the scaling they interpret that as incompetence, you know what I mean? Like if I submit my grades and I don't have enough C's, they see that as incompetence....

I have to think about this for a second.

"That's you doing a bad job?" I ask... "if you've got too many $A^{\prime}$ 's and your students are doing real well...?"

“Exactly...Too many A's and you're an easy grader, you're incompetent, you're a liberal, you're a humanist or whatever or you're just trying to be popular or whatever and you're not being properly critical..."

Marking is enough of a mission without this type of convoluted judgment wanting to see all students as data on a perfect bell shape curve. A frustrating situation to say the least, and I have to ask how Joe deals with such demands .

“It's like resistance. To me it's all political, which I think is a classic postmodern way to look at it, you know like Foucault, everything is political and if you look at it as politics, you play the game and you resist it as best you can. And the art of it now, as it probably always has been, is how to do that effectively when they tolerate no resistance. It used to be you could resist it and because they gave you freedom, you resisted it by exercising your freedom. Now they take our freedom away 
and you have to find other ways to resist it, by being seen to be playing the game, by changing the wording of things, to jump through their hoops and then do what you want even though you said to them that you were doing something different, which is really ...it's not dishonest. I don't consider it dishonest coz it's political".

We both crack up with laughter, I guess at the thought of honest workplace politics, before Joe begins to sum up what he's saying:

“...Basically what I'm trying to do is do the best I can do and sometimes you actually have to fudge the system to do it. Because they're holding you back, and you refuse to let them hold you back. So you find ways to... Like with the final exam, if I have to call the final research essay, a final exam so that you will allow me to do it, then let's call it the final exam. I'll write on the course outline that the final exam for this course is a final research essay and if the bean counters let you get away with it...But it depends on the bureaucrat and whether they're going to let you resist..."

Here, Joe highlights the very heart of what this project is about; the systems holding us back from fulfilling the roles we find important as academics, and the modes of resistance, no matter how seemingly insignificant, that people are using in order to diverge from the restricted role that their institution pushes. In this chapter, I want to look at the small yet significant forms of everyday resistance that academics are employing against the demands of the institutions in which they work. In line with what Joe said, this can often be seen as 'playing the game' at the same time as you 'resist it as best you can'. While these actions are 
often small, they add up to a significant political statement as well as a form of praxis, merging theory with practice. Something as seemingly insignificant as leaving your office door open, talking openly, honestly, and constructively about our common condition as students and academics, are significant in that they prove that there are other modes of doing academia that don't have to fit into this market driven model, which many of us see as destructive to the quality of our universities. While it would be great if academics became 'activists' within their own universities, this may be unrealistic. What is certainly possible however is a heightened engagement with what's going on around us, an active engagement which makes a conscious effort to challenge ourselves, our students, our lecturers, our institutions, our communities, as well as those in positions of power.

I don't think our universities were ever places for the pure pursuit of knowledge and betterment of society; they have always been a place for the wealthy and power holders who use that knowledge for various vested interests, with money usually somewhere at the centre. Was the university ever really such a great place that we should be battling to protect it? According to Roberts (1979) “Sexism, Racism, ageism, Eurocentrism, and homophobia have all been present in different sectors of the university world, and have at times been manifested in course programmes, reading materials, appointments, and promotion decisions. For much of its history, the university has been available as an educational option for only the most privileged - i.e wealthieststudents." Anarchist literature is well versed in this type of debate as we have heard earlier from authors like Goldman (1906), Bakunin (1869), and more recently Haworth (2012), Amster (et al, 2009) and Deleon (2008). What we also learn from anarchism is the importance of challenging these aspects of the university. To challenge and critique our institutions 
is the first small step in the right direction. This doesn't even mean we need to do anything drastic, but it does call for a change in the way we do academia. As Sandra told me:

"I expect no more activists here than I do in the general public and that's only about one per-cent of the population. I expect active engagement from a hell of a lot more people. So when there are silly rules in this institution, actually the legislation says we should speak and say that that is a silly rule. We have an obligation to enact that in our classrooms, we have an obligation to challenge ourselves, our students and the communities in which we sit. So that's actually our job. To challenge our disciplines. There is a whole lot of ways we do critic and conscience. Challenging the dominant paradigm in our discipline is a critic and conscience act...challenging the political elite, economic elite, scientific elite; that's a critic and conscience function. Now, it might be done in a classroom...or in the boardroom."

Drawing on my methodology as well as the work of French scholar Michel De Certeau, particularly his work The Practice of Everyday life (1984) and my conversations, interviews, and experience with academics and the university, I explore the various paths students and academics take in order to resist the ongoing commercial attack of our workplace. While we may need to recognise that the university has never been what many hold it up to be, it has come to be a significant part in our lives and we shouldn't let it slip further into the realm of business and the hands of business people. The work of De Certeau, as well as a methodology which draws on punk, anarchism, and the daily experiences of students and academics, calls on us to move beyond the critique that we are so used to, and toward an enactment of the type of academia 
that we find personally stimulating as well as directed towards our communities and the people in them. Sometimes we may feel disheartened at the direction our universities are moving in, but after talking with academics I have become more positive that while it is a battle that may never be won, this doesn't mean that we should give up the fight completely. Not a heroic call to arms or anything like that, but a recognition that there is hope for the future in some of our most everyday but fundamental actions. As academics, we need to move beyond a mere understanding of the world around us, towards enacting real change and connecting our emancipatory ideas, with emancipatory action. Sandra highlighted this point, saying:

“...Academics understand the kind of world that constrains them and enables them at the same time...but if all we do is talk to each other about that condition and we don't actually try and reclaim something or claim something different, we're never going back.... and the 1970's universities weren't that grand anyway. So let's claim a public space that is the critic and conscience university type space. If we're going to do that, we need to do more than write academic articles and hold academic conferences. So good...but... But, what next? But did anyone leave there and go and challenge something? But did anyone leave there and change a behaviour that they know is a bad behaviour, that they know is a behaviour driven by the system. So closed doors. I mean mine is closed now for a very good reason of course, but you know I don't work with my door closed. I don't work with my door closed because it implicates an insularity that is counter productive to knowledge. So did anybody get moved into saying 'yes I've reconsidered and there are little things on a day-to-day basis I can challenge'?" 


\section{Challenging your discipline}

I talked with an academic named Mark, who I had been told had quite a different view of sociology than many other sociologists. In fact, I had heard that he saw mainstream sociology as being in a pretty depressing state. The interview with Mark was quite different from the rest of the interviews I did with senior academics; He was less 'academic', if I can make such a statement. He talked less, didn't use as many big words, and was less inclined to explain his experiences in relation to a theory.

I asked Mark about his time at university as a student. He told me that he never really felt at home within a university environment. Still today, his way of 'doing' sociology has a strained place within the discipline as a whole.

“...I was the first one in my family that ever went to university... and I went there after school... and found it interesting. I mean I obviously did sociology, but at the same time I didn't really feel at home, so I actually left after the first year and I went out and worked for about five years. But then I ended up working as a technician at Lincoln university. So in that kind of university environment I started to think again about what I wanted to do and kind of realised I was going to get bored pretty quickly so I ended up enrolling part time in some sociology papers at Canterbury and eventually decided I'd go back and finish the degree and kept going from there. So it just happened fortuitously for me, that when I finished my PhD the job here came up almost within a month of me finishing and I was lucky enough to get the position so..." 
"What do you think about it made you feel out of place or that it wasn't right for you in the beginning?" I asked Mark.

"Well you know for pretty much a class kind of thing really. Yea I mean I came from a working class family and it was a clash of culture for want of a better word..."

A 'clash of culture' also occurred within Marks academic career within a discipline he had some concerns over...

"For me as a sociologist I just continually wonder how much further there is in sociology as a discipline. But this is probably a broader question, I mean the same thing might apply to anthropology too...you know, how much longer will it keep its status?"

Sometimes I think we feel compelled to defend our beloved disciplines. To hear an academic talk about the possible end of the own discipline was kind of exciting.

Mark continued....

"I mean if I talk about sociology, I think one of the problems with it is it's successful, it's got some core to it for want of a better word, and yet after over 100 years or whatever it is, to me it doesn't seem to have moved on in any sort of progressive notion, and I mean that could conceivably go on but, what's increasingly threatening, or on the horizon, is fragmentation into studies areas, which I think potentially could be good thing, and so that poses the problem for well what is the core of sociology? And if you problematize that, there's nothing to stop it from disintegrating, which is not necessarily a bad thing. So in some senses I'm 
increasingly fraught about... well do I claim to be a sociologist anymore? So for arguments sake, or for example, I don't actually often go to sociology conferences, I don't... They don't do a lot for me anymore. So I go to things for what I'm working on and they aren't usually full of sociologists but that's fine, that's not a problem...."

"why don't you go to these sociology things anymore?, I asked.

I expected something about years of boring academic presentations, but found that Marks disinterest in sociology conferences came from disciplinary differences.

“...ah well for one reason or another in my sociological career I ended up kind of aligning with a branch of sociology that was always sort of peripheral or problematic or troublesome or whatever and I mean it's a branch of sociology called ethnomethodology and I never went about calling myself such but always found it useful and always kind of drew upon it managing to do work within sociology, but as times gone on, standard sociology didn't. I mean I respect it and I know It's important, but I don't want to go to a conference and hear two days of it you know...

We laugh at the thought of two days of sociology. "What is ethnomethodology?", I figure I should ask. “...Well the term literally means members methods, so it's how people do whatever they do as a joint product between people, so it's a sort of descriptive enterprise which tends to avoid theorising and just about always 
says 'let's see if we can get some good data and do a good study' ... and the point being made is that people do whatever they do using available methods which are quite different to how a sociologist would theorise or conceptualise what they're doing...."

A 'descriptive enterprise which tends to avoid theorising'.... I can see why this could be seen as problematic within mainstream academia where theory is held high and there is a distinct and elite way that we talk about it. As Shannon (et al. 2009:184-186) says, it is often "written in a privileged language for those privileged enough to go to university" and that "all to often, theoretical perspectives become ossified by their own outmoded, doctrine, and the dogmatic discourses". Anarchist theorist David Graeber (2004:8) comments on this as well, and argues that although the above may be true, this doesn't mean we should to be 'against' theory altogether. Instead, he encourages "accepting the need for a diversity of high theoretical perspectives, united only by certain shared commitments and understandings". Rather than seeking the one ultimate theory to rule them all, we need to accept a diversity of ideas and look for areas where we can build on the commonalities that exist between them. Alongside these 'high theories' though, and perhaps more importantly, we need what Graeber calls 'low theories' or "a way of grappling with those real, immediate questions that emerge from a transformative project"(2004:9). For such a project to occur within academia, Graeber offers us three ideas for a 'useable' anarchist theory; it would be against policy, it would be against 'anti-utopianism' (because another world is only possible if we believe it is), and it would be against vanguardism. Like Mark's way of 'doing' sociology, this type of theory may well be useful, but it doesn't mean it will be accepted within academia: 
"So the approach you take to researching is quite different to a lot of other sociologists?", I ask Mark.

“Yea I tend to do case studies of quite particular things. I mean for example I've been working on, just beginning to work on a little video tape. It's a fiveminute video of a fight that develops between two mountain bikers, and it's enough... I think I could write three or four papers on it and I could keep myself busy for six months. But for example, I've just been asked to... The schools got this website thing and I've just been asked by the secretary if I'll put up a little paragraph on my research, and I know what's up there already and what other people are doing and I'm thinking 'oh god everybody will think this is ridiculous'. It's not ridiculous but it is markedly different from what most other people do. I know it's not ridiculous, but it's like before you even open your mouth you have to kind of bracket and say 'oh don't think this' you know..."

I feel like I kind of know what Mark is talking about; that my own work is not exactly a perfect fit within the academic environment, for whatever reason...Too simplified, lacking in any real academic significance, too light on the use of theory, so on and so forth. I tell myself that this is because academia is academia...it is what it is...it has become comfortable with it's beats and rhythms, has it's standards an ideas of value, which I and my work sometimes struggle to align with. Although, I'm not sure if I agree with Shannon (et al. 2009:187) who says that academia "require[s] our work to be boring, repetitive, and written in a language that is barley decipherable to anyone without a graduate degree". I do think though, that there is a 'correct' way to write academically and that although this is deemed the 'correct' 
way, it doesn't mean it's the best. Peter Elbow, for example, argues that "discourse carries power", and 'academic discourse' privileges those students who have been lucky enough to familiarise themselves with it (1991:135). What he is calling for is not the throwing out of academic discourse, but the recognition that there are other competing discourses, voices and styles. To place all the emphasis on becoming a master of any particular one of these, is to ignore all the others as well as what we can learn from them. My writing style has been refereed to as polemical, and informal, as well as engaging and accessible. I was told to use words like "this suggests" or "the literature argues" instead of something more...opinionated. I recognise that sometimes my writing can be polemical and informal, and full of my often 'regrettable opinions', but that's because I'm a human who is polemical and informal and full of opinions which I may regret and not an objective robot. In a somewhat hypocritical sign that I am also 'playing the game' (see note on writing style), I have tried to 'tone down' some of that style; what Deleon (2008) and Shannon (et al. 2009) refer to as 'domestication' so as it might be better received within the confines and discipline of institutional academic discourse. While I consider such a measure, in many ways, to be against what this project is all about, I have to recognise my own desire for it to 'do well' in a number of different settings, academia being one of those.

Unfortunately, “in educational research most gatekeepers have been generally committed to an assumedly objective and value free research methodology" and there is this idea that being 'involved' in a 'cause' will some how take away from the quality of academic research (Siraj-Blatchford 1995:214). Sandra Grey writes on this, saying, "the desire of academics to connect themselves to social and political 'causes' is frequently seen as being at odds with academic notions of 
objectivity" (2013:702). These positivistic ideas are alive and well within academia; a view which sees society as being made up by a set of rules and laws which we can find through observation, experimentation, and comparison (Crotty, 1998). However, it fails to consider the various complex and subjective influences of social, political, and economic factors and instead views knowledge gained through scientific endeavour as 'pure', 'factual' 'truth'. If we are to encourage an academia that truly stands for the betterment of our communities, then we need to discard these traditional yet enduring notions, and realise that this doesn't have to result in any loss of quality. As Sandra continues in her article, "while advocating for activism by university staff means discarding positivistic notions of research, it does not mean discarding a commitment to rigorous research" (Grey 2013:702). 
The small yet significant acts of everyday resistance

On a slow day at uni, I broached, with maybe a little bit of caution, an idea I had with some fellow students:

"Do you think that because everyone's so busy and there's so much pressure on us to be working efficiently all the time, that pissing around could be a political act?"

For the past few weeks I had been finding it hard to focus on my work and seemed to be spending lots of time in the corridors doing just that- 'pissing around'. As the pressure of dead lines grew nearer, I think I began to resent the task I had in front of me. What started out as a project I was passionate about had become an exercise of drudgery. I don't know if anyone actually ended up answering my question. It was probably a ridiculous thing to say and maybe a recipe for being branded the lazy academic. But I think there is value in the act of 'doing less'; it builds community, boosts moral, and results in a happier and healthier workplace. If we aren't enjoying what we're doing, then the results aren't going to be that great either.

When I suggested the same thing to Amy during an interview I was so relieved that she not only believed in it, but had been practicing 'doing less' as a political act for quite some time.

“...you use whatever is at your disposal. So they're subversive in the sense of, yea just whatever tool you can get your hands on regardless of who you are...so you could be a meat packer and you've got tools at your disposal to fuck off for part of the day and even if it's only day dreaming while you're doing something, you're giving your attention to something that's more 
meaningful. They may have your body for a few hours, but they don't have your mind and vice versa. of course slacking off is a political act! It just depends on how you define your politics. I mean what do you think anarchists do? It's a shame you guys aren't being taught to read this stuff. The French have written about it for decades. de Certeau understood it better than anybody; he was an amazing guy. He was a Jesuit priest before he became a sociologist; I don't know what the two have to do with each other, but I think they have something to do with each other, I've just never figured it out. It's always treading the line. It can never be complete structurelessness. It always has to be directed, but it can't be over directed. It's always tweaking and tinkering with the system, tinkering with yourself, your job, your students, your research. It is in fact what we do, I think we just seriously undervalue it. I find great hope in it"

This de Certeau guy sounded like the exact kind of thinker I needed to go along side a chapter on resistance within the university and I agreed with Amy when she said it was a shame we weren't learning about this stuff, because she was right; there is great hope in the small everyday actions of people.

Amy continued...

“...Little tiny things. de Certeau talks about something called 'La Perruque' and it's the idea that when you're at work you steal some of your employer's time. This is the person who uses the photocopier for fliers of their lost dog, and it can be something really simple like that, or talking to on the phone, making personal calls. It's stealing back the labour in little tiny bits, and I think that's actually a really powerful tactic we have 
against big systems. Its not the overthrow of the system, it's the insidious chipping away at it everyday and getting what you need while simultaneously giving them enough of what they need that they back the fuck off"

\section{The University as a resource}

The humble photocopier has enabled alternative voices to be disseminated for years. Academics and post-graduate students often get free printing (although the price is no doubt worked into our fees), and although lost dogs need to be found, there are other matters for which we can make use of these valuable machines. If you have something to say, the photocopier can insure that it gets distributed widely. I've used my free printing for lots of stuff; I made album covers for band I was in, printed guitar tablature and lyrics so that band could learn to play some songs, happily printed undergraduates (who pay 20 cents a page or something) essays and journal articles, and printed hundreds of flyers when as tutors we realised we were doing work we weren't getting paid for, or when our university decided they didn't want to pay people enough to live a good life (see flyers below). Even if campus security did quickly go about removing all the flyers and throwing them in the bin (see flyers in the bin) the beauty of free printing and access to photocopiers means we just printed some more... and some more... and some more...

By using the universities resources for something well outside their strategic goals, we are resisting the neoliberal pressures that push us to perform efficiently with revenue and industry as our concern. In de Certeau's words:

\footnotetext{
"La perruque' is the workers own work disguised as work of the employer. It differs from pilfering in that
} 
nothing of material value is stolen. It differs from absenteeism in that the worker is officially on the job. La perruque may be as simple a matter as a secretary's writing a love letter on 'company time' or as complex as a cabinet maker 'borrowing' a lathe to make a piece of furniture for his living room...Accused of stealing or turning material to his own ends and using the machines for his own profit, the worker who indulges in la perruque actually diverts time (not good, since he uses only scrap) from the factory for work that is free, creative, and precisely not directed towards profit. In the very place where the machine he must serve reigns supreme, he cunningly takes pleasure in finding a way to create gratuitous products whose sole purpose is to signify his work and to confirm his solidarity with other workers or his family, through spending time this way." (25)

Within today's neoliberal university, there is barely time to stop and consider the possibilities of what academia could be. We are driven into isolation as the constant threat of deadlines loom overhead and drives us to shut our office doors and produce sellable knowledge, and produce it quickly. Maybe we forget that even though we are restrained by these big powerful structures, as people within these structures, we have the significant ability to act, or not act, in certain ways that subvert their dominance. The work of de Certeau teaches us that, and to use Amy's words, "they may have your body for a few hours, but they don't have your mind and vice versa". 


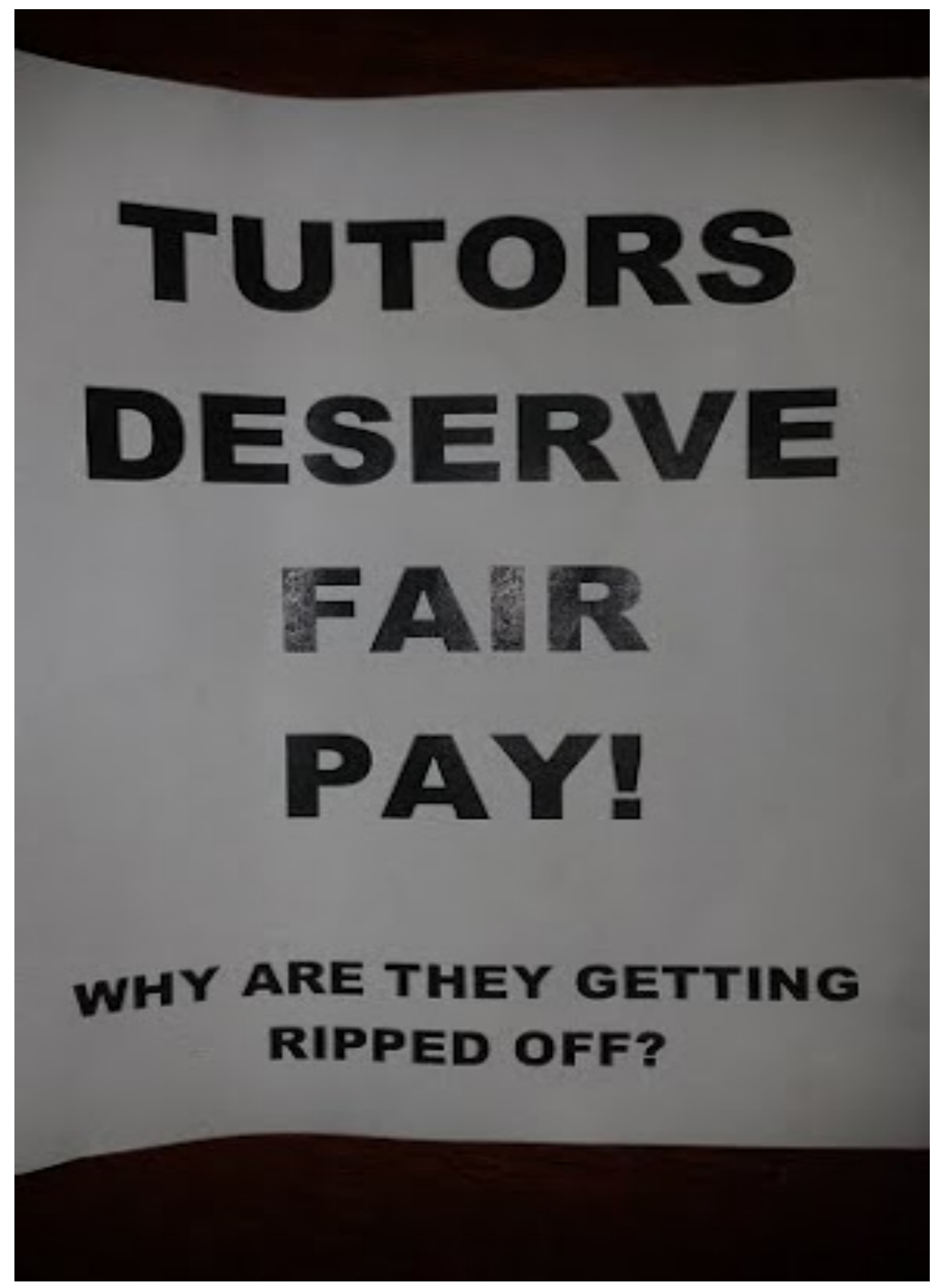




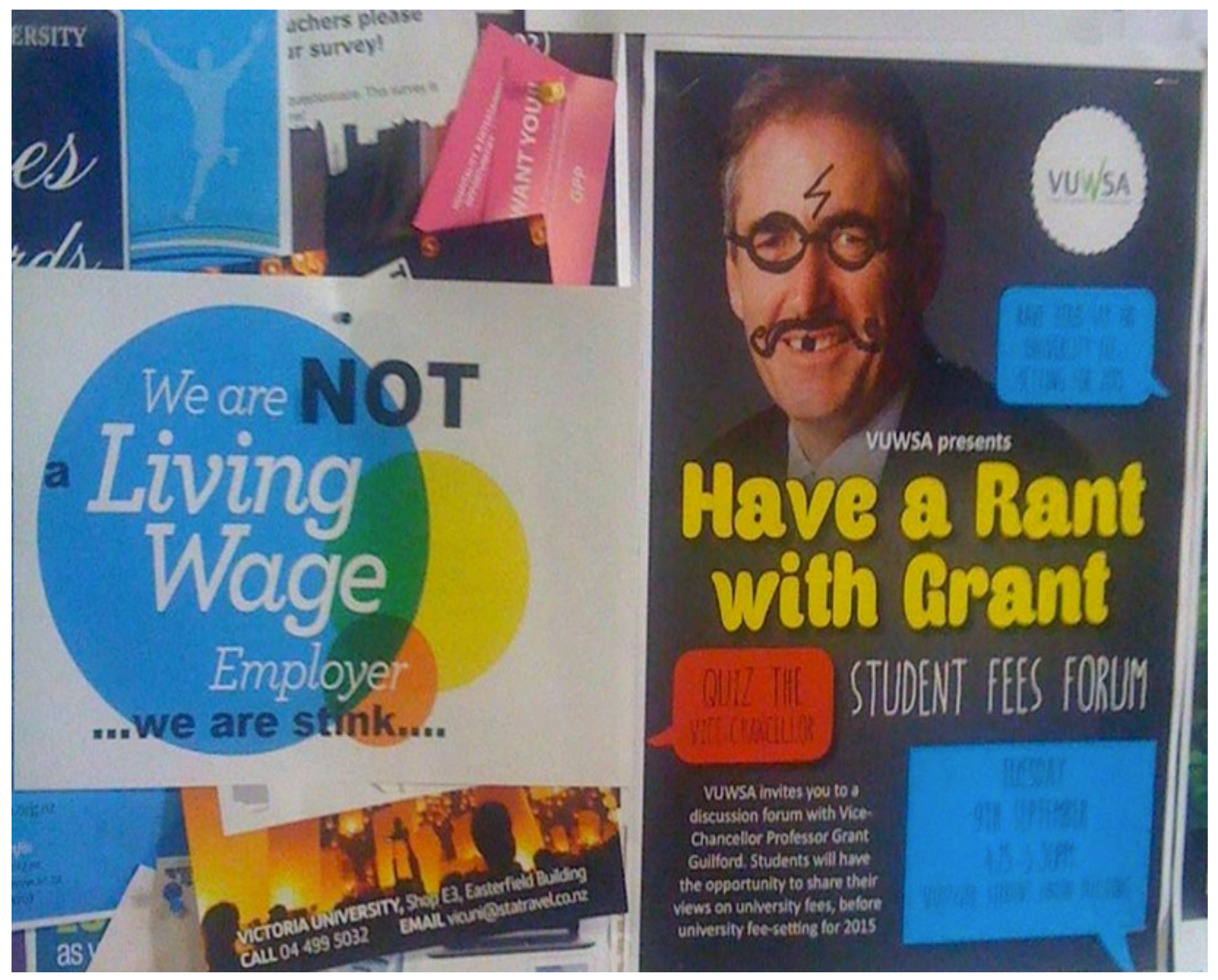



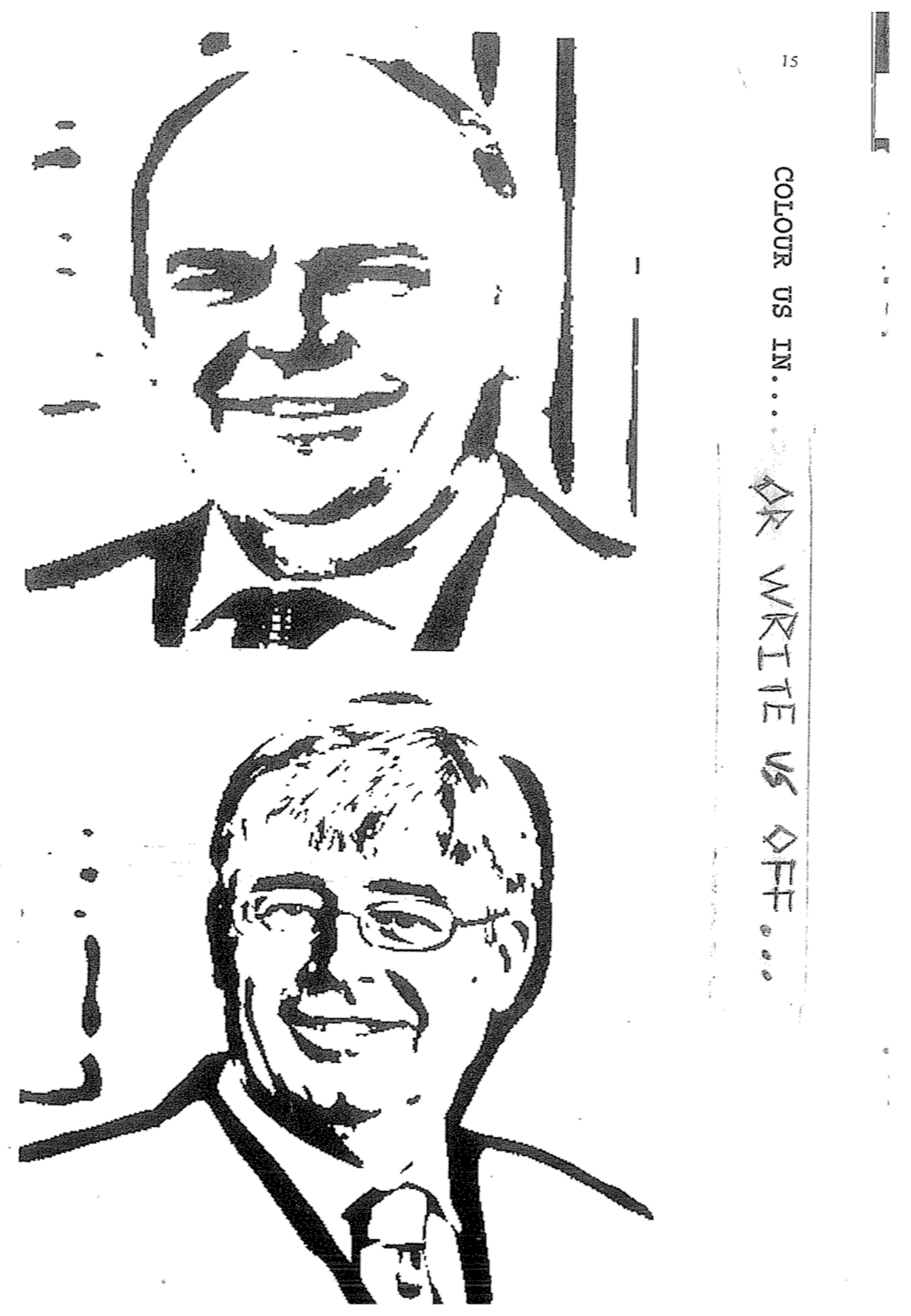


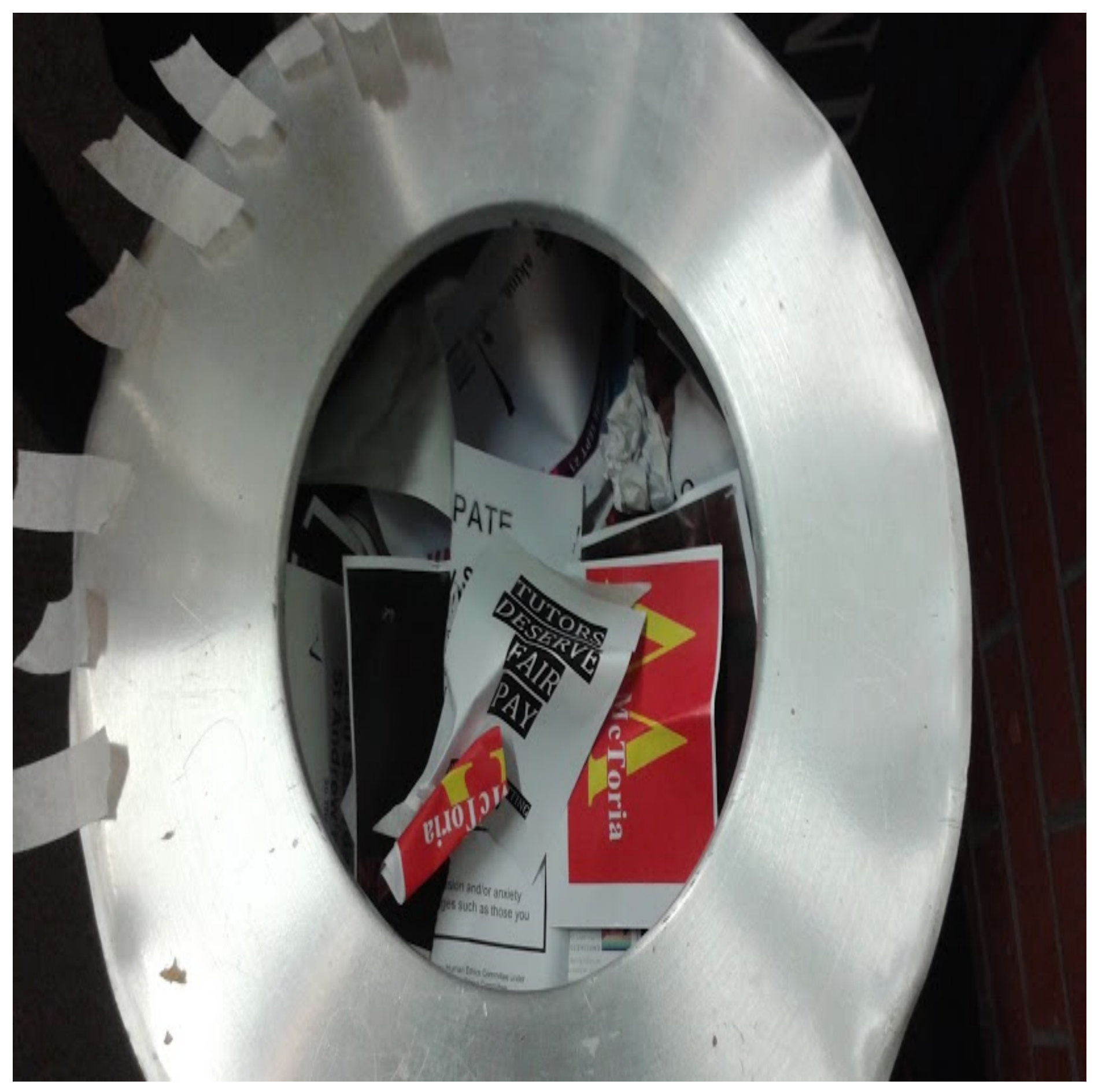




\section{'Bending' the rules of the game}

While critical pedagogical theories like that of Freire aim for emancipation within the classroom, anarchists take a more direct approach to confronting institutional control. These methods of direct action, when considered alongside theories like Freire's, offer more than critique and move towards everyday change in which we can all participate. While direct action may take on a different feel within the university than it does in a factory, for example, it can still be applied within an educational setting. At the beginning of this chapter, Joe told us how he was under pressure to have a final exam for a course he was teaching. Instead of Joe caving in to this pressure (he didn't think on the spot tests and exams where that useful or fair on the students), he simply relabelled the 'take-home test' a 'final exam'. By doing this, Joe was resisting what Deleon (2008: 16) calls the "cult of measurement proposed by neoliberal educational reforms". These measuring mechanisms are supposedly in place to support quality assurance and accountability, however there is a growing body of literature that argues that they signify the coercive, disciplining, governmentality that is today's neoliberal university (see Shore and Wright 1999, 2004, Shore, $2008)$.

\section{Resistance within the classroom}

The role of the radical teacher should not only be one of resistance, but should also foster resistance in their students. Through divergences from standardised curriculum, and by working certain topics into course work, teachers can open up the possibilities of social protest to their students. I learnt what a 'sit-in' was from a group of 'trouble making student protesters' and not in my first year sociology and 
anthropology courses where I learnt about capitalism and alternatives to capitalism, and inequality, and power, and stateless societies etc. It doesn't matter where I learnt it, the important thing is I learnt it, but there is no reason why it couldn't have occurred within the classroom; I would argue that it should, and in many cases it does.

Although I know many people, including some anarchists think we need to destroy the old university completely and make sure we never waste our time building anything like it again. But for one reason or another, many of us have found ourselves rather liking at least some of what goes on in these ugly concrete buildings. The thing that makes these ugly buildings worth having in the first place, is the people inside them. Like Bowen (2005:119), “I believe the anarchist project begins, with the boring, small scale, mundane business of making positive, non-alienated relationships with our friends and neighbours and remaining open to new people and ideas". While a lot of academic work on academia tends to focus on the bigger structural forces acting on the institution, I think that there is real value in looking at the smaller, but no less significant idea that we, as the people within our universities, have the power to change them. Anarchism can be of value here because it demands that we participate together in order to achieve that change. In Utopian pedagogy: Creating Radical Alternatives in the Neoliberal Age, Coté et al. (2007:317) use the conceptual tool and creative practice of 'utopian pedagogy', not as a goal of perfection but as a reference to the continuous carving out of elbow room for "resistance and reconstruction here and now". According to the authors, one of the goals of academics should be to "participate in the creation of autonomous spaces of radical teaching and learning that stand apart from, but relay with, pockets of dissent in the university" (317). The authors give an example of a course taught at a typical conservative 
university, which aimed to explore and enhance the connections between alternative media and social movements and NGO's; a radical cause some might say. The funny thing is, the existence of the course was protected by the previously very corporate connections that that particular school had already made. With a teacher from the school being quoted as saying:

\begin{abstract}
“University-business linkages have been rationalised under the name of breaking down the 'ivory tower' and connecting academia to the 'community'. Once such an ideological motif has been launched, however, it is very hard to reject arguments for connections that go beyond the business community" (Coté et al 2007:318).
\end{abstract}

Does this mean then, that we can use the neoliberal and dominant ideas within our institutions in order to create a form of resistance? And if not, then perhaps we should be looking for signs of hope which are happening, or waiting to happen, right under our noses. Academics could even act as a catalyst that fosters and encourages this type of behaviour.

Sandra, for example taught a course on social movements, largely out of which formed a student protest group. I asked Sandra about this and wondered if it was more than a coincidence that many of the people involved in the group had been in that course. Sandra told me:

"I had a very radical group for the social movements group this year, and people ask me, 'do I see radical students?'... Yeah I do...but I don't know whether they gravitate towards my courses because of the types of course they are, therefore I see a different slice of the population than other lecturers see, because I teach critical social policy, I teach social movements, I teach social inequality. I mean, people come into the social 
movements course because they have seen me speaking at protests, so they gravitated because they admired the protester not the academic..."

"Do you consider encouraging those more engaged students a political thing?" I asked, knowing that the answer would be yes.

"Yeah, and also encouraging them to get engaged. Some of them had never been engaged in political protests and joined political protests for the first time. It's probably not my job..."

I see Sandra's face screw up slightly before she backtracks and corrects herself...

“...well no it is my job. My job is to create critically engaged citizens and I'm happy to do that. I don't want passive citizens around me and I suppose the very structure of my courses to some extent, allows a bit more of that. So for the past five or six years I've always made it my point to make it an interactive space, not just with me, but with each other. And I did that because I saw the dehumanizing effect of the modern university as quite problematic to me. And you know, I got some really lovely student evaluations where people said, 'you turned us into a group of people who got on, you turned us into a collective of people', and that was really neat and it was the first time in 3 years that I felt connected, and that in and of itself is a radical project..."

Berry and Worthen (2012:438) add to this idea, saying that “Teachers, if they are organised, have a uniquely strategic place in shaping the political and economic discourse of a society, but only if they are organised and collectively 
pointed at the main enemy". There is room for individuals to make a big difference. Some of this room is in the classroom and the teaching that takes place within it can be a form of activism in itself. Like Sandra's comments above, Chris, a senior Social Science lecturer, also saw the role of a teacher as a political one:
“While I'm not as politically active as I'd like to be and as I used to be, I still think the university is a small place where you can do a rather modest thing, and that is being really receptive to the students who are a bit more counter cultural and being able to be excited about the stuff that they want to do. But also switching to the students who don't give a shit...that kind of seems like a modest political thing we can be doing as well as a purely intellectual thing".

I had admired both of these lecturers, and in both of them I had gained confidence that maybe one day I could be an academic. But they, as well as other teachers, had also been the mode that I began to learn some very valuable things in life; both academically and personally. While anarchists may take a more direct approach than critical pedagogists, both recognise the importance of education and teaching and the effect it can have toward social change. Both also recognise that the best way to achieve this is to break convention. Horton and Freire (1990:44) for example, state "...the problem is that most people don't allow themselves to experiment with ideas, because they assume that they have to fit into the system...I just think most people can't think outside the socially approved way of doing things and consequently don't open up their minds to making any kind of discoveries. I think you have to think outside the conventional framework". 
The anarchist way of 'breaking convention' may appear to some to result in confrontation and violence. Confrontation? Sure. Violence? At this stage, definitely not. There may be a hope that through direct action, education will lead us into a society that has dismantled capitalism, but our main concern should be the very real change we can make everyday.

This was something Amy touched on. After witnessing a lot of her colleagues leave academia due to what they saw as destructive reforms, Amy made the decision to stay "in the system" in the hope of changing it:

"My idea of revolution when I was 20 was all or nothing, because I could afford all or nothing. I can't afford all or nothing now, for lots of reasons. And I've learnt that you can't change things unless you're involved in them. It's the 'how' you're involved that has become important to me now".

Rather than wage some heroic uprising, this entails a sustained mindset and mode of being which resists oppressive institutional structures and makes positive changes on a dayto-day basis.

\section{Resistance as transparency}

A small yet significant thing academics can do in order to resist harmful effects of neoliberalism, is talk openly and honestly with their students about what is going on in our institutions. As undergrads we are told only good things about the university and our departments, but as we progress through the ranks we begin to get an idea that things aren't so settled. It's not until we get to post-graduate level that we begin to hear all of the behind-the-scenes politics that goes 
on. The lack of democracy, the rift between management and academic staff, constant monitoring, strange redundancies and pay-outs, workplace bullying and intimidation, the fact it's becoming more like a business, as well as a range of other disciplining tools and everyday power relationships that occur within universities. There's an Australian anthropologist called Michael Taussig (1991:7) who says "[w]herever there is power, there is secrecy, except it is not only secrecy that lies at the core of power, but public secrecy". Now I'm no philosopher, but is a public secret a secret at all, or just something none of us are prepared to say even though we're all thinking it? Within the university, this sort of thing occurs all the time. On the Victoria university website, for example, there is the following statement:

“The 2012 Performance Based Research Fund (PBRF) Quality Evaluation by the Tertiary Education Commission has ranked Victoria University of Wellington number one in New Zealand for overall research quality"

Cause for celebration some might say. However, the tactics used to achieve that number one position were decidedly dodgy, including the altering of academics contracts so that the ones who were not going to score as highly, were not counted at all, and so therefore did not bring down the institutions score. This was something that became common knowledge around the university, even as the celebrations and add campaigns spouting numerous "we're number one" type slogans commenced. Some academics were less willing than others to accept and celebrate this:

"When Vic got the announcement that they were number one my heart sank...that's the first thing it did, because I thought how can they justify all of the bad behaviour that has gone on at this institution in the lead up to 
the PBRF, because we got number 1? And we got the email saying there was going to be a celebration for our school because our departments got number one, and I emailed the head of school and I said I do not want to take away from the quality of work done by my colleagues, but I know they do quality work. I don't need an external ranking exercise to tell me this. I think there is nothing to celebrate in the PBRF. And the Vice Chancellor called a celebration and I sent the same email very politely saying I will not be attending because the actions you took in the lead up were horrific. And I told colleagues I'd done it. I was public about the fact that I was doing these emails, and people said 'that's fantastic, that's exactly how I feel' and I said 'why didn't you do the same'... and they said 'oh I couldn't possibly'. So they agree with the sentiment, they agree with the words, they agree with the ideas but they're not prepared to make a stand..."

At times, there may be a lack of collegial support within academia. Perhaps as students, we aren't made aware of the pressure our lecturers are under. I think academics should be more open about the politics of their work place and willing to talk with their students about it, because at the very least, we deserve to know, and what the university tells us through their advertisements, marketing, and various other sources of propaganda, isn't exactly well-rounded. On a more important level and as Grey (2013) writes, "Part of being active academic citizens involves challenging our students to do and be more". If academics are willing to be more open with their students, then perhaps both groups can work to support each other, something that unfortunately doesn't happen enough within the university. 


\section{Resisting Together}

One of the biggest tools we have to fight the Neoliberal University is each other. In some cases, we may not have the support we need from our colleagues, and when this occurs it is important that we seek support elsewhere and protect ourselves in other ways. Becoming familiar with employment rights, your institution's code of conduct and connecting with your union are all good ways of doing this. But nothing beats collegiality and a sense of community in the workplace, and while the neoliberal university may be pushing individualism and conformity, this only increases the need for us to connect with those around us.

Resistance works best when we participate with a collective of people. One of the biggest allies within the neoliberal university is our colleagues, students, and lecturers, and if we can work well together, there are ways to 'work around' the neoliberalisation of the university and the managers who monitor it. It may even help us to not get fired or put on suspension.

At Joe's university for example, there was a debate about the way in which they elected the head of the programme. As Joe told me, this was a "political game":

"you know when I clash with the head of my school she says 'well Joe this is my job description and it says that I have the power to decide who your next programme coordinator is going to be' for example, because that's just happened to us recently. Traditionally the head of our programme rotates, we all do it, we do it consensually as a kind of idea that we should share it, and it rotates around. We never make anybody do it that doesn't want to do it at that moment or is too busy, but 
the idea is that we'll all do it, and when that person has done their three year stint or whatever, then we sit down and decide who will do it next. You know for 28 years I've been here that's how it's worked. Well, this time... we just did it...it goes to our boss, our blind manager, and she says 'well it's her authority to appoint the head of the programme', and instead of us deciding and telling her who it will be, what she wants to do is call for expressions of interest, and then those who are interested will send her a memo, and then she will decide amongst the applicants. And we said 'well why would you be able to do that?' and she said ' well because she knows about work load balances and she could say well I think this person should do it because this other person has too heavy a work load' and we said 'well actually we do that in the programme already', because we do our annual plan of what we're going to teach next year and we have that all worked out and we make sure everyone has equivalence and no one is teaching more than anybody else. We always do that. But that's a classic example of where the managerialsm comes in. So no longer do they accept that for 28 years this is how we've determined the head of our programme. Now that's changed. That's not the official way it's done. The official way that it's done is that the head of the school appoints. She has the fascist authority. There's no like, come up from the bottom and we decide who we want to do it. She decides, and if she decides then we can't appeal."

But I feel like Joe wouldn't just give up that easily.

"And she's decided?" I ask. Joes face cracks a wide but uncertain smile. 
“um well we play this political game.... and the political game is that we talk among ourselves and we make sure that nobody breaks ranks and expresses interest that isn't somebody that we've already put forward....but somebody could...if we weren't all together...if we had factions..."

The idea of 'playing the game' has become a central demand of academia. In fact, just the other day while going through the frustratingly bureaucratic process of applying for an extension, I was told, "we don't play with them unless they play with us. But if they play with us, then we play with them". The thought that I was engaging in some sort of game (which I had no idea how to play) with a rather intimidating sounding them was quite daunting as I carefully (and with difficulty) worded, dated, and manipulated a personal situation into a tidy, streamlined application form. This was only made better by the fact that an academic just made a Rambo like statement in support of me, an academic who knew 'the game' so well, that any manager that dared 'play' would surely lose. Perhaps though, we should be more willing to play, and to be the ones that initiate the play. Rather than simply react and resist changes, why not act in order to bring change about? As Graeber (2004) says, in what I assume is a 'just kidding, but seriously' type statement; the lecture podium is the wrong sort of barricade to be standing behind in a revolution.

As we have seen though, a lot of influence can be shared from the lecture podium, and teaching, in itself, is a political act in which academics can connect with students as part of a wider academic community. With this solidarity, we can work together in order to challenge the destruction and speed with which neoliberal informed practices are gutting our once communal institutions. First, this is going to take an honest 
self-critique of our places of work and study, and an open and inclusive discussion free from the fear of discipline. There are many small acts we can make to bring this sort of institution closer to a reality. While they are small, it is their everyday-ness that makes these acts so significant. They move past the familiar critiques and begin to effect real change by merging theory with practice, thought with action. By drawing on the tactics of de Certeau and anarchism, we are able to challenge our academic institutions, our disciplines, and the norms that prevail within them. Not a rejection of the entire institution, but a recognition of the need to find answers to what Graeber (2004:9) calls those "real, immediate questions that emerge from a transformative project", like the one encouraged within this thesis. 


\section{Conclusion}

If this project was a personal exploration attempting to figure out what academia is and if it's a place for me, I am still unsure. All I can say at this point, is I'm looking forward to getting out of the place.

But I leave having gained so much, and not just a qualification on a piece of paper or some letters to put at the end of my name. I have learnt that even in the darkest, most ancient of institutions like the university; and even in the most market driven, money obsessed, disciplining and controlling, neoliberal times, there are always people, (sometimes just one or two), who are working against this dominant machine. I believe, that by connecting with each other, we can gain support, ideas, tactics, and a community of people, collectively working for change.

While academics are aware of the destructive nature of a market driven university, the task is now to move into action. This action can take whatever form we desire, from keeping your office door open or talking honestly with your students, to speaking publicly at demonstrations about harmful university policies. The universities we attend may have certain ideas around what they consider an academic to be, or how they expect a student to act, but we don't have to simply fulfil these roles without questioning them. In chapter three, I looked at a range of theories around the academic. These ideas come to us from theorists like Freire, Gramsci, Marx, Mills, Said, and Foucault, all of whom focus on merging theory with practice and call on us to do more. These ideas, when considered in relation to anarchist thought on pedagogy, combine to produce a theory of the academic that is aware of their privileged position and the power that comes with it, 
but is equally aware of their responsibility to use that power and privilege for good. As Edward Said taught us "I think the major choice faced by the intellectual is whether to be allied with the stability of the victors and rulers or- the more difficult path- to consider that stability as a state of emergency threatening the less fortunate with the danger of extinction" (Said 1994: 35). Rather than place the academic in an elite role of 'critic and conscience of society', such a theory of the academic aims to produce a society in which all our voices are heard, no matter who we are. The role of the academic in enabling this is an important one; In Foucault's words "the role of the intellectual is no longer to place himself a 'little bit ahead or a bit to the side' so as to speak the silent truth to all...[r]ather, it is to struggle against the forms of power in relation to which he is both object and instrument" (Foucault 1977a 206-207).

As academics and students, our ideas are shaped by the environment in which they are formed. The effects that neoliberalism is having within our universities is severe and cannot be ignored. Along with a hyper-commercial mind-set, we are also under the influences of disciplining mechanisms that aim to shape us into business minded 'entrepreneurial academics'. While it is easy to jump on the 'blame it all on neoliberalism' bandwagon (and I think I'd quite happily ride along on that wagon), we need to move beyond critique, and into the realm of action. It's important that for those of us who see more to the university than a business producing sellable products, that we 'go the other way' and do this visibly, vocally, and proudly. Because it's those people that keep the university a place of meaning, and it's those people that this thesis has been about.

As a student there is nothing better than seeing an academic doing what they love. They are passionate, inspiring, frantic, 
chaotic, and doggedly focused. There are academics who seem unlike the others; the 'weird' ones, the unorganised ones, the ones that refuse to fit the mould, the 'heathen' academics, the 'trouble-makers', the disillusioned, the disenfranchised, so-on and so-forth. These are the academics who have shown me that there is room in academia for everyone, and although it may at times be precarious, by working together in everyday, on-the-ground ways, we can find some more 'elbow-room' (Scott 2013). These are the pockets of dissent that we need to support, connect, and nurture, because their place within today's university are being made smaller and smaller, as well as more crucial than ever.

The neoliberal assault is not just happening within the university though. It is being forced into all aspects of our lives, as the business elite becomes the only elite. Whether academics are part of the working class, or are a mouthpiece for the elite, as individuals they have goals, desires, motives and aspirations, which often do not align as well with the goals of the institutions and workplaces that employ them.

What hope is there when the personal meets the institutional? While we often like to focus on those 'big' and 'powerful' forces that reign down on us, we often forget the power we hold to resist, and better yet, the power we have to act. Like Bowen (2005:119), I believe that "the anarchist project begins, with the boring, small scale, mundane business of making positive, non-alienated relationships with our friends and neighbours and remaining open to new people and ideas". If we can take this from the anarchists, and apply it within our universities, then we have in front of ourselves, a very achievable, and significant goal.

In this thesis, I have shown that although many aspects of the university have become taken over by commercial and neoliberal 
interests, it is still a vibrant, multi-faceted space made up of a number of complex contradictions. While this makes the university an interesting and important topic for further study, it is the people inside who are of real importance. It is the people who hold the responsibility of handing down these institutions to the next generation. It is the people who can act now in order to hand down something with more than just economic value. Given this, surely we are all invested in a closer and more critical look at our institutions and our own roles within them and the communities in which they sit. 


\section{References}

Amster, R. DeLeon A. Fernandez, L. Nocella II, AJ. Shannon D, (eds) Contemporary Anarchist Studies. New York: Routledge, 1

Armaline, W. T. (2009). 13 Thoughts on anarchist pedagogy and epistemology. Contemporary anarchist studies, 136.

Bakunin, M. (1869). Equal Opportunity in Education II by Mikhail Bakunin. Retrieved March 20th, 2009.

Bently, T. Mcleod, L. Teo, S. (2014) The State of the Tertiary Education Sector in New Zealand-2013. Final Report of Findings from the Survey of Work and Wellbeing in the Tertiary Education Sector. New Zealand Work Research Institute

Berry, J., \& Worthen, H. (2012). Why We Should Support Organizing in the For-Profits. Radical Teacher, 93(1), 35-37.

Birtwistle*, T. (2004). Academic freedom and complacency: the possible effects if 'good men do nothing'. Education and the Law, $16(4), 203-216$.

Boas, T. C., \& Gans-Morse, J. (2009). Neoliberalism: From new liberal philosophy to anti-liberal slogan. Studies in Comparative International Development, 44(2), 137-161.

Boston, J. (2007, June). The Performance-Based Research Fund: issues and options for the future. Forum on the PerformanceBased Research Fund.

Bourdieu, P. (1988). Homo academicus. Stanford University Press.

Bowen, J. (2005). Moving targets: Rethinking anarchist strategies. In Purkis, J.\&

Bowen, J. (Eds.). Changing anarchism: Anarchist theory and practice in a global age. Manchester: Manchester University Press.

Bridgman, T. (2007). Assassins in academia? New Zealand academics as critic and conscience of society.

Brogden, L.M. (2010). Identities (academic + private) = subjectivities(desire) : re:collecting art*I/f/acts. Qualitative Inquiry, 16(5), 368-377. 
Brown, W. (2006). American nightmare: Neoliberalism, neoconservatism, and de-democratization. Political Theory, $34(6), 690-714$

Burawoy, M. (Ed.) . (1991). Ethnography unbound: Power and resistance in the modern metropolis. Univ of California Press.

Butler, J. (1999) A 'Bad Writer' Bites Back. New York times. Retrieved from:

http: / / query.nytimes.com/gst/fullpage.html?res=950 CE5D61531F93 3A15750C0A96F958260 on 25/5/2015

Chmiel, M. (1995). Taking Responsibility.

Chomsky, N. (2005). Chomsky on anarchism. Oakland: AK Press.

Coghlan, D., \& Brannick, T. (2014). Doing action research in your own organization. Sage.

Collins, A. (1977). Processes in acquiring knowledge. In R. C.Anderson, R. J. , \& W.E.Montague (Eds.), Schooling and the acquisition of knowledge. Hillsdale, NJ: Erlbaum

Coté, M., Day, R., \& de Peuter, G. (2007). Utopian Pedagogy: Creating Radical Alternatives in the Neoliberal Age 1 . The Review of Education, Pedagogy, and Cultural Studies, 29(4), $317-336$.

Crotty, M. (2003) Positivism: The March of Science. The Foundation of Social Research, Meaning, Perspective in the Research Process, Sage, London

Cupples, J., \& Pawson, E. (2012). Giving an account of oneself: The PBRF and the neoliberal university. New Zealand Geographer, 68(1), 14-23.

Kurzman, C., \& Owens, L. (2002). The sociology of intellectuals. Annual Review of Sociology, 63-90.

de Acosta, A. (2010). Anarchist Meditations, or: Three Wild Interstices of Anarchism and Philosophy. Anarchist Developments in Cultural Studies, 1, 117-138.

De Certeau, M. (1998). The Practice of Everyday Life: Living and cooking. Volume 2 (Vol. 2). U of Minnesota Press.

Debord, G. (1955). Introduction to a critique of urban geography. Critical Geographies A Collection of Readings. 
DeLeon, A. (2008). Oh no, not the "A" word! Proposing an "anarchism" for education. Educational Studies, 44(2), 122141.

Deleuze, G., \& Guattari, F. (1988). A thousand plateaus: Capitalism and schizophrenia. Bloomsbury Publishing.

DeWalt, K. M., \& DeWalt, B. R. (2010). Participant observation: A guide for fieldworkers. Rowman Altamira. Doty, R. L. (2010). Autoethnography-making human connections. Review of International Studies, 36(04), 1047-1050.

Ehrlich, H. J. (Ed.) . (1979). Reinventing anarchy: what are anarchists thinking these days?. Routledge.

Elbow, P. (1991). Reflections on academic discourse: How it relates to freshmen and colleagues. College English, 135-155.

el-ojeili, C. (2012). Anarchism as the spirit of Contemporary Anti-Capitalism? A Critical Survey of Recent Debates. Critical Sociology, 0896920512452023.

Escobar, M. (Ed.). (1994). Paulo Freire on higher education: A dialogue at the National University of Mexico. SUNY Press.

Fabish, R. (2014). Black Rainbow: Stories of Māori and Pākehā working across difference.

Feyerabend, P. (1975). Against method: Outline of an anarchistic theory of knowledge. Atlantic Highlands. Ferroni, F., (2012,) Occhi indiscreti sul neutrino, Il sole, 24.

Fischer, M. J. (2007) Four Genealogies for a Recombinant Anthropology of Science and Technology, Cultural Anthropology, 22 (4): 539-615

Fischman, G. E., \& McLaren, P. (2005). Rethinking critical pedagogy and the Gramscian and Freirean legacies: From organic to committed intellectuals or critical pedagogy, commitment, and praxis. Cultural Studies↔ Critical Methodologies, 5(4), 425-446.

Flew, T. (2014). Six theories of neoliberalism. Thesis Eleven, $122(1), 49-71$.

Forte, M. (2014, April). Anthropology: The Empire on which the Sun Never Sets. In Anthropological Forum (Vol. 24, No. 2, pp. 197-218). Routledge. 
Foucault, M. 1991. Governmentality, in G. Burchell, C. Gordon and P. Miller (eds.), The Foucault effect: studies in governmentality, 87-104. Chicago : University of Chicago Press

Foucault, M., \& Deleuze, G. (1977). Intellectuals and power. Language, counter-memory, practice, 205-17.

Freire, P. (1970/1993). Pedagogy of the Oppressed. 1970. New York: Continuum.

Game, A. (1991). Undoing the social: Towards a deconstructive sociology. Milton Keynes: Open University Press.

Geertz, C. (1988). Works and lives: The anthropologist as author. Stanford University Press.

Gelderloos, P. (2009) The Difference between Anarchy and the Academy. Retrieved from

http://theanarchistlibrary.org/library/peter-gelderloos-thedifference-between-anarchy-and-the-academy on 13/12/14

Giroux, H. A. (2004). The terror of neoliberalism. Paradigm Pub.

Giroux, H. A. (2009). Democracy's nemesis: The rise of the corporate university. Cultural studies↔ Critical

Methodologies.

Gordon, U. (2008). Anarchy alive!: anti-authoritarian politics from practice to theory. London: Pluto Press.

Goldman, E. (1906). The Child and its enemies. Mother Earth, $1(2), 7-14$.

Graeber, D. (2002). The new anarchists. New left review, $13(6), 61-73$.

Graeber, D. (2004). Fragments of an anarchist anthropology (Vol. 5). Chicago: Prickly Paradigm Press.

Gramsci A. 1971. Prison Notebooks: Selections from the Prison Notebooks of Antonio Gramsci [Quaderni del carcere], ed. transl. Q Hoare, GN Smith. London: Lawrence \& Wishar

Grey, S. J. (2013). Activist Academics: what future?. Policy Futures in Education, 11(6), 700-711.

Harvey, D. (2005). A brief history of neoliberalism. Oxford University Press. 
Haworth, R. H. (Ed.). (2012). Anarchist Pedagogies: Collective Actions, Theories, and Critical Relfections on Education. PM Press.

Henderson, K. M. (1974). Elite and Specialized Interviewing. By Dexter Lewis Anthony. (Evanston: Northwestern University Press, 1970. Pp. 205. \$6.50.). American Political Science Review, 68(02), 752-753.

Holt, N. L. (2008). Representation, legitimation, and autoethnography: An autoethnographic writing story. International Journal of Qualitative Methods, 2(1), 18-28.

Horton, M., \& Freire, P. (1990). We make the road by walking: Conversations on education and social change. Temple University Press.

Humphreys, M. (2005). Getting personal: Reflexivity and autoethnographic vignettes. Qualitative Inquiry, 11(6), 840860 .

Jenks, E. B. (2002). Searching for autoethnographic credibility, reflections from a mom with a notepad. In A. P. Bochner \& C. Ellis (Eds.), Ethnographically speaking: Autoethnography, literature and aesthetic (pp. 170-186). Walnut Creek, CA: AltaMira

Jeppesen, S. (2014). Becoming anarchist: The function of anarchist literature. ADCS, (2).

Kasper, G., \& Ross, S. J. (2007). Multiple questions in oral proficiency interviews. Journal of Pragmatics, 39(11), 20452070 .

Kelsey, J. (1993) Rolling Back the StateBridget Williams Books, Wellington

Kelsey, J. (1998). Privatizing the universities. Journal of Law and Society, 25(1), 51-70.

Kinna, R. (2005). Anarchism: a beginner's guide. Oneworld Publications.

Kinna, R. (2012) (ed.), Continuum Companion to Anarchism (London: Continuum, 2012), 53-74

Larner, W., \& Le Heron, R. (2005). Neo-liberalizing spaces and subjectivities: Reinventing New Zealand universities. Organization, $12(6), 843-862$. 
Law, J. (2004). After method: Mess in social science research. Routledge.

Law, John (2007). Making a mess with method. In: Outhwaite, William and Turner, Stephen P. eds. The Sage Handbook of Social Science Methodology. London: Sage, pp. 595-606

Lerum, K. (2001). Subjects of desire: Academic armor, intimate ethnography, and the production of critical knowledge. Qualitative Inquiry, 7(4), 466-483.

Malcolm, J., \& Zukas, M. (2009). Making a mess of academic work: Experience, purpose and identity. Teaching in Higher Education, 14(5), 495-506.

Martin, E. (1996) Meeting Polemics with Irenics in the Science Wars. Social text No. 46/47. Duke University Press

Marx, K. (1845). Theses on feuerbach (Vol. 11). na.

Mikecz, R. (2012). Interviewing elites addressing methodological issues. Qualitative inquiry, 18(6), 482-493.

Mills CW. [1944] 1963. The social role of the intellectual. In Power, Politics and People, ed. IL Horowitz, pp. 292-304. New York: Ballantin

Milojevic, I. (1989) Women's Higher Education in the $21^{\text {st }}$ Century. Futures 30,7:693-704

Milojevic, I. (2003). Hegemonic and marginalised educational utopias in the contemporary western world. Policy Futures in Education, 1(3), 440-466.

Mudge, S. L. (2008). What is neo-liberalism?. Socio-Economic Review, 6(4), 703-731.

Nelson, C. (2010) No university is an island: Saving academic freedom. NYU Press

Ortner, S (2005) [2003] New Jersey Dreaming: Capital, Culture, and the Class of '58. Durham: Duke University Press

Pauken, P. D. (2007). Academic Freedom and Institutional Autonomy in American and Australian Universities: A TwentyFirst Century Dialogue and a Call to Leaders. Austl. \& NZJL \& Educ., 12, 7 .

Pelias, R. J. (2003). The academic tourist: An autoethnography. Qualitative Inquiry, 9(3), 369-373. 
Perlman, F. (1969) The Incoherence of the Intellectual. C. Wright Mills' Struggle to Unite Knowledge and Action. Retrieved from http://theanarchistlibrary.org/library/fredyperlman-the-incoherence-of-the-intellectual-c-wright-millsstruggle-to-unite-knowledge-an. Accessed on 6/6/14

Peters, M. A. (2001). Poststructuralism, Marxism, and neoliberalism: Between theory and politics. Rowman \& Littlefield Publishers.

Pool, I. de S. (1957) 'A critique of the twentieth anniversary issue', Public Opinion Quarterly, 21: 190-8

Press .

Purkis, J. (2012). The Hitchhiker as Theorist: Rethinking Sociology and Anthropology from an Anarchist Perspective. The Bloomsbury Companion to Anarchism, 140.

Reed-Danahay, D. (1997). Auto/ethnography. Berg, New York. Rice, G. (2010). Reflections on interviewing elites. Area, $42(1), 70-75$.

Rizvi, F., \& Lingard, B. (2006). Edward Said and the cultural politics of education. Discourse: Studies in the cultural politics of education, 27(3), 293-308.

Ritzer, G. (1995). Expressing America: A critique of the global credit card society. Sage Publications.

Roberts, P. (1999). The future of the university: Reflections from New Zealand. International Review of Education, 45(1), 65-86.

Rose, Nikolas (1992) Towards a critical sociology of freedom. Inaug. Lect., Goldsmiths Coll., London, May 5

Rose, N. 1998 [1996]. Inventing our selves: psychology, power, and personhood. Cambridge : Cambridge University Press

Said, E. (1994). Representation of the intellectual: The 1993 Reith lectures. Vintage, London.

Saldaña, J. (2003). Dramatizing data: A primer. Qualitative inquiry, 9(2), 218-236.

Salient student magazine (2014) 7:76:7 Available at: http://salient.org.nz/2014/03/mo-money-mo-money/

Sawchuk, K. (2001). C. Wright Mills: A political writer and his fan mail. Canadian Journal of Communication, 26(2). 
Scott, K. (2013). The politics of influence: An anthropological analysis of collective political action in contemporary democracy. PhD Thesis, Anthropology, The University of Auckland.

Shannon, D. (2009). 18 As beautiful as a brick through a bank window. Contemporary Anarchist Studies, 183.

Shantz, J., \& Williams, D. M. (2013). Anarchy and Society: Reflections on Anarchist Sociology. Brill.

Shore, C. (2010). Beyond the multiversity: neoliberalism and the rise of the schizophrenic university. Social Anthropology, $18(1), 15-29$.

Shore, C. (2011). How commercialisation is redefining the mission and meaning of the university: a reply to steve Hoffman. Social Anthropology, 19(4), 495-499.

Shore, C., \& McLauchlan, L. (2012). 'Third mission'activities, commercialisation and academic entrepreneurs. Social Anthropology, 20(3), 267-286.

Shore, C., \& Taitz, M. (2012). Who 'owns' the university? Institutional autonomy and academic freedom in an age of knowledge capitalism. Globalisation, Societies and Education, $10(2), 201-219$.

Shore, C., \& Wright, S. (1999). Audit culture and anthropology: neo-liberalism in British higher education. Journal of the Royal Anthropological Institute, 557-575.

SIRAJ-BLATCHFORD, I. (1995) Critical social research and the academy, British Journal of Sociology of Education, 16, pp. 205-220.

Skinner, J. (Ed.). (2013). The interview: an ethnographic approach (Vol. 49). A\&C Black.

Spry, T. (2001). Performing autoethnography: An embodied methodological praxis. Qualitative inquiry, 7(6), 706-732.

Stoller, P. (1997). Sensuous scholarship, Philadelphia: University of Pennsylvania Press

Strathern, M. (Ed.). (2000). Audit cultures: anthropological studies in accountability, ethics, and the academy. Psychology Press.

Taussig, M. (1991). Tactility and distraction. Cultural Anthropology, 6(2), 147-153. 
Taussig, M. (2013). I Swear I Read This: John Cline Interviews Michael Taussig. Retrieved from:

https://lareviewofbooks.org/interview/i-swear-i-read-thisjohn-cline-interviews-michael-taussig on 23/12/14

The Smashed Academy \#1: Punk Ethic from the Streets to the Universities (a one-off zine) available at

http: // thesmashedacademy.wordpress.com/

Swinnerton-Dyer, P. (1995). The importance of academic freedom. Nature, 373, 186-188.

Tsou, J. Y. (2003). Reconsidering Feyerabend's "Anarchism". Perspectives on Science, 11(2), 208-235.

Wacquant, L. J. (1989). For a Socio-Analysis of Intellectuals: On" Homo Academicus". Berkeley Journal of Sociology, 1-29.

Ward, C. (1966). Anarchism as a Theory of Organization. Anarchy, 62, 97-109.

Wilson, E. O. (1999) Consilience. The Unity of Knowledge. Vintage, New York 